\title{
ESTUDO GENÉTICO DA DEPOSIÇÃO DE GORDURA ABDOMINAL E DE CARACTERÍSTICAS DE DESEMPENHO, CARCAÇA E COMPOSIÇÃO CORPORAL EM LINHAGEM MACHO DE FRANGOS DE CORTE
}

\section{Leila de Genova Gaya}

Dissertação de Mestrado apresentada à Comissão de Pós-Graduação da Faculdade de Zootecnia e Engenharia de Alimentos da USP, como parte dos requisitos para a obtenção do Título de Mestre em Zootecnia, na área de Concentração de Qualidade e Produtividade Animal.

Orientador: Prof. Dr. José Bento Sterman Ferraz 


\section{FICHA CATALOGRÁFICA}

Biblioteca da Faculdade de Zootecnia e Engenharia de Alimentos da Universidade de São Paulo

\begin{tabular}{|l|}
\hline Gaya, Leila de Genova \\
Estudo genético da deposição de gordura abdominal e de caracterís- \\
ticas de desempenho, carcaça e composição corporal em linhagem \\
macho de frangos de corte / Leila de Genova Gaya - Pirassununga, \\
2003. \\
99 p. \\
Dissertação (Mestrado) -- Faculdade de Zootecnia e Engenharia \\
de Alimentos - Universidade de São Paulo. \\
Departamento de Ciências Básicas. \\
Área de Concentração: Qualidade e Produtividade Animal. \\
Orientador: Prof. Dr. José Bento Sterman Ferraz. \\
Unitermos: 1. Gordura abdominal placa 2. Herdabilidade \\
3. Correlação genética 4. Parâmetro genético I. Título.
\end{tabular}


"O valor das coisas não está no tempo que elas duram, mas na intensidade com que acontecem. Por isso existem momentos inesquecíveis, coisas inexplicáveis $e$ pessoas incomparáveis.”

- Fernando Pessoa - 


\section{Dedicatória}

À minha mãe, Rosa, minha maior encorajadora e a quem devo todos os meus valores e as minhas conquistas, dedico este trabalho. Obrigada por ser meu exemplo de mulher, de mãe e de vida. 


\section{Agradecimento Especial}

Ao meu namorado, Joca, agradeço pela paciência e pelo carinho. Obrigada por fazer parte da minha vida. 


\section{Agradecimentos}

Ao Professor José Bento, por todas as oportunidades de crescimento pessoal e profissional;

À Faculdade de Zootecnia e Engenharia de Alimentos da USP, pela oportunidade de realização deste curso;

À FAPESP, pela concessão da bolsa de Mestrado;

À Agroceres Ross Melhoramento de Aves S.A., pelo apoio ao desenvolvimento do estudo;

Ao meu pai, Carlos, minha prima, Carolina, e meus irmãos, Alysson e Larissa, que amo muito;

À grande amiga de toda e qualquer hora, Luciana;

Aos amigos Elisângela, Sancho, Gerson e Augusto, que incansavelmente me auxiliaram e incentivaram durante o desenvolvimento deste trabalho;

Às amigas Kiyumi, Lilian, Marjorie e Mônica;

Aos amigos da Agroceres Tércio, Camila e Jane;

Aos amigos do Grupo de Melhoramento Animal Erica, Fernanda, Prof. Joanir, Prof. Júlio, Robson, Felipe, Heloise, Andréa, José Henrique, Éder, Marcelo, Ivan, Ricardo, Arnaldo e Gilson, que fazem deste um lugar acolhedor e especial;

A todos os colegas da pós-graduação da FZEA, especialmente à Juliane, com quem pude contar em tantos momentos;

Aos funcionários do Matadouro-Escola da FZEA que, com muito zelo, contribuíram para a realização deste trabalho. 


\section{SUMÁRIO}

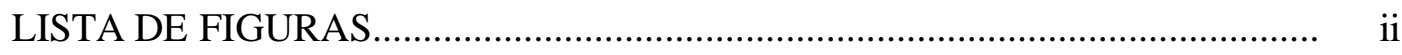

LISTA DE TABELAS .................................................................................... iv

LISTA DE ABREVIATURAS..................................................................... viii

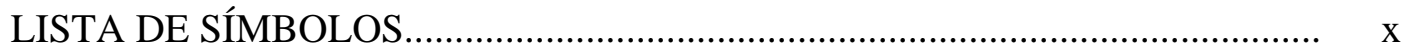

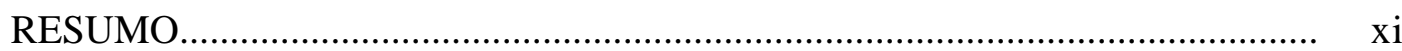

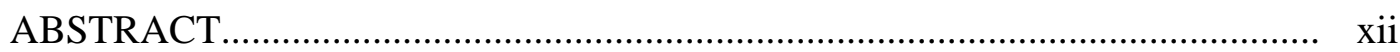

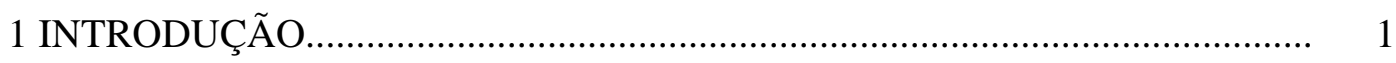

2 REVISÃO DE LITERATURA................................................................. 4

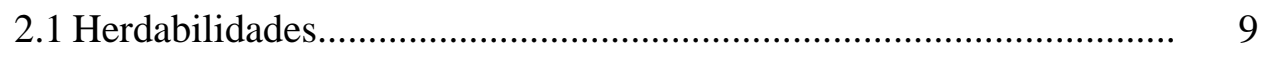

2.2 Correlações Genéticas e Fenotípicas.............................................. 15

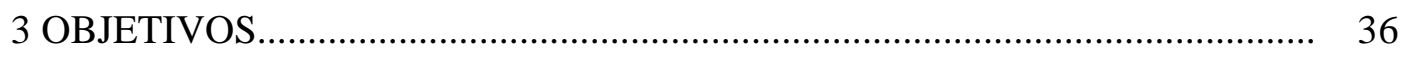

4 MATERIAL E MÉTODOS...................................................................... 37

4.1 Origem dos Dados................................................................... 37

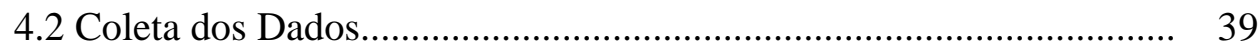

4.2.1 Controle do Pedigree e Automatização do Sistema............... 43

4.3 Metodologia de Análise.................................................................... 46

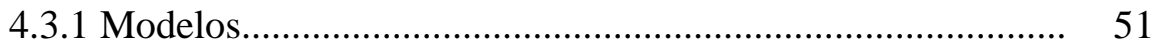

4.4 Tendência Genética.......................................................................... 53

5 RESULTADOS E DISCUSSÃO_.................................................................. 55

5.1 Descrição Estat ística dos Dados...................................................................... 55

5.2 Soluções de Componentes de (Co) Variância........................................ 56

5.3 Herdabilidades.......................................................................... 61

5.4 Correlações Genéticas e Fenotípicas................................................. 66

5.5 Tendência Genética do Peso da Gordura Abdominal......................... 88

6 CONCLUSÕES E IMPLICAÇÕES........................................................... 91

7 REFERÊNCIAS BIBLIOGRÁFICAS....................................................... 93 


\section{LISTA DE FIGURAS}

Figura 1 - Aferição por ultra-sonografia da profundidade do músculo peitoral, no sentido longitudinal

Figura 2 - Registro do peso vivo da ave antes do abate

40

Figura 3 - Peito desossado e sem pele (ao centro) e pernas (coxa mais sobrecoxa com pele e ossos).

Figura 4 - Moela com a gordura aderida.

Figura 5 - Placa de gordura abdominal (à esquerda) e a gordura removida da moela.

Figura 6 - Moela, cheia, sem a gordura aderida

Figura 7 - Anilha presa à asa da ave, contendo sua identificação em número e respectivo código em barras.

Figura 8 - Anilhas presas à asa na carcaça das aves

Figura 9 - Registro da sequiência de abate

Figura 10 - Acondicionamento das vísceras em sacos plásticos na seqüência de abate. 
Figura 11 - Tela do software desenvolvido contendo a opção "Leitura de código de barras", com o registro do número de seqüência de abate das aves.

Figura 12 - Tela do software desenvolvido contendo a opção "Leitura da balança", com o registro dos pesos das vísceras das aves e escores.

Figura 13 - Proporções da variância total devida aos efeitos genéticos aditivos diretos (ou herdabilidades $-\mathrm{h}^{2}$ ) e aos efeitos residuais $\left(\mathrm{e}^{2}\right)$ para as características de desempenho analisadas.

Figura 14 - Proporções da variância total devida aos efeitos genéticos aditivos diretos (ou herdabilidades $-\mathrm{h}^{2}$ ) e aos efeitos residuais $\left(\mathrm{e}^{2}\right)$ para as características de carcaça analisadas.

Figura 15 - Proporções da variância total devida aos efeitos genéticos aditivos diretos (ou herdabilidades $-\mathrm{h}^{2}$ ) e aos efeitos residuais $\left(\mathrm{e}^{2}\right)$ para as características de composição corporal analisadas

Figura 16 - Tendência genética do peso da gordura abdominal por POU (unidade de organização da produção)

Figura 17 - Tendência genética do peso da gordura abdominal por ano 88 
LISTA DE TABELAS

Tabela 1 - Estimativas de herdabilidade $\left(h^{2}\right)$ para características de desempenho em frangos de corte, segundo diversos autores.

Tabela 2 - Estimativas de herdabilidade $\left(\mathrm{h}^{2}\right)$ para características de carcaça em frangos de corte, segundo diversos autores.

Tabela 3 - Estimativas de herdabilidade $\left(h^{2}\right)$ para características de composição corporal em frangos de corte, segundo diversos autores.

Tabela 4 - Estimativas de correlações genéticas $\left(r_{g}\right)$ e fenotípicas $\left(r_{p}\right)$ entre as características de desempenho em frangos de corte, segundo diversos autores

Tabela 5 - Estimativas de correlações genéticas $\left(r_{\mathrm{g}}\right)$ e fenotípicas $\left(r_{\mathrm{p}}\right)$ entre as características de carcaça em frangos de corte, segundo diversos autores.

Tabela 6 - Estimativas de correlações genéticas $\left(r_{g}\right)$ e fenotípicas $\left(r_{p}\right)$ entre as características de composição corporal em frangos de corte, segundo diversos autores

Tabela 7 - Estimativas de correlações genéticas $\left(r_{g}\right)$ e fenotípicas $\left(r_{p}\right)$ entre características de desempenho e características de carcaça em frangos de corte, segundo diversos autores 
Tabela 8 - Estimativas de correlações genéticas $\left(r_{g}\right)$ e fenotípicas $\left(r_{p}\right)$ entre características de desempenho e características de composição corporal em frangos de corte, segundo diversos autores

Tabela 9 - Correlações genéticas $\left(r_{\mathrm{g}}\right)$ e fenotípicas $\left(\mathrm{r}_{\mathrm{p}}\right)$ encontradas em literatura entre características de carcaça e características de composição corporal em frangos de corte

Tabela 10 - Estimativas iniciais de variâncias (na diagonal) e covariâncias genéticas das características de desempenho, carcaça e composição corporal para realização das análises no programa MTDFREML

Tabela 11 - Estimativas iniciais de variâncias (na diagonal) e covariâncias ambientais das características de desempenho, carcaça e composição corporal para realização das análises no programa MTDFREML

Tabela 12 - Número inicial de observações $(\mathrm{Ni})$, igual ao número total de observações coletadas, número final de observações (Nf), igual ao Ni menos o número de outliers retirados, média (M), desvio-padrão (DP), coeficiente de variação (CV) e valores mínimo (MIN) e máximo (MAX) das características de desempenho avaliadas.

Tabela 13 - Número inicial de observações (Ni), igual ao número total de observações coletadas, número final de observações $(\mathrm{Nf})$, igual ao $\mathrm{Ni}$ menos o número de outliers retirados, média (M), desvio-padrão (DP), coeficiente de variação (CV) e valores mínimo (MIN) e máximo (MAX) das características de carcaça avaliadas 
Tabela 14 - Número inicial de observações (Ni), igual ao número total de observações coletadas, número final de observações (Nf), igual ao Ni menos o número de outliers retirados, média $(\mathrm{M})$, desvio-padrão (DP), coeficiente de variação (CV) e valores mínimo (MIN) e máximo (MAX) das características de composição corporal avaliadas.

Tabela 15 - Número de observações (N), valores mínimo (MIN) e máximo (MAX) e incidência (INC) dos escores visuais

Tabela 16 - Estimativas de variâncias (na diagonal) e covariâncias genéticas das características de desempenho, carcaça e composição corporal resultantes das análises no programa MTDFREML

Tabela 17 - Estimativas de variâncias (na diagonal) e covariâncias ambientais das características de desempenho, carcaça e composição corporal resultantes das análises no programa MTDFREML

Tabela 18 - Estimativas de variâncias (na diagonal) e covariâncias fenotípicas das características de desempenho, carcaça e composição corporal resultantes das análises no programa MTDFREML 60

Tabela 19 - Estimativas de correlações genéticas (acima da diagonal) e fenotípicas (abaixo da diagonal) entre as características de desempenho analisadas 66

Tabela 20 - Estimativas de correlações genéticas (acima da diagonal) e fenotípicas (abaixo da diagonal) entre as características de carcaça analisadas. 
Tabela 21 - Estimativas de correlações genéticas (acima da diagonal) e fenotípicas (abaixo da diagonal) entre as características de composição corporal analisadas

Tabela 22 - Estimativas de correlações genéticas entre as características de desempenho e carcaça analisadas

Tabela 23 - Estimativas de correlações fenotípicas entre as características de desempenho e carcaça analisadas

Tabela 24 - Estimativas de correlações genéticas entre as característ icas de desempenho e composição corporal analisadas.

Tabela 25 - Estimativas de correlações fenotípicas entre as características de desempenho e composição corporal analisadas.

Tabela 26 - Estimativas de correlações genéticas entre as características de carcaça e composição corporal analisadas 82

Tabela 27 - Estimativas de correlações fenotípicas entre as características de carcaça e composição corporal analisadas....

Tabela 28 - Herdabilidades $\left(h^{2}\right)$ dos escores visuais estimadas por máxima verossimilhança restrita, com o respectivo erro-padrão (EP) entre parênteses 


\title{
LISTA DE ABREVIATURAS
}

\begin{abstract}
ABTK - animal breeder's toolkit
CA - conversão alimentar

CV - coeficiente de variação

DP - desvio-padrão
\end{abstract}

DSCAT - software para dados categóricos

EA - eficiência alimentar

EP - erro-padrão

ESCC - escore de coração

ESCF - escore de fígado

g - gramas

INC - incidência

ING - ingestão

M - média

MA - modelo animal

MAX - máximo

MIN - mínimo

mm - milímetros

MTDFREML - multiple trait derivative free restricted maximun likelihood

$\mathrm{N}$ - número de observações

$\mathrm{Nf}$ - número final de observações

$\mathrm{Ni}$ - número inicial de observações

PC - peso do coração

PD - peso do duodeno

PE - peso eviscerado

$\mathrm{PF}$ - peso do fígado

PGA - peso da gordura abdominal

PI - peso do intestino 
PIL - peso do íleo

$\mathrm{PJ}$ - peso do jejuno

PM - peso da moela

$\mathrm{PN}$ - peso ao nascimento

POU - unidade de organização da produção

PPEI - peso de peito

PPER - peso de pernas

PS - peso à seleção

PV - peso vivo

RCAR - rendimento de carcaça

REML - método da máxima verossimilhança restrita

RPEI - rendimento de peito

RPER - rendimento de pernas

$\mathrm{SAS}^{\circledR}$ - Statistical Analysis System

US - profundidade de músculo peitoral 


\title{
LISTA DE SÍMBOLOS
}

\author{
$\mathrm{h}^{2}$ - coeficiente de herdabilidade \\ $\mathrm{e}^{2}$ - fração da variância total devida aos efeitos residuais \\ $\mathrm{r}_{\mathrm{g}}$ - correlação genética \\ $r_{p}$ - correlação fenotípica
}




\title{
RESUMO
}

\begin{abstract}
GAYA, L. de G. Estudo genético da deposição de gordura abdominal e de características de desempenho, carcaça e composição corporal em linhagem macho de frangos de corte. 2003, 99 p. Dissertação de mestrado - Faculdade de Zootecnia e Engenharia de Alimentos, Universidade de São Paulo, Pirassununga.
\end{abstract}

O presente trabalho teve como objetivo estimar parâmetros genéticos e fenotípicos do peso da gordura abdominal e de características de desempenho, carcaça e composição corporal em uma linhagem macho de frangos de corte fornecida pela Agroceres Ross Melhoramento de Aves S. A. As aves faziam parte do programa denominado sib test, ou teste de irmãos, onde são coletadas informações de carcaça dos irmãos dos indivíduos a serem selecionados, estes chamados de rebanho elite. 30273 informações de granja das aves elite e de seus irmãos foram concedidas pela Empresa e 6167 dados de abatedouro dos irmãos das aves elite foram coletados. As características analisadas foram: peso à seleção (PS), medidas de ultra-sonografia do músculo peitoral (US1 e US2), conversão alimentar (CA), eficiência alimentar (EA), ingestão (ING), peso vivo (PV), peso eviscerado (PE), peso do peito (PPEI), peso de pernas (PPER), rendimento de carcaça (RCAR), rendimento de peito (RPEI), rendimento de pernas (RPER), peso da gordura abdominal (PGA), peso do coração (PC), peso da moela (PM), peso do fígado (PF), peso do intestino (PI), escore do coração (ESCC) e escore do fígado (ESCF). Os componentes de (co) variância foram estimados por verossimilhança restrita, utilizando-se o programa MTDFREML. As estimativas de herdabilidade foram em sua maioria moderadas, sendo alta para peso da gordura abdominal, o que sugere que esta característica é passível de seleção. As correlações genéticas e fenotípicas variaram de acordo com as características analisadas.

Palavras -chave: placa de gordura abdominal, sib test, herdabilidade, correlação, parâmetros genéticos. 


\begin{abstract}
GAYA, L. de G. Genetic study of abdominal fat deposition and performance, carcass and body composition traits in a male broiler line.
\end{abstract}

This research was conducted to estimate genetic and phenotypic parameters of abdominal fat and performance, carcass and body composition traits in a male broiler line provided by Agroceres Ross Melhoramento de Aves S. A. The broilers belonged to sib test program, in which data from brothers and sisters of the individuals to be selected, called elite flock, are collected. 30273 farm data of chicken from elite flock and their sibs were conceded by the Company and 6167 processing data from sibs of elite flock were collected. The traits analyzed were: body weight at juvenile selection (PS), ultrasound records of pectoral muscle (US1 e US2), feed conversion ratio (CA), feed efficiency (EA), feed intake (ING), live weight at processing (PV), carcass weight (PE), breast weight (PPEI), leg weight (PPER), carcass yield (RCAR), breast yield (RPEI), leg yield (RPER), abdominal fat weight (PGA), heart weight (PC), gizzard weight (PM), liver weight (PF), intestine weight (PI), heart score (ESCC) and liver score (ESCF). (Co) variance components were estimated by restricted maximum likelihood method, using the software MTDFREML. Heritability coefficients estimated were mostly moderate, and the heritability of abdominal fat weight was high, which suggests that this trait can be selected. Genetic and phenotypic correlations coefficients estimated varied according to the trait studied.

Key-words : abdominal fat pad, sib test, heritability, correlation, genetic parameters. 


\section{INTRODUÇÃO}

O Brasil é o segundo maior produtor e exportador de carne de frango do mundo, com cerca de 6,5 milhões de toneladas produzidas e 1,3 milhões exportadas em 2001. Possui aproximadamente 3,5 milhões de pintos de corte alojados em todo o país, número que vem crescendo a cada ano. A avicultura é a atividade da pecuária que apresentou os maiores índices de evolução nas últimas décadas. Nos últimos dez anos (1992 a 2001), o Brasil aumentou em 128\% a produção (passando de cerca de 3 milhões para 6,5 milhões de toneladas) e em $236 \%$ a exportação (de 373 mil toneladas para 1,3 milhões de toneladas) de carne de frango (Anualpec, 2002).

Essa evolução é decorrente, principalmente, do intenso processo de seleção realizado desde os primórdios do uso do cruzamento entre raças. A escassez de alimentos, durante e após a segunda guerra mundial, fez da avicultura brasileira e mundial um negócio bastante atraente (Camargo, 1999). Nesse contexto, a procura por um produto destinado a corte aumentou, e a partir de então até os dias atuais tem havido um intenso processo de seleção e cruzamentos. 
Cada vez mais esse processo de seleção se aprimorou, resultando na descaracterização das raças e originando linhagens específicas, com características próprias. As aves destinadas à produção de carne, conhecidas como frangos de corte, foram selecionadas principalmente para características de desempenho, o que proporcionou avanços na taxa de crescimento dos animais. Contudo, a seleção intensa para essas características levou também a um aumento de proporção e quantidade de gordura nessas aves, além de provocar alterações no tamanho, na forma e na função dos órgãos das aves.

A placa de gordura abdominal é uma das principais regiões de deposição de gordura nos frangos de corte. A gordura excessiva tem sido reconhecida como um dos principais problemas da indústria da carne de frango atual, representando muitas perdas nessa indústria. A deposição excessiva de gordura não apenas reduz o rendimento da carcaça e a eficiência alimentar das aves, mas também leva o consumidor à rejeição da carne de frango, já que o mercado de hoje exige uma carne magra.

Tanto os parâmetros genéticos (herdabilidades e correlações genéticas) como os fenotípicos (correlações fenotípicas) das características utilizadas em programas de seleção, bem como a tendência genética da característica peso da gordura abdominal em uma linhagem macho de frango de corte têm como objetivo orientar, conduzir e até avaliar a eficiência da seleção empregada nas gerações que compuseram essa linhagem, e se essa seleção está sendo adequada às exigências atuais do mercado. Além disto, estimativas de parâmetros genéticos e fenotípicos e tendências genéticas em frangos de corte raramente são descritas na literatura científica pertinente, especialmente no que diz respeito ao peso da gordura abdominal, o que torna ainda 
mais importantes as determinações e o monitoramento desses itens num programa de seleção. 


\section{REVISÃO DE LITERATURA}

Os pilares do desenvolvimento avícola estão sustentados na utilização de genética avançada, a qual deve buscar aves compatíveis com as exigências altamente competitivas dos mercados produtivo, industrial e consumidor (Campos \& Pereira, 1999). Segundo Figueiredo et al. (2000) é necessário um estudo detalhado das necessidades da indústria de alimentos e das tendências do mercado para que sejam estabelecidos os alvos de progresso genético. De acordo com Schmidt \& Figueiredo (1996) cada vez mais a indústria avícola definirá o produto a ser utilizado com base nos benefícios que este proporcionará em toda a cadeia, da reprodução ao processamento pós-abate. No caso da indústria de frangos de corte, as mudanças de mercado são bastante comuns, o que requer uma melhoria contínua no esquema e nas ferramentas dos programas de melhoramento genético (Yang et al., 1999). Como resultado desse processo, o estabelecimento de critérios de seleção adequados e eficientes torna-se um grande obstáculo ao desenvolvimento de programas de melhoramento genético de aves. 
No que diz respeito às linhas macho de programas de melhoramento, características relacionadas ao desempenho, como peso vivo e conversão alimentar, e à carcaça, como pesos da carcaça, de peito e de coxas, recebem maior ênfase (Leeson \& Summers, 2000).

De acordo com Campos \& Pereira (1999) o melhoramento genético de frangos de corte tem sido extraordinário, notadamente nas quatro últimas décadas. A taxa de crescimento nesse período foi praticamente triplicada. Segundo os mesmos autores basicamente dois fatores contribuíram para esse sucesso: a intensa pressão de seleção exercida sobre o ganho de peso das aves e o fato de esta ser uma característica bastante herdável. Obteve-se, então, um crescimento mais rápido das aves, alcançando-se idades mais precoces ao abate, reduzindo-se os custos de produção e aumentando-se a lucratividade da atividade.

Todavia, o direcionamento de frangos de corte para o aumento de ganho de peso está associado à grande quantidade de gordura que os frangos de corte atuais apresentam na carcaça, a qual se deve ao incremento da capacidade de consumo desses animais (Cartwright, 1991; Kessler et al., 2000; Rance et al., 2002), e a alterações nos órgãos das aves e em sua fisiologia (Cartwright, 1991; Rance et al., 2002). De acordo com Sütó et al. (1998) os critérios centrais de seleção utilizados em frangos de corte provocaram modificações mais aparentes em crescimento e conversão alimentar, ou seja, no desempenho dos animais, mas afetaram também características de carcaça (pesos e rendimentos das partes da carcaça) e de composição corporal (quantidade de gordura e pesos dos órgãos).

Segundo Griffiths et al. (1978) o desempenho, o rendimento de carcaça e a composição corporal dos frangos de corte também podem ser afetados por fatores 
como composição da dieta, temperatura ambiente, idade e sexo. De acordo com Kessler et al (2000) o papel da genética é o de maior impacto entre todos.

Com base nos critérios de seleção utilizados, uma maior massa corporal tem sido consistentemente alcançada num período de tempo cada vez mais curto (Gyles, 1989; Havenstein et al., 1994). No entanto, simultaneamente a este melhoramento do desempenho dos frangos, há um destacado aumento na incidência de várias desordens metabólicas (Shlosberg et al., 1996; Silversides et al., 1997; Buyse et al., 1999), associadas com aumento do ganho de peso e do rendimento de carcaça. O desenvolvimento de algumas destas desordens, como a ascite e a síndrome da morte súbita, tem sido atribuído em parte aos critérios de seleção utilizados (Rauw et al., 1998).

De acordo com Lin (1981) a gordura, a proteína, os minerais e a água são os constituintes básicos do organismo, e, se expressos em porcentagem do peso vivo, qualquer aumento em um componente acarretará na diminuição de outro. Havenstein et al. (1994) comprovaram esta afirmação, comparando uma linhagem típica de frangos de corte de 1957 com outra de 1991. Estes autores constataram que o resultado da seleção genética para ganho de peso levou à diminuição do tamanho relativo do coração, o que pode levar à deficiência deste órgão em servir adequadamente à demanda tecidual de oxigênio. Segundo McEntee et al. citados por Rance et al. (2002), em termos relativos, todos os órgãos das aves vêm diminuindo, dando espaço a uma maior deposição protéica. Segundo Rance et al. (2002) uma continuidade nesta diminuição prejudicará ainda mais a integridade fisiológica das aves. A seleção artificial tem resultado, portanto, em alterações no tamanho, na forma 
e na função dos órgãos das aves, entre eles o coração, o fígado e os componentes do trato gastrintestinal (Rance et al., 2002).

Simultaneamente aos avanços alcançados na produção de frangos, aumentout se também a deposição de gordura nestes animais, possivelmente devido às fortes correlações entre o peso vivo e a ingestão de alimentos (Leenstra et al., 1986; Wang et al., 1991). Segundo Leenstra (1986) como o critério de seleção ap licado favoreceu aves de maior apetite, estas são capazes de comer além de suas necessidades metabólicas e sua capacidade de depositar proteína é excedida, então este excesso é depositado na forma de gordura. Ou seja, a ave que é selecionada para maior peso vivo, de modo geral, ingere mais alimento e por isso deposita mais gordura (Lin, 1981; Leenstra, 1986; Havenstein et al., 1988).

Segundo Michelan Filho (1986) a gordura abdominal é uma das principais regiões de deposição de gordura no frango e está diretamente correlacionada com a quantidade total de gordura na carcaça. Griffiths et al. (1978) e Becker et al. (1981), comprovaram esta afirmação, pois encontraram fortes correlações entre peso de gordura abdominal e porcentagem de gordura na carcaça. Portanto, a quantidade de gordura abdominal é um bom estimador da quantidade de gordura da carcaça.

Com a crescente demanda por produtos cárneos cada vez mais magros, faz se necessária cada vez mais atenção em relação ao teor de gordura na carne de frangos de corte (Kessler et al, 2000). De acordo com Michelan Filho (1986), embora uma certa quantidade de gordura seja necessária para melhorar o sabor da carne, a gordura excessiva na carcaça é indesejável do ponto de vista nutricional.

Segundo Kessler et al (2000) a maior parte da gordura dos frangos de corte é depositada em partes do animal que podem ser retiradas durante o processamento ou 
na produção de cortes, embora isso possa dificultar o processamento (Chambers, 1990). No entanto, de acordo com Kessler et al. (2000) depósitos de gordura que são retirados têm um alto custo de produção, que deverá ser, então, repassado aos chamados cortes magros. Assim, a gordura abdominal, quando em excesso, prejudica a qualidade da carcaça e a eficiência da produção e, do ponto de vista econômico, as carcaças com maior proporção de gordura estão associadas com maior custo de processamento e comercialização (Chambers, 1990).

Segundo Mallard \& Douaire citados por Kessler et al. (2000) a seleção simultânea para ganho de peso e carcaças mais magras é economicamente superior à seleção somente para incrementos no peso dos animais. Conclui-se, portanto, que a seleção de frangos de corte para um menor peso de gordura abdominal é favorável sob vários aspectos. De acordo com Leenstra \& Pit (1988) os programas de melhoramento devem procurar diminuir o conteúdo de lipídios na carcaça e, como já comentado, isso é possível através da seleção para diminuição da gordura abdominal. Segundo Figueiredo et al (2000) o teor de gordura da carcaça deve ser incluído como critério de seleção em programas de melhoramento de frangos de corte.

O teste de irmãos (sib test) é um teste utilizado em programas de melhoramento no qual são produzidos irmãos das aves a serem selecionadas. As aves deste teste s̃o abatidas e assim são obtidas informações de carcaça dos parentes das aves que serão submetidas à seleção. Este teste tem se mostrado eficiente em produzir frangos com menor deposição de gordura, mediante seleção (Leenstra et al., 1986).

Num programa de melhoramento genético são, portanto, fundamentais as estimativas dos parâmetros genéticos e fenotípicos das características utilizadas, especialmente quando se pretende incluir um novo critério de seleção. Estas 
estimativas permitem o monitoramento da variabilidade genética dos animais da linhagem utilizada para várias características. Desta forma, pode-se verificar quanto da variabilidade total ligada à expressão de uma característica está correspondendo à variação genética aditiva, o que permitirá o estabelecimento de programas de seleção mais eficientes. Segundo Campos \& Pereira (1999) a quantificação da variação genética das características, pela herdabilidade, e as associações genéticas entre diferentes características, pelas correlações genéticas, permite estabelecer estratégias de melhoramento animal e predizer a evolução genética das aves.

\subsection{Herdabilidade}

A herdabilidade $\left(\mathrm{h}^{2}\right)$ constitui a expressão da proporção da variância total que é atribuível aos efeitos médios aditivos dos genes, ou seja, à variância genética aditiva (Falconer, 1960). Desta forma, segundo Euclides Filho (1999), sua principal função é seu caráter preditivo, ou seja, ela expressa o grau de confiança do valor fenotípico como indicador do valor genético.

De acordo com Eler (2001) o conhecimento do coeficiente de herdabilidade das características é fundamental na predição do valor genético, na formulação de programas de melhoramento genético e na predição da resposta esperada à seleção. As características que possuem herdabilidade de moderada a alta são características capazes de responder à seleção (Campos \& Pereira, 1999).

Estimativas de herdabilidade para as características de desempenho, carcaça e composição corporal em frangos de corte podem ser encontradas na literatura. Nos trabalhos revisados, os métodos utilizados para a estimativa dos parâmetros genéticos e fenotípicos se basearam em sua maioria na comparação da semelhança genética e 
fenotípica entre indivíduos parentes. Os parâmetros podem ser calculados através da correlação entre os dados das progênies (entre meio-irmãos ou entre irmãos completos), entretanto, mais recentemente, passou a ser utilizado um sistema de avaliação genética denominado "modelo animal", em que o modelo matemático inclui o valor genético do animal, e no qual são utilizados registros de produção do próprio animal e de todos os seus parentes, ou seja, todas as informações genealógicas disponíveis (Eler, 2001).

Estimativas de herdabilidade para características de desempenho em frangos de corte foram descritas por alguns autores, especialmente para a característica de peso vivo, como é apresentado na Tabela 1.

TABELA 1 - Estimativas de herdabilidade $\left(h^{2}\right)$ para características de desempenho em frangos de corte, segundo diversos autores. Entre parênteses encontram-se os respectivos erros-padrão (EP)

\begin{tabular}{|c|c|c|c|c|c|c|}
\hline Característica ${ }^{1}$ & $\mathbf{h}^{2}(\mathrm{EP})$ & $\begin{array}{c}\mathrm{N}^{0} \text { de } \\
\text { informações }\end{array}$ & $\begin{array}{c}\text { Idade } \\
\text { das aves }\end{array}$ & $\begin{array}{c}\text { Linhagem (ns) } \\
\text { utilizada (s) }\end{array}$ & $\begin{array}{l}\text { Método de } \\
\text { estimativa }^{2}\end{array}$ & Referência \\
\hline \multirow{3}{*}{$\mathrm{CA}$} & $0,44(0,15)$ & 864 & $21-42$ dias & Macho & $\mathrm{P}$ & Leenstra \& Pit (1988) \\
\hline & $0,14(0,18)$ & 864 & $21-42$ dias & Macho & M & Leenstra \& Pit (1988) \\
\hline & 0,22 & 6536 & & Comercial macho & MA & Argentão et al. (2002) \\
\hline \multirow{2}{*}{$\mathrm{PN}$} & $0,94(0,13)$ & 1281 & & Experimental & $\mathrm{P}$ & Ledur et al. (1992) \\
\hline & $0,20(0,08)$ & 1326 & & Experimental & $\mathrm{P}$ & Ledur et al. (1992) \\
\hline \multirow{17}{*}{ PV } & $0,34(0,08)$ & 1281 & 28 dias & Experimental & $\mathrm{P}$ & Ledur et al. (1992) \\
\hline & $0,49(0,12)$ & 1326 & 28 dias & Experimental & $\mathrm{P}$ & Ledur et al. (1992) \\
\hline & $0,52(0,07)$ & 1326 & 28 dias & Experimental & $\mathrm{C}$ & Ledur et al. (1992) \\
\hline & $0,56(0,13)$ & 1326 & 28 dias & Experimental & M & Ledur et al. (1992) \\
\hline & $0,28(0,08)$ & 1281 & 35 dias & Experimental & $\mathrm{P}$ & Ledur et al. (1992) \\
\hline & $0,63(0,13)$ & 1326 & 35 dias & Experimental & $P$ & Ledur et al. (1992) \\
\hline & $0,60(0,07)$ & 1326 & 35 dias & Experimental & $\mathrm{C}$ & Ledur et al. (1992) \\
\hline & $0,57(0,13)$ & 1326 & 35 dias & Experimental & M & Ledur et al. (1992) \\
\hline & 0,43 & 11532 & 35 dias & Experimental & MA & Lopes \& Quaas (1997) \\
\hline & 0,43 & 9638 & 35 dias & Experimental & MA & Lopes \& Quaas (1997) \\
\hline & 0,45 & 24549 & 35 dias & Comercial macho & MA & Argentão et al. (2002) \\
\hline & $0,32(0,03)$ & 8173 & 42 dias & Experimental & $\mathrm{C}$ & Schmidt et al. (1992) \\
\hline & $0,32(0,05)$ & 8173 & 42 dias & Experimental & $\mathrm{P}$ & Schmidt et al. (1992) \\
\hline & $0,30(0,04)$ & 5389 & 42 dias & Experimental & M & Schmidt et al. (1992) \\
\hline & $0,32(0,03)$ & 8173 & 42 dias & Experimental & M & Schmidt et al. (1992) \\
\hline & $0,27(0,08)$ & 1281 & 42 dias & Experimental & $\mathrm{P}$ & Ledur et al. (1992) \\
\hline & $0,56(0,13)$ & 1326 & 42 dias & Experimental & $\mathrm{P}$ & Ledur et al. (1992) \\
\hline
\end{tabular}


conclusão

\begin{tabular}{|c|c|c|c|c|c|c|}
\hline Característica ${ }^{1}$ & $h^{2}(E P)$ & $\begin{array}{c}\mathrm{N}^{0} \text { de } \\
\text { informações }\end{array}$ & $\begin{array}{c}\text { Idade } \\
\text { das aves }\end{array}$ & $\begin{array}{c}\text { Linhagem (ns) } \\
\text { utilizada (s) }\end{array}$ & $\begin{array}{l}\text { Método de } \\
\text { estimativa }\end{array}$ & Referência \\
\hline \multirow{8}{*}{ PV } & $0,54(0,07)$ & 1326 & 42 dias & Experimental & $\mathrm{C}$ & Ledur et al. (1992) \\
\hline & $0,52(0,13)$ & 1326 & 42 dias & Experimental & M & Ledur et al. (1992) \\
\hline & $0,55(0,07)$ & 9825 & 42 dias & Experimentais & M & Ledur et al. (1994) \\
\hline & $0,26(0,05)$ & 9825 & 42 dias & Experimentais & $\mathrm{P}$ & Ledur et al. (1994) \\
\hline & $0,41(0,04)$ & 9825 & 42 dias & Experimentais & $\mathrm{C}$ & Ledur et al. (1994) \\
\hline & 0,33 & 9463 & 42 dias & Comercial macho & MA & Argentão et al. (2002) \\
\hline & $0,52(0,08)$ & 483 & 42 dias & Comercial macho & MA & Rance et al. (2002) \\
\hline & $0,55(0,23)$ & 180 & 63 dias & White Rock & $\mathrm{C}$ & Cahaner \& Nitsan (1985) \\
\hline \multirow{5}{*}{ PV em machos } & $0,30(0,27)$ & 208 & 42 dias & Experimental & $\mathrm{P}$ & Singh \& Trehan (1994) \\
\hline & $0,52(0,34)$ & 224 & 42 dias & Experimental & $\mathrm{P}$ & Singh \& Trehan (1994) \\
\hline & $0,39(0,03)$ & 5886 & 42 dias & Experimental & MA & $\begin{array}{l}\text { Le Bihan-Duval et al. } \\
\qquad(1998)\end{array}$ \\
\hline & $0,39(0,01)$ & 18096 & 56 dias & Experimental & MA & $\begin{array}{c}\text { Mignon-Grasteau et al. } \\
\text { (1999) }\end{array}$ \\
\hline & $0,61(0,01)$ & 4770 & 252 dias & Experimental & MA & $\begin{array}{c}\text { Mignon-Grasteau et al. } \\
\text { (1999) }\end{array}$ \\
\hline \multirow{5}{*}{ PV em fêmeas } & $0,33(0,26)$ & 208 & 42 dias & Experimental & $\mathrm{P}$ & Singh \& Trehan (1994) \\
\hline & $0,56(0,34)$ & 224 & 42 dias & Experimental & $\mathrm{P}$ & Singh \& Trehan (1994) \\
\hline & $0,46(0,02)$ & 6204 & 42 dias & Experimental & MA & Le Bihan-Duval et al. \\
\hline & $0,45(0,01)$ & 20211 & 56 dias & Experimental & MA & $\begin{array}{c}\text { Mignon-Grasteau et al. } \\
\text { (1999) }\end{array}$ \\
\hline & $0,64(0,01)$ & 10867 & 252 dias & Experimental & MA & $\begin{array}{c}\text { Mignon-Grasteau et al. } \\
\text { (1999) }\end{array}$ \\
\hline PV em piso & $\begin{array}{l}0,27(0,06) \\
0,64(0,08)\end{array}$ & $\begin{array}{l}2400 \\
2400\end{array}$ & $\begin{array}{l}\text { 43-44 dias } \\
43-44 \text { dias }\end{array}$ & $\begin{array}{l}\text { Macho } \\
\text { Macho }\end{array}$ & $\begin{array}{l}\mathrm{P} \\
\mathrm{M}\end{array}$ & $\begin{array}{l}\text { Leenstra \& Pit (1988) } \\
\text { Leenstra \& Pit (1988) }\end{array}$ \\
\hline PV em gaiola & $\begin{array}{l}0,22(0,13) \\
0,41(0,18)\end{array}$ & $\begin{array}{l}864 \\
864\end{array}$ & $\begin{array}{l}42 \text { dias } \\
42 \text { dias }\end{array}$ & $\begin{array}{l}\text { Macho } \\
\text { Macho }\end{array}$ & $\begin{array}{l}\mathrm{P} \\
\mathrm{M}\end{array}$ & $\begin{array}{l}\text { Leenstra \& Pit (1988) } \\
\text { Leenstra \& Pit (1988) }\end{array}$ \\
\hline US 1 & 0,46 & 12259 & 35 dias & Comercial macho & MA & Argentão et al. (2002) \\
\hline US 2 & 0,51 & 12259 & 35 dias & Comercial macho & MA & Argentão et al. (2002) \\
\hline
\end{tabular}

De modo geral, as estimativas de herdabilidade das características de desempenho são de moderadas a altas. Leenstra \& Pit (1988) encontraram estimativas de herdabilidade para a conversão alimentar de $0,14 \pm 0,18$ e $0,44 \pm 0,15$. Já Argentão et al. (2002) encontraram herdabilidade de 0,22 para esta característica. Segundo Campos \& Pereira (1999) a conversão alimentar tem apresentado diferentes valores de herdabilidade nos estudos que vem sendo conduzidos, porém é uma característica importante em um programa de seleção, já que os gastos com alimentação representam de 50 a $70 \%$ dos custos nesta atividade (Wang et al., 1991), e desperdícios devem ser evitados. 
A herdabilidade para peso vivo em diferentes idades variou de $0,20 \pm 0,08$ a 0,94 $\pm 0,13$ de acordo com Ledur et al. (1992). Valores intermediários a estes para a mesma característica foram encontrados por diversos autores, sob diferentes métodos de estimação e condições experimentais. Segundo Campos \& Pereira (1999) a herdabilidade moderada a alta do peso é um dos principais fatores responsáveis pela grande evolução alcançada no melhoramento dos frangos de corte. As profundidades de músculo peitoral aos 35 dias de idade, medidas in vivo através de ultra-sonografia, foram estimadas por Argentão et al. (2002), e os valores encontrados foram de 0,46 e 0,51 .

Foram encontradas na literatura algumas estimativas de herdabilidade para características de carcaça, como é apresentado na Tabela 2.

TABELA 2 - Estimativas de herdabilidade $\left(h^{2}\right)$ para características de carcaça em frangos de corte, segundo diversos autores. Entre parênteses encontram-se os respectivos erros-padrão (EP)

\begin{tabular}{|c|c|c|c|c|c|c|}
\hline Característica & $1 h^{2}(E P)$ & $\begin{array}{c}\mathrm{N}^{0} \text { de } \\
\text { informações }\end{array}$ & $\begin{array}{c}\text { Idade } \\
\text { das aves }\end{array}$ & $\begin{array}{l}\text { Linhagem (ns) } \\
\text { utilizada (s) }\end{array}$ & $\begin{array}{l}\text { Método de } \\
\text { estimativa }^{2}\end{array}$ & Referência \\
\hline \multirow{2}{*}{$\mathrm{PE}$} & 0,34 & 9463 & 42 dias & Comercial macho & MA & Argentão et al. (2002) \\
\hline & $0,52(0,07)$ & 483 & 42 dias & Comercial macho & MA & Rance et al. (2002) \\
\hline \multirow{3}{*}{ PPEI } & $0,55(0,23)$ & 180 & 63 dias & White Rock & $\mathrm{C}$ & Cahaner \& Nitsan (1985) \\
\hline & 0,45 & 9463 & 42 dias & Comercial macho & MA & Argentão et al. (2002) \\
\hline & $0,59(0,08)$ & 483 & 42 dias & Comercial macho & MA & Rance et al. (2002) \\
\hline & $0,29(0,27)$ & 208 & 42 dias & Experimental & $\mathrm{P}$ & Singh \& Trehan (1994) \\
\hline \multirow{3}{*}{ PPEI em machos } & s $0,57(0,35)$ & 224 & 42 dias & Experimental & $\mathrm{P}$ & Singh \& Trehan (1994) \\
\hline & $0,48(0,04)$ & 964 & 42 dias & Experimental & MA & Le Bihan-Duval et al. (1998) \\
\hline & $0,45(0,30)$ & 208 & 42 dias & Experimental & $\mathrm{P}$ & Singh \& Trehan (1994) \\
\hline \multirow{2}{*}{ PPEI em fêmeas } & $0,54(0,33)$ & 224 & 42 dias & Experimental & $\mathrm{P}$ & Singh \& Trehan (1994) \\
\hline & $0,58(0,04)$ & 940 & 42 dias & Experimental & MA & Le Bihan-Duval et al. (1998) \\
\hline \multirow{3}{*}{ PPER } & $0,65(0,25)$ & 180 & 63 dias & White Rock & $\mathrm{C}$ & Cahaner \& Nitsan (1985) \\
\hline & 0,34 & 9463 & 42 dias & Comercial macho & MA & Argentão et al. (2002) \\
\hline & $0,48(0,07)$ & 483 & 42 dias & Comercial macho & MA & Rance et al. (2002) \\
\hline
\end{tabular}

${ }^{\mathrm{T}} \mathrm{PE}=$ Peso eviscerado PPEI $=$ Peso de peito PPER $=$ Peso de pernas

${ }^{2} \mathrm{MA}=$ Modelo animal; $\mathrm{P}=$ Correlação entre meio-irmãos paternos; $\mathrm{C}=$ Correlação entre irmãos completos. 
Estas estimativas variaram de valores moderados a altos. Para peso eviscerado, Argentão et al. (2002) encontraram herdabilidade de 0,34 e Rance et al. (2002) de 0,52 $\pm 0,07$. A herdabilidade para peso de peito variou de 0,29 $\pm 0,27$ (Singh \& Trehan, 1994) a 0,59 $\pm 0,08$ (Rance et al., 2002). Segundo Le Bihan-Duval et al. (1998) o maior peso de peito têm sido um objetivo de seleção importante. Para a característica de peso de pernas, as herdabilidades encontradas foram de 0,34

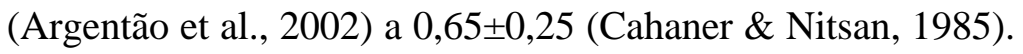

As estimativas de herdabilidade para características de composição corporal estimadas por alguns autores são apresentadas na Tabela 3.

TABELA 3 - Estimativas de herdabilidades $\left(\mathrm{h}^{2}\right)$ para características de composição corporal em frangos de corte, segundo diversos autores. Entre parênteses encontram-se os respectivos erros-padrão (EP)

\begin{tabular}{|c|c|c|c|c|c|c|}
\hline Característica ${ }^{1}$ & $\mathbf{h}^{2}(\mathrm{EP})$ & $\begin{array}{c}\mathrm{N}^{0} \text { de } \\
\text { informações }\end{array}$ & $\begin{array}{c}\text { Idade } \\
\text { das aves }\end{array}$ & $\begin{array}{c}\text { Linhagem (ns) } \\
\text { utilizada (s) }\end{array}$ & $\begin{array}{l}\text { Método de } \\
\text { estimativa }^{2}\end{array}$ & Referência \\
\hline \multirow{2}{*}{ PGA } & $0,57(0,08)$ & 483 & 42 dias & Comercial macho & MA & Rance et al. (2002) \\
\hline & $0,82(0,28)$ & 180 & 63 dias & White Rock & $\mathrm{C}$ & Cahaner \& Nitsan (1985) \\
\hline \multirow{3}{*}{ PGA em machos } & $0,61(0,32)$ & 208 & 42 dias & Experimental & $\mathrm{P}$ & Singh \& Trehan (1994) \\
\hline & $0,71(0,38)$ & 224 & 42 dias & Experimental & $\mathrm{P}$ & Singh \& Trehan (1994) \\
\hline & $0,61(0,07)$ & 964 & 42 dias & Experimental & MA & $\begin{array}{c}\text { Le Bihan-Duval et al. } \\
\text { (1998) }\end{array}$ \\
\hline \multirow{3}{*}{ PGA em fêmeas } & $0,67(0,35)$ & 208 & 42 dias & Experimental & $\mathrm{P}$ & Singh \& Trehan (1994) \\
\hline & $0,74(0,41)$ & 224 & 42 dias & Experimental & $\mathrm{P}$ & Singh \& Trehan (1994) \\
\hline & $0,50(0,05)$ & 940 & 42 dias & Experimental & MA & $\begin{array}{l}\text { Le Bihan-Duval et al. } \\
\text { (1998) }\end{array}$ \\
\hline \multirow{2}{*}{ PGA em piso } & $0,54(0,09)$ & 2400 & 43-44 dias & Macho & $\mathrm{P}$ & Leenstra \& Pit (1988) \\
\hline & $0,52(0,08)$ & 2400 & 43- 44 dias & Macho & M & Leenstra \& Pit (1988) \\
\hline \multirow{2}{*}{ PGA em gaiola } & $0,40(0,15)$ & 864 & 42 dias & Macho & $\mathrm{P}$ & Leenstra \& Pit (1988) \\
\hline & $0,77(0,18)$ & 864 & 42 dias & Macho & M & Leenstra \& Pit (1988) \\
\hline PF & $\begin{array}{l}0,50(0,21) \\
0,08(0,06)\end{array}$ & $\begin{array}{l}180 \\
483\end{array}$ & $\begin{array}{l}63 \text { dias } \\
42 \text { dias }\end{array}$ & $\begin{array}{l}\text { White Rock } \\
\text { Comercial macho }\end{array}$ & $\begin{array}{c}\mathrm{C} \\
\mathrm{MA}\end{array}$ & $\begin{array}{l}\text { Cahaner \& Nitsan (1985) } \\
\text { Rance et al. (2002) }\end{array}$ \\
\hline PM & $\begin{array}{l}0,57(0,24) \\
0,52(0,10)\end{array}$ & $\begin{array}{l}180 \\
483\end{array}$ & $\begin{array}{l}63 \text { dias } \\
42 \text { dias }\end{array}$ & $\begin{array}{c}\text { White Rock } \\
\text { Comercial macho }\end{array}$ & $\begin{array}{c}\mathrm{C} \\
\mathrm{MA}\end{array}$ & $\begin{array}{l}\text { Cahaner \& Nitsan (1985) } \\
\text { Rance et al. (2002) }\end{array}$ \\
\hline PD & $0,38(0,12)$ & 483 & 42 dias & Comercial macho & MA & Rance et al. (2002) \\
\hline PJ & $0,01(0,04)$ & 483 & 42 dias & Comercial macho & MA & Rance et al. (2002) \\
\hline PIL & $0,13(0,07)$ & 483 & 42 dias & Comercial macho & MA & Rance et al. (2002) \\
\hline $\mathrm{PC}$ & $0,30(0,08)$ & 483 & 42 dias & Comercial macho & MA & Rance et al. (2002) \\
\hline
\end{tabular}

${ }^{\mathrm{T}} \mathrm{PGA}=$ Peso da gordura abdominal; $\mathrm{PF}=$ Peso do fígado; $\mathrm{PM}=$ Peso da moela; $\mathrm{PD}=$ Peso do duodeno; $\mathrm{PJ}=$ Peso do jejuno; $\mathrm{PIL}=$ Peso do íleo; $\mathrm{PC}=$ Peso do coração.

${ }^{2} \mathrm{MA}=$ Modelo animal; $\mathrm{P}=$ Correlação entre meio-irmãos paternos; $\mathrm{M}$ = Correlação entre meio-irmãos maternos; $\mathrm{C}=$ Correlação entre irmãos completos. 
As estimativas de herdabilidade para a característica de peso de gordura abdominal foram encontradas na literatura, com valores de moderados a altos. Segundo Michelan Filho (1986) o conteúdo de gordura em aves tem sido caracterizado como bastante herdável. Singh \& Trehan (1994) estimaram altas herdabilidades para peso da gordura abdominal aos 42 dias, as quais variaram de $0,61 \pm 0,32$ a $0,74 \pm 0,41$. Le Bihan-Duval et al. (1998) encontraram estimativas de

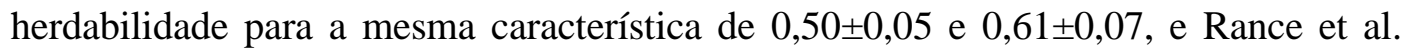
(2002) de $0,57 \pm 0,08$. Leenstra \& Pit (1988) encontraram valores de herdabilidade para peso da gordura abdominal entre $0,52 \pm 0,08$ e $0,77 \pm 0,18$. Para peso da gordura abdominal aos 63 dias, a herdabilidade encontrada por Cahaner \& Nitsan (1985) foi de $0,82 \pm 0,28$.

Há pequenas diferenças na definição de gordura abdominal entre os trabalhos da literatura. Cahaner \& Nitsan (1985), Le Bihan-Duval et al. (1998) e Rance et al. (2002) consideraram como gordura abdominal a gordura aderida à parede abdominal, enquanto Singh \& Trehan (1994) consideraram como gordura abdominal a gordura aderida à parede abdominal mais a gordura aderida ao pró-ventrículo e à moela. Leenstra \& Pit (1988) não fizeram referência ao que consideraram como gordura abdominal.

Para peso do fígado aos 63 dias, Cahaner \& Nitsan (1985) encontraram

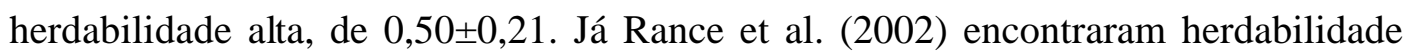
para peso do fígado aos 42 dias próxima de zero, de $0,08 \pm 0,06$. Para peso da moela,

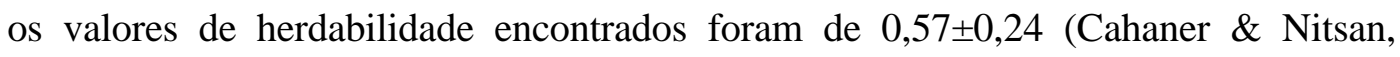

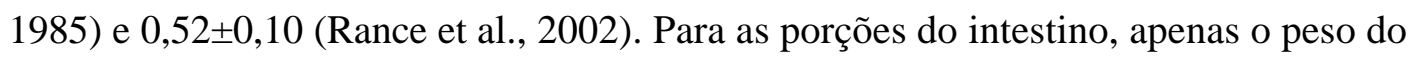
duodeno apresentou herdabilidade moderada, de 0,38 $\pm 0,12$ de acordo com Rance et 
al. (2002). Para peso do jejuno e peso do íleo, os valores de herdabilidade encontrados por estes autores foram baixos. O peso do coração apresentou herdabilidade moderada (Rance et al., 2002), o que é suficiente para que a seleção a favor do peso do coração seja eficiente, podendo prevenir ou mesmo reduzir a incidência de desordens metabólicas.

De acordo McEntee et al. citados por Rance et al. (2002) o valore relativo do tamanho dos órgãos das aves vêm diminuindo, tornando-se fundamental conhecer os valores de herdabilidade para estas características. Assim, é possível saber se as características de importância no metabolsmo dos frangos e que podem ser fatores limitantes ao seu desenvolvimento são capazes de responder à seleção (Lin, 1981).

\subsection{Correlações Genéticas e Fenotípicas}

A correlação genética $\left(\mathrm{r}_{\mathrm{g}}\right)$ entre duas características é a correlação entre os efeitos dos genes que as influenciam (Pirchner, 1983). De acordo com Falconer (1960) ela representa a correlação entre os valores genéticos de um indivíduo para as características sob consideração. Segundo Van Vleck et al. (1987) se algum gene afeta duas características, então estas características são correlacionadas geneticamente. De acordo com Campos \& Pereira (1999) a correlação mede a probabilidade de duas características diferentes serem afetadas pelos mesmos genes, ou seja, é a correlação entre o valor genético de duas características.

A importância do estudo das correlações está no fato de que a seleção para uma determinada característica pode causar resposta em outra geneticamente relacionada (Eler, 2001). Segundo o mesmo autor o coeficiente de correlação 
fenotípica $\left(\mathrm{r}_{\mathrm{p}}\right)$ é o coeficiente de correlação entre os valores fenotípicos do indivíduo, para as duas características.

Como a seleção em frangos de corte ocorre para várias características simultaneamente, torna-se necessário conhecer a relação entre estas carac terísticas de interesse (Wang et al., 1991).

Estimativas de correlações entre características de desempenho em frangos de corte foram descritas por alguns autores, como é apresentado na Tabela 4. 
TABELA 4 - Estimativas de correlações genéticas $\left(r_{\mathrm{g}}\right)$ e femtípicas $\left(\mathrm{r}_{\mathrm{p}}\right)$ entre as características de desempenho em frangos de corte, segundo diversos autores. Entre parênteses encontram-se os respectivos erros-padrão (EP)

\begin{tabular}{|c|c|c|c|c|c|c|}
\hline Características $^{1}$ & $\mathbf{r}_{\mathrm{g}}(\mathbf{E P})$ & $\mathbf{r}_{\mathbf{p}}$ & $\begin{array}{c}\mathrm{N}^{0} \text { de } \\
\text { informações }\end{array}$ & $\begin{array}{c}\text { Linhagem (ns) } \\
\text { utilizada (s) }\end{array}$ & $\begin{array}{l}\text { Método de } \\
\text { estimati va }^{2}\end{array}$ & Referência \\
\hline \multirow{3}{*}{ PN x PV 28 dias } & $0,42(0,13)$ & 0,14 & 1281 & Experimental & $\mathrm{P}$ & Ledur et al. (1992) \\
\hline & $0,24(0,08)$ & 0,14 & 1326 & Experimental & $\mathrm{C}$ & Ledur et al. (1992) \\
\hline & $0,53(0,11)$ & 0,14 & 1326 & Experimental & M & Ledur et al. (1992) \\
\hline \multirow{3}{*}{ PN x PV 35 dias } & $0,42(0,14)$ & 0,13 & 1281 & Experimental & $\mathrm{P}$ & Ledur et al. (1992) \\
\hline & $0,15(0,08)$ & 0,11 & 1326 & Experimental & $\mathrm{C}$ & Ledur et al. (1992) \\
\hline & $0,43(0,11)$ & 0,11 & 1326 & Experimental & M & Ledur et al. (1992) \\
\hline \multirow{3}{*}{ PN x PV 42 dias } & $0,58(0,13)$ & 0,17 & 1281 & Experimental & $\mathrm{P}$ & Ledur et al. (1992) \\
\hline & $0,15(0,08)$ & 0,10 & 1326 & Experimental & $\mathrm{C}$ & Ledur et al. (1992) \\
\hline & $0,43(0,11)$ & 0,10 & 1326 & Experimental & M & Ledur et al. (1992) \\
\hline \multirow{3}{*}{ PV 28 dias x PV 35 dias } & $0,94(0,02)$ & 0,89 & 1326 & Experimental & $\mathrm{P}$ & Ledur et al. (1992) \\
\hline & $0,97(0,01)$ & 0,89 & 1326 & Experimental & $\mathrm{C}$ & Ledur et al. (1992) \\
\hline & $0,99(0,03)$ & 0,89 & 1326 & Experimental & $M$ & Ledur et al. (1992) \\
\hline \multirow{5}{*}{ PV 28 dias x PV 42 dias } & 0,94 & & 6987 & Comerciais macho e fêmea & M & Wang et al. (1991) \\
\hline & 0,83 & & 8184 & Comerciais macho e fêmea & $\mathrm{P}$ & Wang et al. (1991) \\
\hline & $0,99(0,07)$ & 0,59 & 1281 & Experimental & $\mathrm{P}$ & Ledur et al. (1992) \\
\hline & $0,97(0,01)$ & 0,86 & 1326 & Experimental & $\mathrm{C}$ & Ledur et al. (1992) \\
\hline & $0,98(0,04)$ & 0,86 & 1326 & Experimental & M & Ledur et al. (1992) \\
\hline \multirow{4}{*}{ PV 35 dias $x$ PV 42 dias } & $0,90(0,09)$ & 0,58 & 1281 & Experimental & $\mathrm{P}$ & Ledur et al. (1992) \\
\hline & $0,98(0,01)$ & 0,95 & 1326 & Experimental & $\mathrm{C}$ & Ledur et al. (1992) \\
\hline & $0,99(0,01)$ & 0,95 & 1326 & Experimental & $\mathrm{M}$ & Ledur et al. (1992) \\
\hline & 0,85 & 0,47 & 9463 & Comercial macho & MA & Argentão et al. (2002) \\
\hline PV 56 dias x PV 252 dias em machos & $0,50(0,02)$ & $0,94(0,04)$ & 4770 & Experimental & MA & Mignon-Grasteau et al. (1999) \\
\hline PV 56 dias x PV 252 dias em fêmeas & $0,60(0,01)$ & $0,88(0,07)$ & 10867 & Experimental & MA & Mignon-Grasteau et al. (1999) \\
\hline PV 35 dias $\mathrm{x}$ US1 35 dias & 0,41 & 0,43 & 12259 & Comercial macho & MA & Argentão et al. (2002) \\
\hline PV 35 dias $x$ US2 35 dias & 0,43 & 0,56 & 12259 & Comercial macho & MA & Argentão et al. (2002) \\
\hline PV 42 dias $x$ US1 35 dias & 0,42 & 0,46 & 9463 & Comercial macho & MA & Argentão et al. (2002) \\
\hline PV 42 dias $x$ US2 35 dias & 0,43 & 0,46 & 9463 & Comercial macho & MA & Argentão et al. (2002) \\
\hline PV 35 dias $\mathrm{x}$ CA & 0,24 & 0,19 & 6536 & Comercial macho & MA & Argentão et al. (2002) \\
\hline & $0,16(0,27)$ & $-0,18$ & 864 & Macho & $\mathrm{P}$ & Leenstra \& Pit (1988) \\
\hline PV 42 dias X CA (21-42 dias) & $0,56(0,74)$ & $-0,18$ & 864 & Macho & M & Leenstra \& Pit (1988) \\
\hline PV (46-47 dias) x CA (21-42 dias) & $-0,23(0,26)$ & $-0,25$ & 1000 & White Cornish & M & Leenstra et al. (1986) \\
\hline
\end{tabular}


conclusão

\begin{tabular}{|c|c|c|c|c|c|c|}
\hline Características $^{1}$ & $\mathbf{r}_{\mathbf{g}}(\mathbf{E P})$ & $\mathbf{r}_{\mathbf{p}}$ & $\begin{array}{c}\mathrm{N}^{0} \text { de } \\
\text { informações }\end{array}$ & $\begin{array}{c}\text { Linhagem (ns) } \\
\text { utilizada (s) }\end{array}$ & $\begin{array}{l}\text { Método de } \\
\text { estimativa }^{2}\end{array}$ & Referência \\
\hline \multirow{2}{*}{ PV 28 dias x EA (28-42 dias) } & $-0,23$ & & 6987 & Comerciais macho e fêmea & $\mathrm{M}$ & Wang et al. (1991) \\
\hline & $-0,58$ & & 8184 & Comerciais macho e fêmea & $\mathrm{P}$ & Wang et al. (1991) \\
\hline PV 42 dias $x$ EA (28-42 dias) & 0,16 & & 6987 & Comerciais macho e fêmea & M & Wang et al. (1991) \\
\hline \multirow{2}{*}{ PV 28 dias x ING (28-42 dias) } & 0,71 & & 6987 & Comerciais macho e fêmea & M & Wang et al. (1991) \\
\hline & 0,77 & & 8184 & Comerciais macho e fêmea & $\mathrm{P}$ & Wang et al. (1991) \\
\hline \multirow{2}{*}{ PV 42 dias $x$ ING (28-42 dias) } & 0,88 & & 6987 & Comerciais macho e fêmea & M & Wang et al. (1991) \\
\hline & 0,94 & & 8184 & Comerciais macho e fêmea & $\mathrm{P}$ & Wang et al. (1991) \\
\hline
\end{tabular}

${ }^{\mathrm{T}} \mathrm{PN}=$ Peso ao nascimento; PV = Peso vivo; US 1 = Profundidade de músculo peitoral aferida no sentido longitudinal; US $2=$ Profundidade de músculo peitoral aferida no sentido transversal; $\mathrm{CA}=$ Conversão alimentar; EA = Eficiência alimentar; $\mathrm{ING}=$ Ingestão.

${ }^{2} \mathrm{MA}=$ Modelo animal; $\mathrm{P}=$ Correlação entre meio-irmãos paternos; $\mathrm{M}=$ Correlação entre meio-irmãos maternos; $\mathrm{C}=$ Correlação entre irmãos completos 
De acordo com Ledur et al. (1992) o peso ao nascimento apresentou

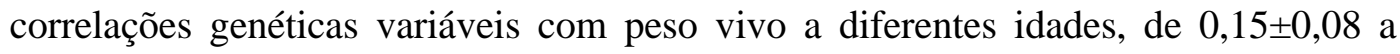
$0,58 \pm 0,13$. As características de peso vivo a diferentes idades apresentaram correlações genéticas bastante fortes entre si, de $0,90 \pm 0,09$ a $0,99 \pm 0,01$, com exceção das que envolvem o peso ao nascer (Ledur et al., 1992). Wang et al. (1991), MignonGrasteau et al. (1999) e Argentão et al. (2002) também descreveram fortes correlações genéticas entre estas características. As correlações fenotípicas entre pesos variaram de 0,10 a 0,95 segundo Ledur et al. (1992).

Argentão et al. (2002) estimaram as correlações genéticas entre as características de profundidade de músculo peitoral medidas in vivo por ultrasonografia e peso vivo, e encontraram correlações genéticas moderadas de 0,41 a 0,43, e fenotípicas de 0,43 a 0,56 .

As correlações genéticas entre peso vivo e conversão alimentar encontradas na literatura apresentaram grande variação, com estimativas de $-0,23 \pm 0,26$ (Leenstra et

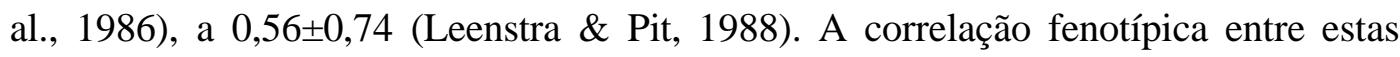
características variou entre -0,25 (Leenstra et al., 1986) e 0,19 (Argentão et al., 2002).

Entre peso vivo e eficiência alimentar, Wang et al. (1991) encontraram correlações genéticas que variaram entre $-0,58$ e 0,16 . Os mesmos autores encontraram fortes correlações genéticas entre peso vivo e ingestão de alimentos, de 0,71 a 0,94 . 
Foi encontrado na literatura um pequeno número de trabalhos com estimativas de correlações entre características de carcaça, as qua is são apresentadas na Tabela 5. 
TABELA 5 - Estimativas de correlações genéticas $\left(r_{g}\right)$ e fenotípicas $\left(r_{p}\right)$ entre características de carcaça em frangos de corte, segundo diversos autores. Entre parênteses encontram-se os respectivos erros-padrão (EP)

\begin{tabular}{|c|c|c|c|c|c|c|c|}
\hline Características $^{1}$ & $\mathbf{r}_{\mathbf{g}}(\mathbf{E P})$ & $\mathbf{r}_{\mathbf{p}}$ & $\begin{array}{c}\mathrm{N}^{0} \text { de } \\
\text { informações }\end{array}$ & $\begin{array}{c}\text { Idade } \\
\text { das aves }\end{array}$ & $\begin{array}{c}\text { Linhagem (ns) } \\
\text { utilizada (s) }\end{array}$ & $\begin{array}{l}\text { Método de } \\
\text { estimativa }\end{array}$ & Referência \\
\hline PE x RCAR & & 0,52 & 800 & 49 dias & Comerciais & & Ávila et al. (1993) \\
\hline PE x PPEI & $\begin{array}{c}0,85 \\
0703)\end{array}$ & 0,89 & 9463 & 42 dias & Comercial macho & MA & Argentão et al. (2002) \\
\hline TE X TILI & $0,87(0,03)$ & 0,90 & 483 & 42 dias & Comercial macho & MA & Rance et al. (2002) \\
\hline PE x PPER & $\begin{array}{c}0,87 \\
0,86(0,03)\end{array}$ & $\begin{array}{l}0,92 \\
0,94\end{array}$ & $\begin{array}{c}9463 \\
483\end{array}$ & $\begin{array}{l}42 \text { dias } \\
42 \text { dias }\end{array}$ & $\begin{array}{l}\text { Comercial macho } \\
\text { Comercial macho }\end{array}$ & $\begin{array}{l}\text { MA } \\
\text { MA }\end{array}$ & $\begin{array}{l}\text { Argentão et al. (2002) } \\
\text { Rance et al. (2002) }\end{array}$ \\
\hline PPEI x PPER & $\begin{array}{c}0,59 \\
0,65(0,07)\end{array}$ & $\begin{array}{l}0,72 \\
0,77\end{array}$ & $\begin{array}{c}9463 \\
483\end{array}$ & $\begin{array}{l}42 \text { dias } \\
42 \text { dias }\end{array}$ & $\begin{array}{l}\text { Comercial macho } \\
\text { Comercial macho }\end{array}$ & $\begin{array}{l}\text { MA } \\
\text { MA }\end{array}$ & $\begin{array}{l}\text { Argentão et al. (2002) } \\
\text { Rance et al. (2002) }\end{array}$ \\
\hline
\end{tabular}

${ }^{1} \mathrm{PE}=$ Peso eviscerado RCAR $=$ Rendimento de carcaça; PPEI = Peso de peito; PPER = Peso de pernas.

${ }^{2} \mathrm{MA}=$ Modelo animal. 
Argentão et al. (2002) e Rance et al. (2002) encontraram fortes correlações entre as características de carcaça, tanto fenotipicamente como geneticamente. Aos 42 dias, a correlação genética estimada por estes autores entre peso eviscerado e peso de peito foi de 0,85 e $0,87 \pm 0,03$, entre peso eviscerado e peso de pernas, de 0,87 e $0,86 \pm 0,03$ e entre peso de peito e peso de pernas, de 0,59 e 0,65 $\pm 0,07$, respectivamente. As correlações fenotípicas encontradas na literatura entre as características de carcaça foram fortes, variando de 0,52 entre peso eviscerado e rendimento de carcaça (Ávila et al., 1993) a 0,94 entre peso eviscerado e peso de pernas (Rance et al., 2002).

Dentre os trabalhos revisados, apenas Rance et al. (2002) estimaram correlações entre as características de composição corporal entre si. Estes resultados são apresentados na Tabela 6.

TABELA 6 - Estimativas de correlações genéticas $\left(r_{g}\right)$ e fenotípicas $\left(r_{p}\right)$ entre características de composição corporal em frangos de corte segundo Rance et al. (2002). Entre parênteses encontramse os respectivos erros-padrão (EP)

\begin{tabular}{|ccc|}
\hline Características $^{\mathbf{1}}$ & $\mathbf{r}_{\mathbf{g}}(\mathbf{E P})$ & $\mathbf{r}_{\mathbf{p}}$ \\
\hline PGA x PC & $0,35(0,15)$ & 0,07 \\
\hline PGA x PF & $0,42(0,26)$ & 0,12 \\
\hline PGA x PM & $0,38(0,14)$ & $-0,09$ \\
\hline PGA x PD & $0,23(0,18)$ & 0,18 \\
\hline PGA x PIL & $0,03(0,24)$ & $-0,03$ \\
\hline PC x PF & $0,19(0,26)$ & 0,59 \\
\hline PC x PM & $-0,49(0,19)$ & 0,09 \\
\hline PC x PD & $0,46(0,19)$ & 0,34 \\
\hline PC x PJ & $-0,48(1,28)$ & 0,34 \\
\hline PC x PIL & $-0,35(0,32)$ & 0,23 \\
\hline PF x PM & $-0,07(0,28)$ & 0,15 \\
\hline PF x PD & $0,41(0,30)$ & 0,30 \\
\hline PF x PJ & $0,78(0,72)$ & 0,39 \\
\hline PF x PIL & $-0,19(0,36)$ & 0,19 \\
\hline PM x PD & $0,61(0,17)$ & 0,20 \\
PM x PIL & $0,79(0,24)$ & 0,08 \\
\hline
\end{tabular}

Adaptado de Rance et al. (2002). Utilizaram-se neste estudo 483 aves de 42 dias de linhagem comercial macho. O método de estimativa utilizado foi o modelo animal. ${ }^{1} \mathrm{PGA}=$ Peso da gordura abdominal; $\mathrm{PC}=$ Peso do coração; $\mathrm{PF}=$ Peso do fígado $; \mathrm{PM}=$ Peso da moela $; \mathrm{PD}=$ Peso do duodeno $; \mathrm{PJ}=$ Peso do jejuno; $\mathrm{PIL}=$ Peso do íleo. 
As correlações fenotípicas entre peso da gordura abdominal e demais características de composição foram fracas ou inversas fracas, variando de $-0,09$ a 0,18 de acordo com Rance et al. (2002). O peso da gordura abdominal de acordo com estes autores apresentou correlação genética moderada com as demais características de composição corporal, com exceção do peso do íleo. Entre peso da gordura abdominal e peso da moela, a correlação genética encontrada foi de $0,38 \pm 0,14$. Entre o peso da gordura abdominal e as porções do intestino as correlações genéticas foram de $0,23 \pm 0,18$ com peso do duodeno e $0,03 \pm 0,24$ com peso do íleo. Entretanto, o erropadrão das estimativas foi alto, sendo estas, portanto, pouco precisas.

Segundo Konarewski et al. (2000) a seleção para maior peso corporal determina um aumento no tamanho e na capacidade do trato gastrintestinal das aves, que está relacionada ao aumento da quantidade de gordura nos frangos de corte, uma vez que o aumento de ganho de peso nestes animais foi obtido através do aumento de sua capacidade de ingestão, e de acordo com Uni et al. (1995) também em sua superfície absortiva intestinal. Como conseqüência, as aves apresentam maior capacidade de absorção intestinal de nutrientes, o que determina uma maior deposição de gordura. Também segundo Cahaner et al. (1986) aves de maior adiposidade possuem maior capacidade digestiva.

Ainda no estudo de Rance et al. (2002), a correlação genética entre peso da gordura e peso do fígado foi igual a 0,42 $\pm 0,26$. Segundo Machado (2002) a atividade do tecido hepático está diretamente relacionada à deposição de gordura, apesar de a lipogênese ser influenciada também a fatores relacionados à nutrição.

Entre peso da gordura e peso do coração, a correlação genética encontrada por Rance et al. (2002) foi moderada, igual a $0,35 \pm 0,15$. De acordo com estes autores o 
peso do coração apresentou correlações genéticas variáveis com as porções do intestino, de $-0,48 \pm 1,28$ a $0,46 \pm 0,19$. A despeito destes resultados, os mesmos autores afirmam que como o coração fornece sangue para todos os tecidos do corpo, seria de se esperar uma correlação genética forte entre ele e todos os tecidos que irriga.

Rance et al. (2002) descreveram também correlações genéticas entre peso do fígado e porções do intestino de $-0,19 \pm 0,36$ a $0,78 \pm 0,72$. As correlações fenotípicas foram de 0,15 a 0,39 entre as mesmas características segundo estes autores. As correlações genéticas entre o peso da moela e as porções do intestino foram fortes, ainda segundo os mesmos autores, ficando em $0,61 \pm 0,17$ com peso do duodeno e

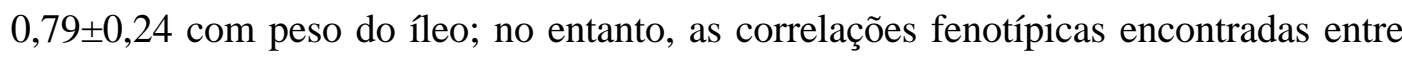
estas características foram baixas.

Foram encontradas na literatura algumas estimativas de corre lações entre características de desempenho e características de carcaça, como é apresentado na Tabela 7. 
TABELA 7 - Estimativas de correlações genéticas $\left(r_{g}\right)$ e fenotípicas $\left(r_{p}\right)$ entre características de desempenho e características de carcaça em frangos de corte, segundo diversos autores. Entre parênteses encontram-se os respectivos erros-padrão (EP)

\begin{tabular}{|c|c|c|c|c|c|c|c|}
\hline Características $^{1}$ & $\mathbf{r}_{\mathrm{g}}(\mathbf{E P})$ & $\mathbf{r}_{\mathbf{p}}$ & $\begin{array}{c}\mathrm{N}^{0} \text { de } \\
\text { informações }\end{array}$ & $\begin{array}{c}\text { Idade } \\
\text { das aves }\end{array}$ & $\begin{array}{c}\text { Linhagem (ns) } \\
\text { utilizada (s) }\end{array}$ & $\begin{array}{l}\text { Método de } \\
\text { estimativa }\end{array}$ & Referência \\
\hline PV x RCAR & & 0,35 & 800 & 49 dias & Comerciais & & Ávila et al. (1993) \\
\hline \multirow{2}{*}{ PV 28 dias x PE 47 dias } & 0,85 & & 1765 & & Comerciais macho e fêmea & M & Wang et al. (1991) \\
\hline & 0,86 & & 4045 & & Comerciais macho e fêmea & $\mathrm{P}$ & Wang et al. (1991) \\
\hline PV 42 dias $x$ PE 47 dias & 0,97 & & 1765 & & Comerciais macho e fêmea & M & Wang et al. (1991) \\
\hline \multirow{4}{*}{ PV x PE } & 0,97 & 0,95 & 9463 & 42 dias & Comercial macho & MA & Argentão et al. (2002) \\
\hline & $0,96(0,01)$ & 0,97 & 483 & 42 dias & Comercial macho & MA & Rance et al. (2002) \\
\hline & & 0,98 & 800 & 49 dias & Comerciais & & Ávila et al. (1993) \\
\hline & & 0,97 & 24 & & Experimentais e comercial & & Schmidt \& Custódio (1995) \\
\hline \multirow{3}{*}{ PV x PPEI } & 0,77 & 0,83 & 9463 & 42 dias & Comercial macho & MA & Argentão et al. (2002) \\
\hline & $0,92(0,02)$ & 0,86 & 483 & 42 dias & Comercial macho & MA & Rance et al. (2002) \\
\hline & $0,82(0,14)$ & 0,82 & 180 & 63 dias & White Rock & $\mathrm{C}$ & Cahaner \& Nitsan (1985) \\
\hline \multirow{2}{*}{ PV x PPEI em machos } & $0,83(0,12)$ & $0,64(0,07)$ & 864 & 42 dias & Experimental & $\mathrm{P}$ & Singh \& Trehan (1994) \\
\hline & $0,76(0,03)$ & & 964 & 42 dias & Experimental & MA & Le Bihan-Duval et al. (1998) \\
\hline \multirow{2}{*}{ PV x PPEI em fêmeas } & $0,86(0,20)$ & $0,66(0,08)$ & 864 & 42 dias & Experimental & $\mathrm{P}$ & Singh \& Trehan (1994) \\
\hline & $0,77(0,03)$ & & 940 & 42 dias & Experimental & MA & Le Bihan-Duval et al. (1998) \\
\hline \multirow{3}{*}{ PV x PPER } & $0,91(0,18)$ & 0,87 & 180 & 63 dias & White Rock & $\mathrm{C}$ & Cahaner \& Nitsan (1985) \\
\hline & 0,87 & 0,89 & 9463 & 42 dias & Comercial macho & MA & Argentão et al. (2002) \\
\hline & $0,88(0,03)$ & 0,91 & 483 & 42 dias & Comercial macho & MA & Rance et al. (2002) \\
\hline US1 35 dias $x$ PPEI 42 dias & 0,68 & 0,59 & 9463 & & Comercial macho & MA & Argentão et al. (2002) \\
\hline US2 35 dias x PPEI 42 dias & 0,67 & 0,56 & 9463 & & Comercial macho & MA & Argentão et al. (2002) \\
\hline $\mathrm{EA}(28-42$ dias) x PE 47 dias & 0,53 & & 1765 & & Comerciais macho e fêmea & M & Wang et al. (1991) \\
\hline
\end{tabular}

${ }^{\mathrm{T}} \mathrm{PV}=$ Peso vivo; RCAR= Rendimento de carcaça; $\mathrm{PE}=$ Peso eviscerado; PPEI = Peso de peito; PPER = Peso de pernas; US 1= Profundidade de músculo peitoral aferida no sentido longitudinal; US 2 = Profundidade de músculo peitoral aferida no sentido transversal; EA = Eficiência alimentar.

${ }^{2} \mathrm{MA}=$ Modelo animal; $\mathrm{P}=$ Correlação entre meio-irmãos paternos; $\mathrm{M}=$ Correlação entre meio-irmãos maternos; $\mathrm{C}=$ Correlação entre irmãos completos. 
Segundo Campos \& Pereira (1999) as características de desempenho são, de modo geral, fortemente correlacionadas com as características de carcaça. De acordo com a maioria dos autores a característica peso vivo apresentou forte correlação genética com as características de carcaça. Entre peso vivo e peso eviscerado, as correlações genéticas encontradas foram de 0,85 (Wang et al., 1991) a 0,97 (Wang et al., 1991; Argentão et al., 2002). As correlações fenotípicas encontradas na literatura para estas características também foram fortes.

Entre peso vivo e peso de peito, as correlações genéticas encontradas na

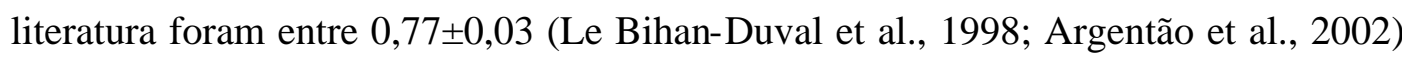
e 0,92 $\pm 0,02$ (Rance et al., 2002), e entre peso vivo e peso de pernas entre 0,87

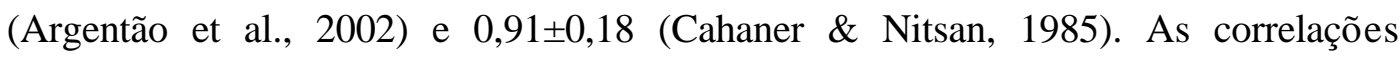
fenotípicas encontradas para estas características também foram fortes. A correlação fenotípica entre peso vivo e rendimento de carcaça aos 49 dias foi de 0,35 de acordo com Ávila et al. (1993). De acordo com Chambers (1990) e Barbato (1992) a seleção para peso vivo aumenta o rendimento de carcaça em frangos de corte.

As correlações genéticas e fenotípicas entre as profundidades de músculo peitoral medidas in vivo através de ultra-sonografia e peso de peito foram estimadas por Argentão et al. (2002) como sendo fortes, sendo as genéticas com valores de 0,68 e 0,67 , o que indica que a seleção para medidas de ultra-sonografia pode ser eficiente em favorecer aves com maior peso de peito. Wang et al. (1991) estimaram a correlação genética entre eficiência alimentar e peso eviscerado e encontraram uma forte correlação de 0,53 .

Correlações entre características de desempenho e de composição corporal foram estimadas por diversos autores e são apresentadas na Tabela 8. 
TABELA 8 - Estimativas de correlações genéticas $\left(r_{g}\right)$ e fenotípicas $\left(r_{p}\right)$ entre características de desempenho e características de composição corporal em frangos de corte, segundo diversos autores. Entre parênteses encontram-se os respectivos erros-padrão (EP)

\begin{tabular}{|c|c|c|c|c|c|c|c|}
\hline Características $^{1}$ & $\mathbf{r}_{\mathbf{g}}(\mathbf{E P})$ & $\mathbf{r}_{\mathbf{p}}$ & $\begin{array}{c}\mathbf{N}^{0} \text { de } \\
\text { informações }\end{array}$ & $\begin{array}{c}\text { Idade } \\
\text { das aves }\end{array}$ & $\begin{array}{c}\text { Linhagem (ns) } \\
\text { utilizada (s) }\end{array}$ & $\begin{array}{l}\text { Método de } \\
\text { estimativa }\end{array}$ & Referência \\
\hline \multirow{7}{*}{ PV x PGA } & 0,50 & & 50 & 28 dias & Comercial & \multirow{6}{*}{$\begin{array}{l}\mathrm{C} \\
\mathrm{M}\end{array}$} & Griffiths et al. (1978) \\
\hline & & 0,56 & 40 & 56 dias & Comercial & & Griffiths et al. (1978) \\
\hline & $0,35(0,29)$ & 0,36 & 180 & 63 dias & White Rock & & Cahaner \& Nitsan (1985) \\
\hline & $0,45(0,17)$ & 0,46 & 1000 & $46-47$ dias & White Cornish & & Leenstra et al. (1986) \\
\hline & & 0,29 & 800 & 49 dias & Comerciais & & Ávila et al. (1993) \\
\hline & & $-0,01$ & 24 & 49 dias & Experimentais e comercial & & Schmidt \& Custódio (1995) \\
\hline & $0,27(0,10)$ & 0,16 & 483 & 42 dias & Comercial macho & MA & Rance et al. (2002) \\
\hline \multirow{3}{*}{ PV x PGA em machos } & & 0,38 & 16 & 84 dias & Comerciais & & Sonaiya \& Benyi (1983) \\
\hline & $0,58(0,50)$ & $0,37(0,08)$ & 864 & 42 dias & Experimental & $\mathrm{P}$ & Singh \& Trehan (1994) \\
\hline & $0,33(0,06)$ & & 964 & 42 dias & Experimental & MA & Le Bihan-Duval et al. (1998) \\
\hline \multirow{3}{*}{ PV x PGA em fêmeas } & & 0,46 & 16 & 84 dias & Comerciais & & Sonaiya \& Benyi (1983) \\
\hline & $0,55(0,42)$ & $0,37(0,08)$ & 864 & 42 dias & Experimental & $\mathrm{P}$ & Singh \& Trehan (1994) \\
\hline & $0,47(0,06)$ & & 940 & 42 dias & Experimental & MA & Le Bihan-Duval et al. (1998) \\
\hline \multirow{2}{*}{ PV x PGA em piso } & $0,58(0,10)$ & 0,56 & 2400 & 43-44 dias & Macho & $\mathrm{P}$ & Leenstra \& Pit (1988) \\
\hline & $0,54(0,09)$ & 0,56 & 2400 & 43-44 dias & Macho & M & Leenstra \& Pit (1988) \\
\hline \multirow{2}{*}{ PV x PGA em gaiola } & $0,55(0,19)$ & 0,51 & 864 & 42 dias & Macho & $\mathrm{P}$ & Leenstra \& Pit (1988) \\
\hline & $0,30(0,22)$ & 0,51 & 864 & 42 dias & Macho & M & Leenstra \& Pit (1988) \\
\hline \multirow{2}{*}{ PV 28 dias x PGA 47 dias } & 0,59 & & 1765 & & Comerciais macho e fêmea & M & Wang et al. (1991) \\
\hline & 0,50 & & 4045 & & Comerciais macho e fêmea & $\mathrm{P}$ & Wang et al. (1991) \\
\hline PV 42 dias $x$ PGA 47 dias & 0,76 & & 1765 & & Comerciais macho e fêmea & M & Wang et al. (1991) \\
\hline \multirow{2}{*}{ CA (21-42 dias) x PGA 42} & $0,43(0,19)$ & 0,18 & 864 & & Macho & $P$ & Leenstra \& Pit (1988) \\
\hline & $0,58(0,46)$ & 0,18 & 864 & & Macho & M & Leenstra \& Pit (1988) \\
\hline $\begin{array}{c}\text { EA }(28-42 \text { dias }) \times \text { PGA } 47 \\
\text { dias }\end{array}$ & $-0,41$ & & 1765 & & Comerciais macho e fêmea & M & Wang et al. (1991) \\
\hline \multirow[t]{3}{*}{ PV $x$ PI } & $0,69(0,20)$ & 0,58 & 180 & 63 dias & White Rock & $\mathrm{C}$ & Cahaner \& Nitsan (1985) \\
\hline & $0,49(0,25)$ & 0,53 & 180 & 63 dias & White Rock & $\mathrm{C}$ & Cahaner \& Nitsan (1985) \\
\hline & $0,32(0,20)$ & 0,49 & 483 & 42 dias & Comercial macho & MA & Rance et al. (2002) \\
\hline \multirow{2}{*}{ PV x PM } & $0,68(0,19)$ & 0,56 & 180 & 63 dias & White Rock & $\mathrm{C}$ & Cahaner \& Nitsan (1985) \\
\hline & $0,22(0,14)$ & 0,14 & 483 & 42 dias & Comercial macho & MA & Rance et al. (2002) \\
\hline PV x PD & $0,50(0,15)$ & 0,36 & 483 & 42 dias & Comercial macho & MA & Rance et al. (2002) \\
\hline PV x PJ & $0,60(1,24)$ & 0,32 & 483 & 42 dias & Comercial macho & MA & Rance et al. (2002) \\
\hline PV x PIL & $0,13(0,24)$ & 0,16 & 483 & 42 dias & Comercial macho & MA & Rance et al. (2002) \\
\hline
\end{tabular}


conclusão

\begin{tabular}{|c|c|c|c|c|c|c|c|}
\hline Características $^{1}$ & $\mathbf{r}_{\mathbf{g}}(\mathbf{E P})$ & $\mathbf{r}_{\mathbf{p}}$ & $\begin{array}{c}\mathbf{N}^{\circ} \text { de } \\
\text { informações }\end{array}$ & $\begin{array}{c}\text { Idade } \\
\text { das aves }\end{array}$ & $\begin{array}{c}\text { Linhagem (ns) } \\
\text { utilizada (s) }\end{array}$ & $\begin{array}{l}\text { Método de } \\
\text { estimativa }^{2}\end{array}$ & Referência \\
\hline PV x PC & $0,61(0,13)$ & $\begin{array}{l}0,45 \\
0,61 \\
0,44 \\
0,52\end{array}$ & $\begin{array}{c}50 \\
50 \\
50 \\
483\end{array}$ & $\begin{array}{c}\text { Ao nascimento } \\
\text { Ao nascimento } \\
\text { Ao nascimento } \\
42 \text { dias }\end{array}$ & $\begin{array}{l}\text { Comercial macho } \\
\text { Comercial macho } \\
\text { Comercial macho } \\
\text { Comercial macho }\end{array}$ & MA & $\begin{array}{l}\text { Yang et al. (1999) } \\
\text { Yang et al. (1999) } \\
\text { Yang et al. (1999) } \\
\text { Rance et al. (2002) }\end{array}$ \\
\hline
\end{tabular}

${ }^{1} \mathrm{PV}=$ Peso vivo; PGA = Peso da gordura abdominal; $\mathrm{CA}=$ Conversão alimentar; EA = Eficiência alimentar; PI = Peso do intestino; PF = Peso do fígado; PM = Peso da moela; PD $=$ Peso do duodeno; $\mathrm{PJ}=$ Peso do jejuno; $\mathrm{PIL}=$ Peso do íleo; $\mathrm{PC}=$ Peso do coração.

${ }^{2} \mathrm{MA}=$ Modelo animal; $\mathrm{P}=$ Correlação entre meio-irmãos paternos; $\mathrm{M}$ = Correlação entre meio-irmãos maternos; $\mathrm{C}$ = Correlação entre irmãos completos . 
Segundo Campos \& Pereira (1999) as características de desempenho são, de modo geral, fortemente correlacionadas com as características de peso de gordura abdominal. Como apresentado na Tabela 8, vários estudos apresentando as correlações entre as características peso vivo e peso da gordura abdominal foram encontrados na literatura. As correlações genéticas encontradas foram de moderadas a

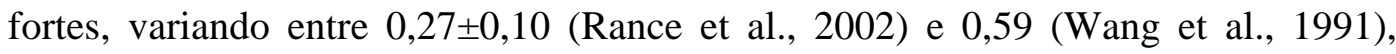
enquanto que as correlações fenotípicas variaram de $-0,01$ (Schmidt \& Custódio, 1995) a 0,56 (Leenstra \& Pit, 1988). De acordo com Lin (1981) a ave que é selecionada para maior peso vivo, ingere mais alimento e por esta razão deposita mais gordura.

O peso da gordura abdominal apresentou correlações genéticas moderadas a fortes com conversão alimentar, com valores de $0,43 \pm 0,19$ e $0,58 \pm 0,46$, entretanto, as correlações fenotípicas entre estas características foram baixas (Leenstra \& Pit , 1988). Por outro lado, a correlação genética entre peso da gordura abdominal e eficiência alimentar foi inversa moderada, igual a $-0,41$ segundo Wang et al. (1991). De acordo com Leenstra (1986), Leenstra \& Pit (1987) e Buyse et al. (1999) uma seleção para menor deposição de gordura está geralmente associada a uma melhor conversão alimentar.

O excesso de gordura tem influência negativa sobre a eficiência alimentar (Campos \& Pereira, 1999). Isso ocorre porque o organismo animal desvia nutrientes para o tecido adiposo (Farrel et al., 1982), já que a gordura tem alta densidade energética e consome bastante energia para ser depositada (Lin, 1981). Foi considerado como gordura abdominal por Griffiths et al. (1978) a gordura aderida à 
parede abdominal mais a gordura aderida à moela e aos intestinos, por Leenstra et al. (1986) a gordura aderida à parede abdominal mais a gordura aderida ao próventrículo e à moela, por Schmidt \& Custódio (1995) a gordura aderida à parede abdominal mais a gordura aderida ao coração e à moela, e por Sonaiya \& Benyi (1983), Wang et al. (1991) e Ávila et al. (1993) a gordura aderida à parede abdominal mais a gordura aderida à moela.

O peso vivo apresentou correlações genéticas moderadas a fortes com o peso das vísceras, com exceção do peso do íleo, cuja correlação com peso vivo foi fraca segundo Rance et al. (2002). Foram encontradas correlações genéticas que vão de $0,22 \pm 0,14$ entre peso vivo e peso da moela (Rance et al., 2002) a 0,69 $\pm 0,20$ entre peso vivo e peso do intestino (Cahaner \& Nitsan, 1985). Como o maior ganho de peso das aves conseguido através dos anos deurse pelo incremento em sua capacidade de consumo (Konarewski et al, 2000), a seleção para maior peso corporal causa um aumento no tamanho e na capacidade do trato gastrintestinal das aves.

A correlação genética entre peso vivo e peso do coração foi de $0,61 \pm 0,13$ segundo Rance et al. (2002), e a correlação fenotípica entre estas características variou de 0,45 a 0,61 (Yang et al., 1999). De acordo com Rance et al. (2002) com o aumento do peso vivo dos frangos como critério de seleção, tem-se, de modo geral, um aumento em termos absolutos dos órgãos e tecidos das aves. As correlações fenotípicas entre peso vivo e peso das vísceras apresentaramse variáveis, indo de 0,14 entre peso vivo e peso da moela (Rance et al., 2002) e 0,61 entre peso vivo e peso do coração (Yang et al., 1991).

As correlações entre características de carcaça e características de composição corporal encontradas na literatura são descritas na Tabela 9. 
TABELA 9 - Estimativas de correlações genéticas $\left(r_{g}\right)$ e fenotípicas $\left(r_{p}\right)$ entre características de carcaça e características de composição corporal em frangos de corte, segundo diversos autores. Entre parênteses encontram-se os respectivos erros-padrão (EP)

\begin{tabular}{|c|c|c|c|c|c|c|c|}
\hline Características $^{1}$ & $\mathbf{r}_{\mathrm{g}}(\mathbf{E P})$ & $\mathbf{r}_{\mathbf{p}}$ & $\begin{array}{c}\mathbf{N}^{0} \text { de } \\
\text { informações }\end{array}$ & $\begin{array}{c}\text { Idade } \\
\text { das aves }\end{array}$ & $\begin{array}{c}\text { Linhagem (ns) } \\
\text { utilizada (s) }\end{array}$ & $\begin{array}{l}\text { Método de } \\
\text { estimativa }^{2}\end{array}$ & Referência \\
\hline PGA $x$ RCAR & & 0,21 & 800 & 49 dias & Comerciais & & Avila et al. (1993) \\
\hline \multirow{4}{*}{ PGA x PE } & 0,18 & & 1765 & 47 dias & Comerciais macho e fêmea & M & Wang et al. (1991) \\
\hline & 0,42 & & 4045 & 47 dias & Comerciais macho e fêmea & $\mathrm{P}$ & Wang et al. (1991) \\
\hline & & 0,30 & 800 & 49 dias & Comerciais & & Ávila et al. (1993) \\
\hline & $0,47(0,10)$ & 0,16 & 483 & 42 dias & Comercial macho & MA & Rance et al. (2002) \\
\hline PGA x PPEI & $0,27(0,10)$ & 0,14 & 483 & 42 dias & Comercial macho & MA & Rance et al. (2002) \\
\hline \multirow{2}{*}{ PGA x PPEI em machos } & $0,15(0,35)$ & $0,09(0,09)$ & 864 & 42 dias & Experimental & $\mathrm{P}$ & Singh \& Trehan (1994) \\
\hline & $0,25(0,06)$ & & 964 & 42 dias & Experimental & MA & Le Bihan-Duval et al. (1998) \\
\hline \multirow{2}{*}{ PGA x PPEI em fêmeas } & $0,09(0,18)$ & $0,19(0,07)$ & 864 & 42 dias & Experimental & $\mathrm{P}$ & Singh \& Trehan (1994) \\
\hline & $0,23(0,07)$ & & 940 & 42 dias & Experimental & MA & Le Bihan-Duval et al. (1998) \\
\hline PGA x PPER & $0,38(0,11)$ & 0,08 & 483 & 42 dias & Comercial macho & MA & Rance et al. (2002) \\
\hline PC x PPEI & $0,55(0,12)$ & 0,48 & 483 & 42 dias & Comercial macho & MA & Rance et al. (2002) \\
\hline PC $x$ PPER & $0,59(0,13)$ & 0,57 & 483 & 42 dias & Comercial macho & MA & Rance et al. (2002) \\
\hline PC x PE & $0,64(0,13)$ & 0,55 & 483 & 42 dias & Comercial macho & MA & Rance et al. (2002) \\
\hline PF x PPEI & $0,24(0,21)$ & 0,46 & 483 & 42 dias & Comercial macho & MA & Rance et al. (2002) \\
\hline PF $x$ PPER & $0,35(0,21)$ & 0,47 & 483 & 42 dias & Comercial macho & MA & Rance et al. (2002) \\
\hline PF x PE & $0,28(0,22)$ & 0,49 & 483 & 42 dias & Comercial macho & MA & Rance et al. (2002) \\
\hline PM x PPEI & $0,29(0,15)$ & 0,04 & 483 & 42 dias & Comercial macho & MA & Rance et al. (2002) \\
\hline PM x PPER & $0,09(0,15)$ & 0,15 & 483 & 42 dias & Comercial macho & MA & Rance et al. (2002) \\
\hline PM x PE & $0,22(0,15)$ & 0,11 & 483 & 42 dias & Comercial macho & MA & Rance et al. (2002) \\
\hline PD x PPEI & $0,54(0,14)$ & 0,29 & 483 & 42 dias & Comercial macho & MA & Rance et al. (2002) \\
\hline PD x PPER & $0,32(0,17)$ & 0,36 & 483 & 42 dias & Comercial macho & MA & Rance et al. (2002) \\
\hline PD x PE & $0,45(0,17)$ & 0,35 & 483 & 42 dias & Comercial macho & MA & Rance et al. (2002) \\
\hline PJ $x$ PPEI & $-0,33(0,76)$ & 0,31 & 483 & 42 dias & Comercial macho & MA & Rance et al. (2002) \\
\hline PJ $x$ PPER & $0,53(1,00)$ & 0,37 & 483 & 42 dias & Comercial macho & MA & Rance et al. (2002) \\
\hline PJ x PE & $0,50(1,30)$ & 0,34 & 483 & 42 dias & Comercial macho & MA & Rance et al. (2002) \\
\hline PIL x PPEI & $-0,18(0,27)$ & 0,17 & 483 & 42 dias & Comercial macho & MA & Rance et al. (2002) \\
\hline PIL $x$ PPER & $0,39(0,24)$ & 0,22 & 483 & 42 dias & Comercial macho & $\mathrm{MA}$ & Rance et al. (2002) \\
\hline PIL x PE & $0,15(0,24)$ & 0,19 & 483 & 42 dias & Comercial macho & MA & Rance et al. (2002) \\
\hline
\end{tabular}

${ }^{1} \mathrm{PGA}=$ Peso da gordura abdominal, RCAR = Rendimento de carcaça; $\mathrm{PE}=$ Peso eviscerado, $\mathrm{PPEI}=$ Peso de peito, $\mathrm{PPER}=$ Peso de pernas, $\mathrm{PC}=\mathrm{Peso}$ do coração, $\mathrm{PF}=\mathrm{Pes}$ o fígado, $\mathrm{PM}=$ Peso da moela, $\mathrm{PD}=$ Peso do duodeno, $\mathrm{PJ}=$ Peso do jejuno, $\mathrm{PIL}=$ Peso do íleo.

${ }^{2} \mathrm{MA}=$ Modelo animal; $\mathrm{P}$ = Correlação entre meio-irmãos paternos; $\mathrm{M}$ = Correlação entre meio-irmãos maternos. 
As correlações genéticas e fenotípicas entre peso de gordura abdominal e as características de carcaça foram bastante variáveis. Ávila et al. (1993) encontraram correlação fenotípica de 0,21 entre peso da gordura abdominal e rendimento de carcaça. Entre peso da gordura abdominal e peso eviscerado, as correlações

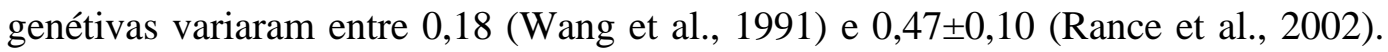
Também entre estas características foi encontrada correlação fenotípica de 0,30 (Ávila et al., 1993).

Entre peso de gordura abdominal e peso de peito as correlações genéticas

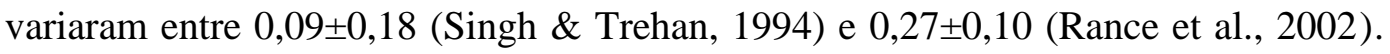
Segundo Le Bihan-Duval et al. (1998) e Buyse et al. (1999) uma seleção para menor deposição de gordura está geralmente associada a um maior rendimento de peito. Já entre peso de gordura abdominal e peso de pernas, Rance et al. (2002) estimaram uma correlação genética de $0,38 \pm 0,11$. De acordo com Leenstra \& Pit (1987) uma seleção para menor deposição de gordura está geralmente associada a maiores rendimentos de carcaça. As correlações fenotípicas encontradas na literatura entre peso de gordura abdominal e peso de peito e pernas foram baixas.

De acordo com Rance et al. (2002), o peso do coração apresentou fortes correlações genéticas com características de carcaça. A correlação genética entre peso de coração e peso de peito foi de $0,55 \pm 0,12$, entre peso de coração e peso de

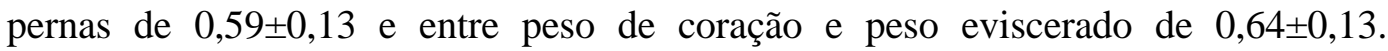
Conforme já mencionado, eram esperadas correlações genéticas positivas entre o coração e os tecidos por ele irrigados (Rance et al., 2002). Ainda segundo estes autores o fígado apresentou correlações genéticas e fenotípicas moderadas com características de carcaça mais baixas que o coração, sendo de $0,24 \pm 0,21$ a 
correlação genética entre peso de fígado e peso de peito, $0,35 \pm 0,21$ entre peso de fígado e peso de pernas e $0,28 \pm 0,22$ entre peso de fígado e peso eviscerado.

Rance et al. (2002) também descreveram as correlações genéticas e fenotípicas entre o trato gastrintestinal e características de carcaça. O peso da moela apresentou correlações genéticas e fenotípicas fracas e moderadas com características de carcaça, e as porções do intestino apresentaram correlações inversas fracas e moderadas com peso de peito. Já o peso do duodeno, segundo os mesmos autores, apresentou correlação genética moderada com peso de peito, de 0,54 $\pm 0,14$. Ainda segundo Rance et al. (2002) entre as porções do intestino e o peso de pernas, as correlações genéticas variaram de $0,32 \pm 0,17$ a $0,53 \pm 1,00$, e entre as porções do intestino e o peso eviscerado, de $0,15 \pm 0,24$ a $0,50 \pm 1,30$.

Os coeficientes de variação das características foram diferentes entre os trabalhos revisados. Estes coeficientes estiveram na faixa de 8,4\% a $13,6 \%$ para características de desempenho e entre 9,2\% e 16,4\% para características de carcaça. Para características de composição corporal, os coeficientes de variação ficaram em torno de $15 \%$, atingindo valores de $20,9 \%$, para peso de moela e de $28,7 \%$ para peso da gordura abdominal (Argentão et al., 2002; Rance et al., 2002). De acordo com Freund \& Wilson (1997) o coeficiente de variação corresponde ao desvio -padrão em porcentagem em relação ao valor médio das observações e é uma medida que representa a variabilidade de um conjunto de dados, sendo a mais indicada para comparação entre resultados de pesquisas com características semelhantes. Em casos de alta variabilidade, o processo de seleção pode ser facilitado para a característica em questão, uma vez que com grande variabilidade são mais nítidas as diferenças entre os animais. Entretanto, a resposta à seleção para uma determinada 
característica depende não só da variabilidade dos dados, mas também da herdabilidade da característica e de sua correlação com as outras características a serem selecionadas, além da confiabilidade das avaliações (Eler, 2001).

Como pode ser observado, poucos estudos vem sendo realizados com várias das características de desempenho, carcaça e composição corporal em frangos de corte, especialmente no tocante à literatura nacional. De acordo com Singh \& Trehan (1994) e Sütó et al (1998) não são muitos os trabalhos que descrevem parâmetros genéticos em frangos. E ainda que descritos, os parâmetros das características precisam ser determinados e monitorados rotineiramente nos programas de seleção específicos, uma vez que são propriedades inerentes não apenas às características, mas também à população em questão e às circunstâncias ambientais a que os animais são submetidos (Eler, 2001).

Com isso, torna-se fundamental a estimação dos parâmetros genéticos e fenotípicos destas características em um programa de melhoramento genético. Com estas informações, é possível conhecer melhor as características para as quais as aves vêm sendo selecionadas, avaliar o programa de seleção empregado, além de analisar o impacto que a seleção para determinada característica pode causar em outras características. Segundo Ledur et al. (1992), Rauw et al. (1998) e Rance et al. (2002) o conhecimento dos parâmetros genéticos oferece mais precisão no estabelecimento dos programas de seleção e através deles tem-se a oportunidade de predizer e potencialmente prevenir respostas correlacionadas indesejadas.

O estudo da tendência genética é também um elemento importante no monitoramento do processo de seleção. Ela corresponde à representação, com auxílio de gráficos, da mudança observada nas médias dos valores genéticos dos animais 
estudados para determinada característica ao longo do trabalho de seleção (Ferraz \& Eler, 2000). De acordo com Costa et al. (2001) o estudo das tendências genéticas permite visualizar a mudança ocasionada pelo processo de seleção, em determinada característica ao longo dos anos. Dessa forma, é possível analisar a eficácia dos procedimentos de seleção empregados e quantificar a mudança genética da característica ao longo do tempo e corrigir eventuais erros no direcionamento da seleção (Van Melis et al., 2001). 


\section{OBJETIVOS}

- Obter informações sobre a deposição de gordura abdominal em uma linhagem macho de frangos de corte fornecida pela Agroceres Ross Melhoramento de Aves S.A. e estimar sua tendência genética.

- Estimar os parâmetros genéticos (herdabilidade e correlações genéticas) e fenotípicos (correlações fenotípicas) da característica peso da gordura abdominal, bem como de características de desempenho, carcaça e composição corporal na referida linhagem. 


\section{MATERIAL E MÉTODOS}

\subsection{Origem dos Dados}

Foram utilizadas informações do rebanho elite, também chamado rebanho de pedigree, de aves pertencentes a Agroceres Ross Melhoramento de Aves S. A., no qual é realizado o processo de seleção para composição de uma linhagem macho de frango de corte da Empresa. Não obstante, informações de carcaça dos irmãos completos dos indivíduos do rebanho elite foram coletadas, as quais fazem parte do programa denominado sib test (teste de irmãos), que tem como objetivo avaliar as características de carcaça desses frangos. Este teste tem a finalidade de auxiliar na escolha dos melhores indivíduos durante o programa de seleção do rebanho elite, o qual origina todas as aves da linhagem.

O banco de dados com as informações de pedig ree da linhagem estudada foi fornecido pela Empresa, o qual era composto por 42912 animais de quatro gerações. Informações de granja de 30273 aves do rebanho elite e de seus irmãos do sib test também foram concedidas pela Empresa, as quais são descritas a seguir: 
- peso à seleção (PS), correspondente ao peso vivo das aves aos 38 dias;

- medidas de ultra-sonografia da profundidade do músculo peitoral aos 38 dias, em milímetros, sendo a $1^{\mathrm{a}}$ medida (US1) aferida junto à quilha, no sentido longitudinal (Figura 1), e a 2a (US2) sobre o osso coracóide, no sentido transversal.

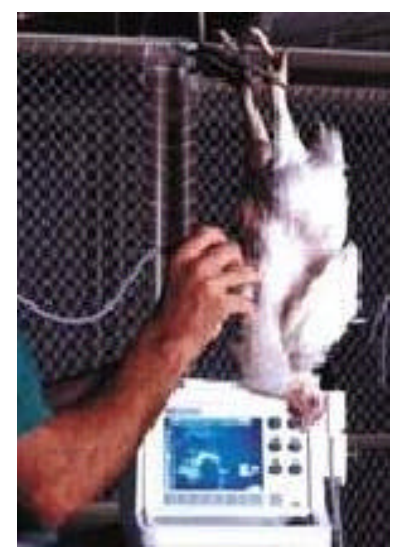

Figura 1 - Aferição por ultra-sonografia da profundidade do músculo peitoral, no sentido longitudinal

Com base nestas informações, as aves do rebanho elite passaram por um processo de seleção e foram dirigidas ao teste de conversão alimentar. Dados de desempenho das aves elite neste teste também foram fornecidas pela Empresa, os quais são descritos a seguir:

- conversão alimentar (CA), correspondente à quantidade (em $\mathrm{kg}$ ) de alimento ingerido em relação à quantidade $(\mathrm{em} \mathrm{kg})$ de ganho de peso, entre a $5^{\mathrm{a}}$ e a $7^{\mathrm{a}}$ semana, durante 14 dias; 
- eficiência alimentar (EA), correspondente à quantidade de ganho de peso (em $\mathrm{kg}$ ) pela quantidade (em $\mathrm{kg}$ ) de alimento ingerido, entre a $5^{\mathrm{a}}$ e a $7^{\mathrm{a}}$ semana, durante 14 dias, cujo resultado é expresso em porcentagem;

- ingestão (ING), correspondente à quantidade de alimento ingerido durante o período de 14 dias, entre a $5^{\mathrm{a}}$ e a $7^{\mathrm{a}}$ semana de idade (período do teste de conversão alimentar).

As aves elite foram alojadas em galpões da Granja de Pedigree da Agroceres Ross Melhoramento de Aves S. A. e criadas com programas de vacinação e manejo nutricional semelhantes a frangos de corte, conforme preconizado pelo Manual de Criação de Frangos da Empresa (Agroceres Ross, 2000), com a diferença de estarem em um ambiente rigorosamente controlado, para garantir a saúde e o desempenho das aves. As aves do sib test foram submetidas às mesmas condições de criação que o rebanho elite e também foram alojadas em galpões da Granja de Pedigree da Agroceres Ross Melhoramento de Aves S. A.

\subsection{Coleta dos Dados}

Ao atingirem os 42 dias de idade, cada lote de animais do sib test, composto por machos e fêmeas, foi sexado e alojado em caixas, sendo, então, transportados ao matadouro. As aves permaneceram em restrição hidro-alimentar por um período de pelo menos 10 horas.

A coleta dos dados de peso vivo aos 42 dias e as informações de carcaça e vísceras dos animais foi realizada no Matadouro Escola do Campus da USP em 
Pirassununga/SP, durante o período de 07/11/02 a 07/06/03, totalizando 10 abates. Estas informações foram coletadas de 6167 aves. Após o abate, as carcaças foram armazenadas dentro de sacos plásticos, em câmara fria a $0^{\circ} \mathrm{C}$, onde permaneceram até o dia seguinte, quando se processava a desossa. As vísceras também foram acondicionadas em sacos plásticos em câmara fria a $0^{\circ} \mathrm{C}$ e pesadas em dois a três dias subseqüentes aos abates.

As características avaliadas nos indivíduos do sib test foram:

- peso vivo (PV), registrado no abatedouro, antecedendo o abate (Figura 2);

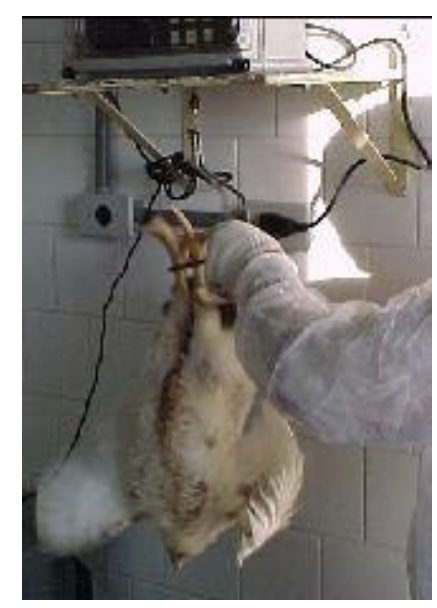

Figura 2 - Registro do peso vivo da ave antes do abate

- peso eviscerado (PE), correspondente ao peso da carcaça quente, eviscerada, sem pescoço e pés;

- peso do peito (PPEI), medida coletada após refrigeração da carcaça, sendo o peito desossado e sem pele (Figura 3); 


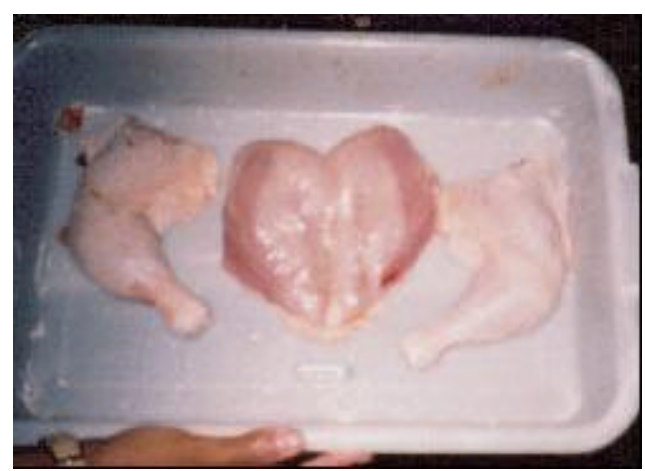

Figura 3 - Peito desossado e sem pele (ao centro) e pernas (coxa mais sobrecoxa com pele e ossos)

- peso de pernas (PPER), medida coletada após refrigeração da carcaça, correspondendo à coxa mais a sobrecoxa (perna) com pele e ossos (Figura 3);

- peso do coração (PC);

- peso da gordura abdominal (PGA), correspondente ao peso da placa de gordura abdominal mais o peso da gordura aderida à moela (Figuras 4 e 5);

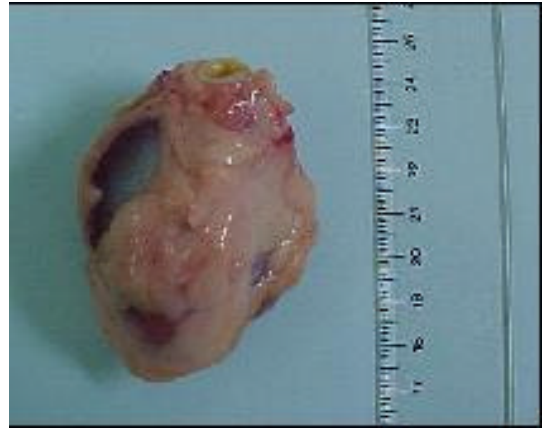

Figura 4 - Moela com a gordura aderida

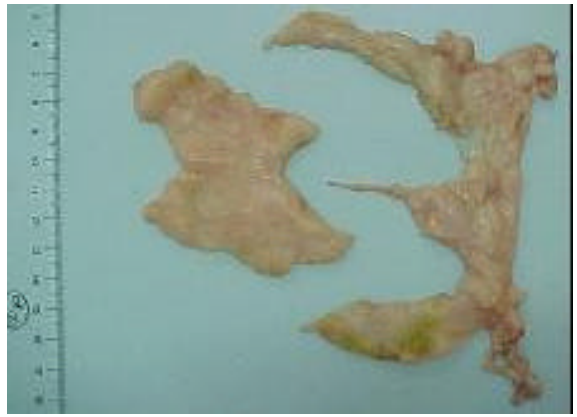

Figura 5 - Placa de gordura abdominal (à esquerda) e a gordura removida da moela 
- peso da moela (PM), cheia, sem a gordura aderida (Figura 6);

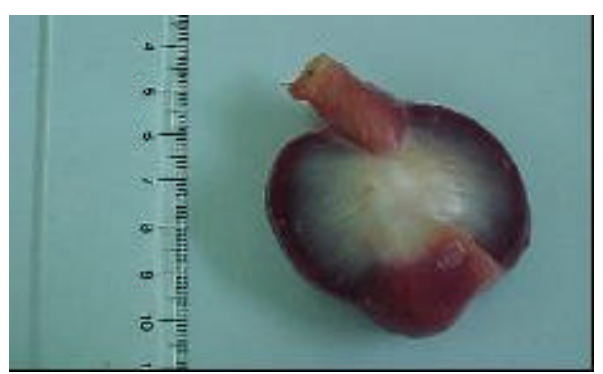

Figura 6 - Moela, cheia, sem a gordura aderida

- peso do fígado (PF);

- peso do intestino (PI), cheio.

Atribuiu-se, ainda, um escore visual para o fígado das aves (ESCF), pois foram observadas alterações variadas de cor e friabilidade deste órgão durante as pesagens. Os escores 0 (zero), 1 (um)e 2 (dois) foram conferidos, respectivamente, a fígados sem alteração de friabilidade e cor, com pouca alteração de friabilidade e/ou cor e com muita alteração de friabilidade e/ou cor. Amostras destes tecidos foram encaminhadas ao Laboratório de Patologia Veterinária da USP, em São Paulo/SP, para análise histopatológica. Também foram atribuídos escores visuais ao coração das aves (ESCC), uma vez que alguns deles apresentaram-se com formato discrepante em relação aos demais. O escore 0 (zero) foi conferido a corações não discrepantes e o escore 1 (um) a corações discrepantes.

Os funcionários responsáveis pela desossa das carcaças de machos não realizaram a desossa das carcaças de fêmeas e vice-versa. Da mesma forma, uma 
mesma pessoa foi responsável pela separação da gordura abdominal das vísceras e outra foi responsável pela pesagem e atribuição dos escores durante todo o período de coleta.

Calculou-se ainda o rendimento de carcaça (RCAR) dos frangos, correspondente à razão entre PE e PV, e os rendimentos de peito (RPEI) e de pernas (RPER), correspondentes à razão entre PPEI e PE e PPER e PE, respectivamente, os quais foram expressos em porcentagem.

\subsubsection{Controle de Pedigree e Automatização do Sistema}

O controle da genealogia dos indivíduos era feito ao seu nascimento, com a colocação de uma anilha, pregada na asa, contendo um número e um código em barras correspondente. Esse número identificava a ave com relação à linhagem, ao grupo de acasalamento dos pais, ao pai, à mãe e ao indivíduo em questão, ou seja, através da anilha tinham-se todas as informações necessárias para a identificação da ave e sua genealogia (Figura 7).

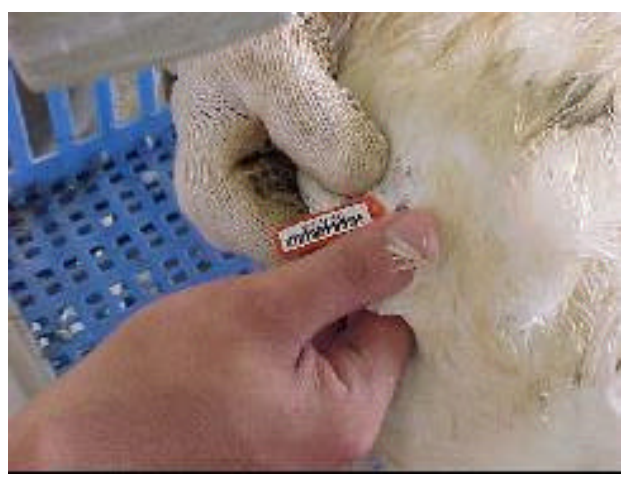

Figura 7 - Anilha presa à asa da ave, contendo sua identificação em número e respectivo código em barras 
A identificação de cada ave, no momento da coleta das informações, foi automatizada. As informações correspondentes aos pesos vivo, de carcaça, de peito e de pernas foram coletadas através de terminais portáteis com leitores de códigos de barras e balanças pertencentes à Empresa, que possuía um sistema computacional próprio. Os dados foram eletronicamente transferidos aos terminais e, após cada atividade, estes dados foram descarregados dos terminais diretamente para o computador, por meio de softwares específicos. No entanto, para pesage $\mathrm{m}$ das vísceras, tornou-se necessária a criação de uma metodologia independente. Como a anilha localizava-se presa à asa da ave, conseqüentemente, seguia com a carcaça durante todo o processo de abate (Figura 8).

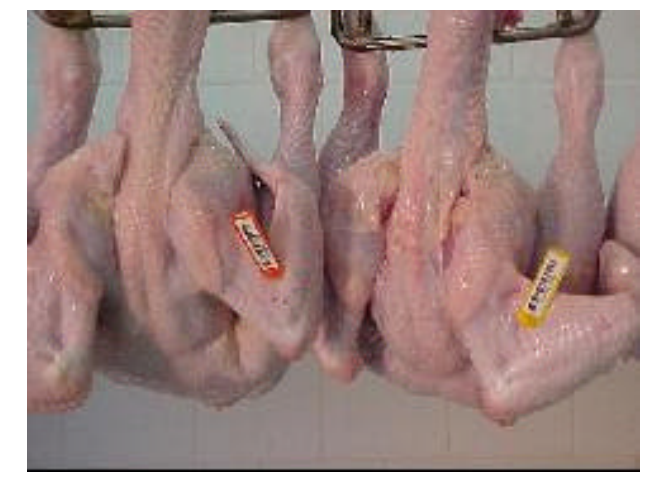

Figura 8 - Anilhas presas à asa na carcaça das aves

No momento em que eram retiradas da carcaça, as vísceras ficariam sem identificação. Portanto, tornourse necessária a criação de uma metodologia para que não se perdesse a identificação destas vísceras quando separadas da carcaça.

Para tanto, elaborou-se um programa computacional no Grupo de Melhoramento Animal, da Faculdade de Zootecnia e Engenharia de Alimentos da 
USP, em Pirassununga/SP. O programa desenvolvido tinha como uma de suas opções o registro dos números das anilhas das aves, por intermédio de um leitor de código de barras, na ordem em que as aves fossem abatidas (Figura 9), pois nesta mesma seqüência dava-se o acondicionamento das vísceras em sacos plásticos, previamente identificados na referida seqüência, (Figura 10), sendo, portanto, a sequiência de abate das aves a ponte que permitiu a identificação das suas vísceras.

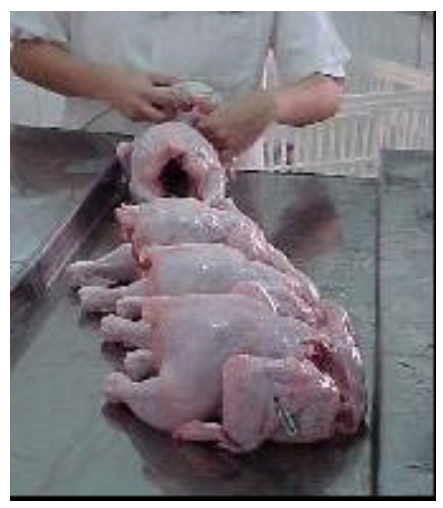

Figura 9 - Registro da seqüência de abate

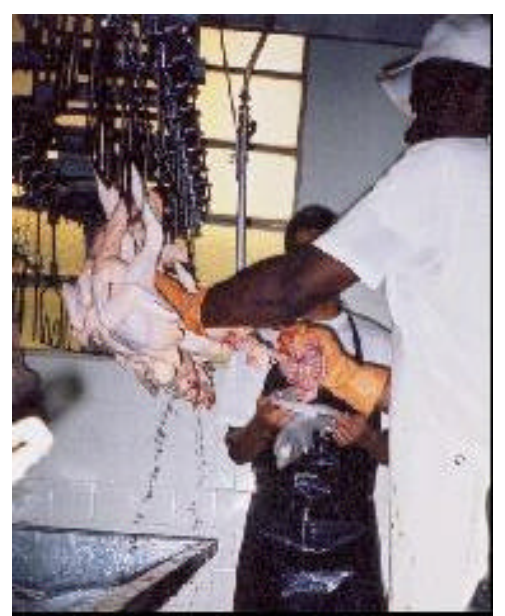

Figura 10 - Acondicionamento das vísceras em sacos plásticos na seqüência de abate 
A pesagem das vísceras deurse em uma balança computadora de precisão 0,2g. O sistema de pesagem também foi automatizado, transmitindo-se os pesos da balança diretamente para o computador por intermédio de um cabo conector, e registrados através da segunda opção existente no software desenvolvido. O sistema automatizado de coleta permite a formação de um conjunto de dados com informações completas e isento de erros (Trovo \& Razook, 1995).

A tela do software desenvolvido contendo a opção "Leitura de códigos de barras" é apresentada na Figura 11

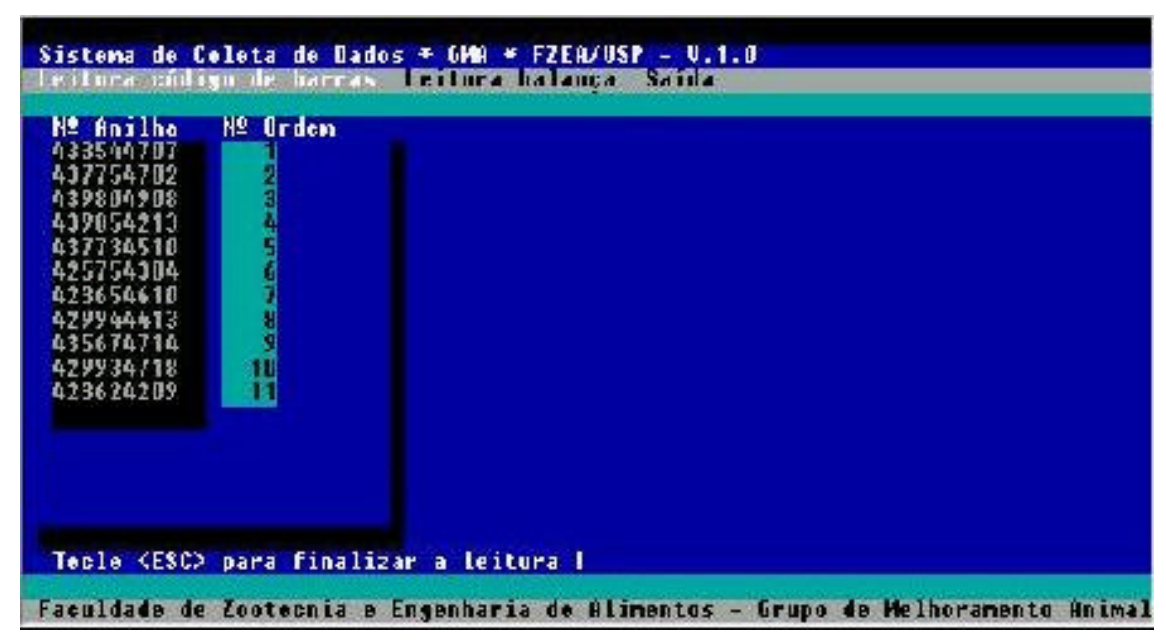

Figura 11 - Tela do software desenvolvido contendo a opção "Leitura de código de barras", com o registro do número de seqüência de abate das aves

A tela do software desenvolvido contendo a opção "Leitura da balança" é apresentada na Figura 12. 


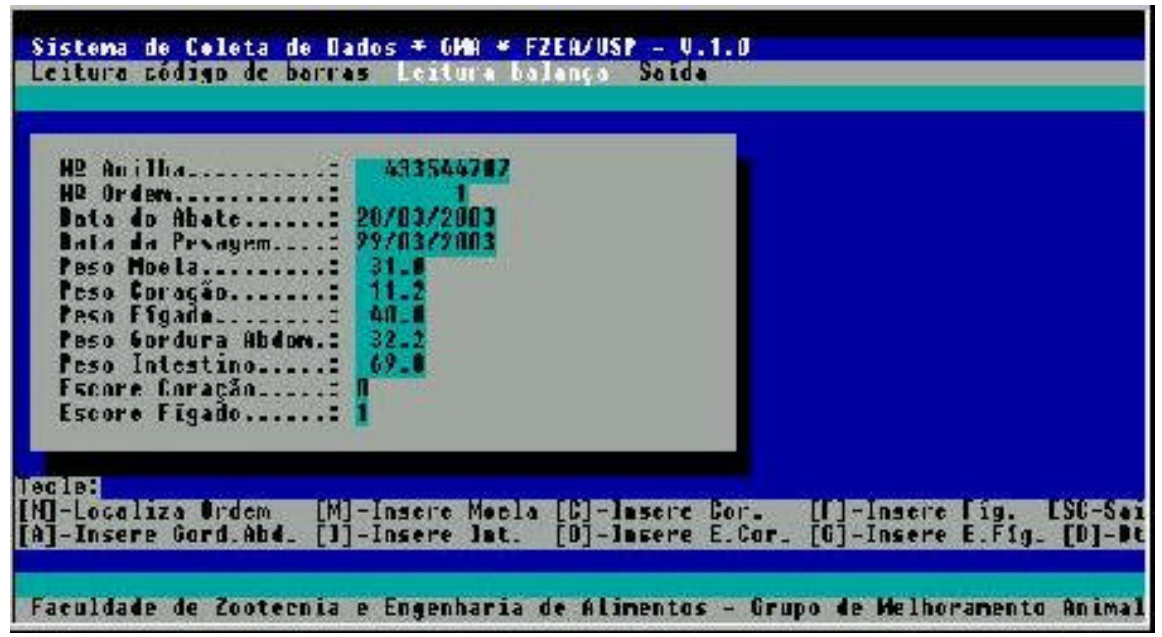

Figura 12 - Tela do software desenvolvido contendo a opção "Leitura da Balança", com o registro dos pesos das vísceras das aves e escores

\subsection{Metodologia de Análise}

O banco de dados foi montado com as informações de desempenho, carcaça e composição corporal das aves e a este banco foram incorporadas informações relativas à genealogia das aves e seus dados de granja. Os dados foram processados no Grupo de Melhoramento Animal, do Departamento de Ciências Básicas da Faculdade de Zootecnia e Engenharia de Alimentos da USP.

Valores extremos das características, definidos como outliers, foram identificados através do uso do box-plot, um tipo de gráfico que revela a distribuição do conjunto de informações de uma determinada característica (Hopkins et al., 1996), e retirados do banco de dados. Segundo Hopkins et al. (1996) os outliers freqüentemente são informações de qualidade duvidosa, podendo consistir em falhas tanto no momento da coleta como na entrada dos dados no sistema computacional. 
As médias, desvios-padrão, coeficientes de variação e valores mínimo e máximo das características foram calculados através do pacote estatístico SAS ${ }^{\circledR}$ (1999), versão 8.2, por intermédio do procedimento PROC MEANS.

Foram realizadas análises genéticas uni e bicaracterísticas para todas as características, com exceção dos escores visuais de fígado e coração, para os quais foram realizadas apenas análises uni-características. As estimativas dos componentes de (co) variância foram obtidas pelo método de máxima verossimilhança restrita (REML), utilizando-se do programa MTDFREML (Multiple trait derivative-free restricted maximum likelihood), desenvolvido por Boldman et al. (1993), o qual faz uso da inversa da matriz de parentesco e do modelo animal, e considera todas as informações genealógicas disponíveis.

Os componentes de variância iniciais aplicados no programa MTDFREML para realização das análises foram calculados através do pacote estatístico SAS ${ }^{\circledR}$ (1999), versão 8.2, por intermédio do procedimento PROC VARCOMP (Rezende et al., 2003). Já os componentes de covariância iniciais utilizados foram calculados utilizando-se os componentes de variância estimados através do PROC VARCOMP e assumindo-se como 0,50 as correlações entre as características, por ser este um valor intermediário.

Os componentes de (co) variância iniciais (priors) calculados e utilizados nas análises são apresentados nas Tabelas 10 e 11. 
TABELA 10 - Estimativas iniciais de variâncias (na diagonal) e covariâncias genéticas das características de desempenho, carcaça e composição corporal para realização das análises no programa MTDFREML

\begin{tabular}{|c|c|c|c|c|c|c|c|c|c|c|c|c|c|c|c|c|c|c|c|}
\hline & $\mathbf{P M}$ & PC & PF & PGA & PI & PV & PE & PPEI & PPER & RCAR & RPEI & RPER & PS & US1 & US2 & EA & CA & ING ESCC & ESCF \\
\hline PM & 22,07 & & & & & & & & & & & & & & & & & & \\
\hline PC & 2,09 & 0,79 & & & & & & & & & & & & & & & & & \\
\hline PF & 6,46 & 1,22 & 7,56 & & & & & & & & & & & & & & & & \\
\hline PGA & 15,77 & 2,98 & 9,23 & 45,08 & & & & & & & & & & & & & & & \\
\hline PI & 10,16 & 1,92 & 5,95 & 14,52 & 18,71 & & & & & & & & & & & & & & \\
\hline PV & 144,10 & 27,26 & 84,34 & 205,94 & 132,67 & 3763,23 & & & & & & & & & & & & & \\
\hline PE & 106,42 & 20,13 & 62,29 & 152,10 & 97,99 & 1389,66 & 2052,67 & & & & & & & & & & & & \\
\hline PPEI & 46,07 & 8,72 & 26,96 & 65,85 & 42,42 & 601,61 & 444,31 & 384,70 & & & & & & & & & & & \\
\hline PPER & 47,54 & 8,99 & 27,82 & 67,94 & 43,77 & 620,77 & 458,47 & 198,48 & 409,60 & & & & & & & & & & \\
\hline RCAR & 1,38 & 0,26 & 0,81 & 1,97 & 1,27 & 18,03 & 13,32 & 5,77 & 5,95 & 0,35 & & & & & & & & & \\
\hline RPEI & 2,36 & 0,45 & 1,38 & 3,37 & 2,17 & 30,83 & 22,77 & 9,86 & 10,17 & 0,30 & 1,01 & & & & & & & & \\
\hline RPER & 1,56 & 0,29 & 0,91 & 2,23 & 1,43 & 20,34 & 15,02 & 6,50 & 6,71 & 0,19 & 0,33 & 0,44 & & & & & & & \\
\hline PS & 29,17 & 5,52 & 17,07 & 41,68 & 26,85 & 380,85 & 281,27 & 121,77 & 125,65 & 3,65 & 6,24 & 4,12 & 154,17 & & & & & & \\
\hline US1 & 2,38 & 0,45 & 1,40 & 3,41 & 2,19 & 31,13 & 22,99 & 9,95 & 10,27 & 0,30 & 0,51 & 0,34 & 6,30 & 1,03 & & & & & \\
\hline US2 & 2,73 & 0,52 & 1,60 & 3,90 & 2,51 & 35,64 & 26,32 & 11,39 & 11,76 & 0,34 & 0,58 & 0,39 & 7,21 & 0,59 & 1,35 & & & & \\
\hline EA & 0,05 & 0,01 & 0,03 & 0,07 & 0,05 & 0,68 & 0,50 & 0,22 & 0,22 & 0,01 & 0,01 & 0,01 & 0,14 & 0,01 & 0,01 & 0,00049 & & & \\
\hline CA & 0,18 & 0,03 & 0,10 & 0,25 & 0,16 & 2,31 & 1,70 & 0,74 & 0,76 & 0,02 & 0,04 & 0,02 & 0,47 & 0,04 & 0,04 & 0,00083 & 0,01 & & \\
\hline ING & 95,61 & 18,09 & 55,96 & 136,65 & 88,03 & 1248,6 & 922,12 & 399,2 & 411,91 & 12,04 & 20,45 & 2,87 & 13,95 & 20,65 & 23,64 & 0,45 & 2,03 & 1656,9 & \\
\hline ESCC & - & - & - & - & - & - & - & - & - & - & - & - & - & - & - & - & - & 0,20 & \\
\hline ESCF & - & - & - & - & - & - & - & - & - & - & - & - & - & - & - & - & - & - & 20 \\
\hline
\end{tabular}

PM - peso da moela; PC - peso do coração; PF peso do fígado; PGA - peso da gordura abdominal; PI - peso do intestino; PV - peso vivo; PE - peso eviscerado PPEI - peso de peito; PPER - peso de pernas; RCAR - rendimento de carcaça; RPEI - rendimento de peito; RPER - rendimento de pernas; PS - peso à seleção; US1 - $1^{a}$ medida de ultra-som; US2 - $2^{a}$ medida de ultra-som; EA - eficiência alimentar; CA - conversão alimentar; ING - ingestão; ESCC - escore visual do coração; ESCF - escore visual do fígado. 
TABELA 11 - Estimativas iniciais de variâncias (na diagonal) e covariâncias ambientais das características de desempenho, carcaça e composição corporal para realização das análises no programa MTDFREML

\begin{tabular}{|c|c|c|c|c|c|c|c|c|c|c|c|c|c|c|c|c|c|c|c|c|}
\hline & $\mathbf{P M}$ & PC & PF & PGA & PI & PV & PE & PPEI & PPER & RCAR & RPEI & RPER & PS & US1 & US2 & EA & CA & ING & ESCC & ESCF \\
\hline PM & 26,01 & & & & & & & & & & & & & & & & & & & \\
\hline PC & 3,05 & 1,43 & & & & & & & & & & & & & & & & & & \\
\hline PF & 10,95 & 2,57 & 18,45 & & & & & & & & & & & & & & & & & \\
\hline PGA & 14,53 & 3,41 & 12,24 & 32,47 & & & & & & & & & & & & & & & & \\
\hline PI & 18,60 & 4,36 & 15,66 & 20,78 & 53,18 & & & & & & & & & & & & & & & \\
\hline PV & 276,72 & 64,88 & 233,06 & 309,18 & 395,68 & 11776,05 & & & & & & & & & & & & & & \\
\hline PE & 209,51 & 49,12 & 176,45 & 234,08 & 299,57 & 4457,85 & 6750,11 & & & & & & & & & & & & & \\
\hline PPEI & 74,13 & 17,38 & 62,43 & 82,83 & 106,00 & 1577,33 & 1194,20 & 845,09 & & & & & & & & & & & & \\
\hline PPER & 79,27 & 18,59 & 66,76 & 88,57 & 113,35 & 1686,69 & 1277,00 & 451,84 & 966,34 & & & & & & & & & & & \\
\hline RCAR & 2,58 & 0,60 & 2,17 & 2,88 & 3,68 & 54,80 & 41,49 & 14,68 & 15,70 & 1,02 & & & & & & & & & & \\
\hline RPEI & 2,58 & 0,60 & 2,17 & 2,88 & 3,68 & 54,80 & 41,49 & 14,68 & 15,70 & 0,51 & 1,02 & & & & & & & & & \\
\hline RPER & 2,59 & 0,61 & 2,18 & 2,89 & 3,70 & 55,07 & 41,69 & 14,75 & 15,77 & 0,51 & 0,51 & 1,03 & & & & & & & & \\
\hline PS & 41,48 & 9,73 & 34,94 & 46,35 & 59,31 & 882,64 & 668,25 & 236,45 & 252,84 & 8,21 & 8,21 & 8,25 & 264,62 & & & & & & & \\
\hline US1 & 4,04 & 0,95 & 3,40 & 4,51 & 5,78 & 85,96 & 65,08 & 23,03 & 24,62 & 0,80 & 0,80 & 0,80 & 12,89 & 2,51 & & & & & & \\
\hline US2 & 4,60 & 1,08 & 3,88 & 5,14 & 6,58 & 97,97 & 74,17 & 26,24 & 28,06 & 0,91 & 0,91 & 0,92 & 14,69 & 1,43 & 3,26 & & & & & \\
\hline EA & 0,10 & 0,02 & 0,09 & 0,11 & 0,15 & 2,18 & 1,65 & 0,59 & 0,63 & 0,02 & 0,02 & 0,02 & 0,33 & 0,03 & 0,04 & 0,0016 & & & & \\
\hline CA & 0,38 & 0,09 & 0,32 & 0,42 & 0,54 & 8,04 & 6,09 & 2,15 & 2,30 & 0,07 & 0,07 & 0,08 & 1,21 & 0,12 & 0,13 & 0,0030 & 0,02 & & & \\
\hline ING & 164,08 & 38,47 & 138,19 & 183,30 & 234,62 & 3491,30 & 2643,20 & 935,26 & 1000,1 & 32,49 & 32,49 & 32,65 & 523,35 & 50,97 & 58,08 & 1,28 & 4,54 & 4140,24 & & \\
\hline ESCC & - & - & - & - & - & - & - & - & - & - & - & - & - & - & - & - & - & - & 0,50 & \\
\hline ESCF & - & - & - & - & - & - & - & - & - & - & - & - & - & - & - & - & - & - & - & 0,50 \\
\hline
\end{tabular}


Por existir a possibilidade de serem obtidos máximos locais em vez de máximos globais durante as análises no MTDFREML (Pres et al., 1986), várias reinicializações foram executadas no sentido de assegurar a convergência no máximo global da função de máxima verossimilhança. Para essas reinicializações, os valores iniciais de componentes de variâncias e covariâncias foram os obtidos na análise anterior. Nas primeiras reinicializações foi utilizado um critério de convergência de $10^{-6}$ e na última reinicialização foi utilizado o critério de $10^{-9}$.

As correlações fenotípicas entre as características foram calculadas através da correlação de Pearson, utilizando-se as soluções de (co)variâncias fenotípicas obtidas através das análises realizadas no MTDFREML.

Foram realizadas ainda análises uni-características de escores visuais de fígado e de coração empregando-se o método R, desenvolvido por Reverter et al. (1994), o qual pode, segundo Van Melis (2002), ser utilizado em substituição ao método da máxima verossimilhança restrita. $\mathrm{O}$ método $\mathrm{R}$, aplicado através do programa DSCAT, presente no pacote ABTK (Golden et al., 1992), é apropriado quando se tratam de modelos não lineares. Estes modelos levam em consideração a distribuição descontínua dos dados para a estimação dos parâmetros, o que é interessante quando se trata de variáveis desta natureza, diferentemente do método da máxima verossimilhança restrita, que é adequado para modelos lineares, os quais pressupõem a distribuição normal dos dados para tal estimação (Snelling et al., 1995). 


\subsubsection{Modelos}

O modelo matemático genérico utilizado nas análises uni-características foi:

$$
y=\mathrm{X} b+\mathrm{Zu}+e
$$

Em que:

$y=$ vetor das variáveis dependentes (observações);

$\mathrm{X}=$ matriz de incidência dos efeitos fixos, associando elementos de $b$ a $y$;

$b=$ vetor dos efeitos fixos;

$\mathrm{Z}=$ matriz de incidência dos efeitos aleatórios, associando elementos de $u$ a

$y$;

$u=$ vetor dos efeitos aleatórios de valor genético;

$e=$ vetor de efeitos do resíduo, NID $\left(0, \mathrm{~s}^{2}\right)$ para cada variável dependente.

O modelo genérico utilizado para as análises bicaracterísticas foi:

$$
\left[\begin{array}{l}
y_{1} \\
y_{2}
\end{array}\right]=\left[\begin{array}{cc}
X_{1} & 0 \\
0 & X_{2}
\end{array}\right]\left[\begin{array}{l}
b_{1} \\
b_{2}
\end{array}\right]+\left[\begin{array}{cc}
Z_{1} & 0 \\
0 & Z_{2}
\end{array}\right]\left[\begin{array}{l}
u_{1} \\
u_{2}
\end{array}\right]+\left[\begin{array}{l}
e_{1} \\
e_{2}
\end{array}\right]
$$

Em que:

$y_{1}=$ vetor dos registros de medidas da característica $1 ;$

$y_{2}=$ vetor dos registros de medidas da característica $2 ;$

$b_{1}=$ vetor de efeitos fixos para a característica 1 ;

$b_{2}=$ vetor de feitos fixos para a característica 2 ;

$u_{1}=$ vetor de efeitos aleatórios de valor genético para a característica $1 ;$ 
$u_{2}=$ vetor de efeitos aleatórios de valor genético para a característica 2;

$X_{1}\left(X_{2}\right)=$ matriz de incidência associando elementos de $b_{1}\left(b_{2}\right)$ a $y_{1}\left(y_{2}\right)$;

$Z_{l}\left(Z_{2}\right)=$ matriz de incidência associando elementos de $u_{l}\left(u_{2}\right)$ a $y_{l}\left(y_{2}\right)$;

$\mathrm{e}_{1}\left(\mathrm{e}_{2}\right)=$ vetor de efeitos do resíduo, NID $\left(0, \mathrm{~s}^{2}\right)$ para cada variável dependente.

Foram considerados como efeitos fixos (vetor $b$ ) o POU (unidade de organização de produção, nome dado pela Empresa a cada lote subseqüente de animais), cada um composto por dois na scimentos, e ainda o grupo de acasalamento dos pais e o sexo das aves, sendo os mesmos para todas as características analisadas. A importância destes efeitos foi determinada pelo procedimento PROC GLM, do pacote estatístico SAS ${ }^{\circledR}$ (1999), versão 8.2, mostrando-se significativos para todas as características. Como efeito aleatório foi considerado o efeito genético aditivo direto (vetor $u$ ) para todas as características analisadas.

\subsection{Tendência Genética}

A tendência genética da característica peso da gordura abdominal foi determinada pela regressão dos valores genéticos médios dos animais sobre a unidade de tempo, esta sendo correspondente ao coeficiente de regressão obtido (Silva et al., 2001). Os animais dos quais utilizaram se os valores genéticos para a plotagem foram os que possuíam as informações de POUs e anos de nascimento. Ao todo, foram utilizadas 32.485 aves para a plotagem, provenientes de 25 diferentes POUs, distribuídos dentro de 3 anos de nascimento. Dessa forma, o estudo da tendência genética do peso da gordura abdominal deu-se através de dois gráficos, 
plotando-se as médias dos valores genéticos dos animais ao longo dos POUs e ao longo dos anos de nascimento. O coeficiente de regressão e o coeficiente de determinação da regressão foram estimados através do procedimento PROC REG do SAS $^{\circledR}$ (1999), versão 8.2. 


\section{RESULTADOS E DISCUSSÃO}

\subsection{Descrição Estatística dos Dados}

A descrição estatística das características de desempenho analisadas é apresentada na Tabela 12 .

TABELA 12 - Número inicial de observações (Ni), igual ao número total de observações coletadas, número final de observações (Nf), igual ao $\mathrm{Ni}$ menos o número de outliers retirados, média $(\mathrm{M})$, desviopadrão (DP), coeficiente de variação (CV) e valores mínimo (MIN) e máximo (MAX) das características de desempenho avaliadas

\begin{tabular}{|c|c|c|c|c|c|c|c|}
\hline Característica & $\mathbf{N i}$ & $\mathbf{N f}$ & $\mathbf{M}$ & DP & CV & MIN & MAX \\
\hline PS (g) & 29040 & 28755 & 2250,75 & 290,40 & 12,90 & 1450,00 & 3030,00 \\
\hline US1 (mm) & 12856 & 12284 & 26,32 & 2,15 & 8,18 & 22,00 & 31,00 \\
\hline US2 (mm) & 12856 & 12048 & 26,53 & 2,22 & 8,37 & 22,00 & 31,00 \\
\hline CA & 4120 & 3189 & 1,91 & 0,19 & 10,28 & 1,24 & 2,29 \\
\hline EA (\%) & 4120 & 2716 & 0,45 & 0,06 & 13,70 & 0,21 & 0,53 \\
\hline ING (g) & 4253 & 4074 & 2680,20 & 455,30 & 16,98 & 1390,00 & 3186,00 \\
\hline PV (g) & 6167 & 6155 & 2354,44 & 286,96 & 12,18 & 1540,00 & 3186,00 \\
\hline
\end{tabular}

A descrição estatística das características de carcaça analisadas é apresentada na Tabela 13. 
TABELA 13 - Número inicial de observações (Ni), igual ao número total de observações coletadas, número final de observações (Nf), igual ao $\mathrm{Ni}$ menos o número de outliers retirados, média $(\mathrm{M})$, desviopadrão (DP), coeficiente de variação $(\mathrm{CV})$ e valores mínimo (MIN) e máximo (MAX) das características de carcaça avaliadas

\begin{tabular}{lccccccc}
\hline Característica & Ni & Nf & M & DP & CV & MIN & MAX \\
\hline PE (g) & 6167 & 6156 & 1671,56 & 214,51 & 12,83 & 1078,00 & 2294,00 \\
PPEI (g) & 6167 & 6123 & 477,74 & 66,87 & 13,99 & 296,00 & 666,00 \\
PPER (g) & 6167 & 6153 & 553,27 & 76,45 & 13,81 & 352,00 & 770,00 \\
RCAR (\%) & 6167 & 6046 & 71,02 & 1,44 & 2,03 & 67,10 & 74,90 \\
RPEI (\%) & 6167 & 6102 & 28,61 & 1,58 & 5,53 & 24,30 & 32,90 \\
RPER (\%) & 6167 & 6065 & 33,07 & 1,33 & 4,04 & 29,40 & 36,70 \\
\hline
\end{tabular}

PE - peso eviscerado; PPEI - peso de peito; PPER - peso de pernas; RCAR - rendimento de carcaça; RPEI - rendimento de peito; RPER - rendimento de pernas.

Os coeficientes de variação encontrados para as características de desempenho e carcaça, com exceção dos rendimentos, variaram entre 8,18\% e 13,99\%, tendo sido semelhantes, portanto, aos descritos por Argentão et al. (2002) e Rance et al. (2002).

A descrição estatística das características de composição corporal analisadas é apresentada na Tabela 14.

TABELA 14 - Número inicial de observações (Ni), igual ao número total de observações coletadas, número final de observações (Nf), igual ao $\mathrm{Ni}$ menos o número de outliers retirados, média $(\mathrm{M})$, desviopadrão (DP), coeficiente de variação (CV) e valores mínimo (MIN) e máximo (MAX) das características de composição corporal avaliadas

\begin{tabular}{lccccccc}
\hline Característica & Ni & Nf & M & DP & CV & MIN & MAX \\
\hline PGA (g) & 6165 & 6089 & 42,70 & 10,66 & 24,98 & 12,80 & 72,20 \\
PC (g) & 6134 & 6022 & 12,15 & 2,31 & 19,06 & 6,40 & 18,60 \\
PM (g) & 6166 & 5996 & 26,50 & 7,21 & 27,22 & 13,00 & 47,00 \\
PF (g) & 6166 & 6092 & 47,74 & 8,68 & 18,18 & 23,60 & 72,40 \\
PI (g) & 6167 & 6045 & 81,16 & 16,48 & 20,31 & 39,40 & 128,40 \\
\hline
\end{tabular}

PGA - peso da gordura abdominal; PC - peso do coração; PM - peso da moela; PF peso do fígado; PI - peso do intestino. 
Os coeficientes de variação encontrados para as características de composição corporal apresentaram-se na faixa de $18,18 \%$ a $27,22 \%$. Para o peso da gordura abdominal, o coeficiente de variação encontrado foi de $24,98 \%$, semelhante ao descrito por Rance et al. (2002). Logo, as características de composição corporal apresentaram maior variabilidade em comparação às demais. A variabilidade destas características, que neste caso foi assegurada mesmo com a retirada de seus outliers, pode ser interessante quando a característica é importante em um processo de seleção, como é o caso da gordura abdominal. A alta variabilidade pode ser capaz de facilitar este processo, pois com ela torna-se mais clara a disparidade dos animais. Entretanto, para que a seleção seja bem-sucedida são necessários também outros elementos importantes, como os parâmetros genéticos da característica (Eler, 2001).

A Tabela 15 apresenta a descrição dos escores visuais analisados.

TABELA 15 - Número de observações (N), valores mínimo (MIN) e máximo (MAX) e incidência (INC) dos escores visuais

\begin{tabular}{|c|c|c|c|c|c|}
\hline \multicolumn{2}{|c|}{ Característica } & $\mathbf{N}$ & MíN & MÁX & INC \\
\hline \multirow{3}{*}{ ESCF } & $\mathbf{0}$ & \multirow{3}{*}{6167} & \multirow{3}{*}{0} & \multirow{3}{*}{2} & 44 \\
\hline & 1 & & & & 6041 \\
\hline & 2 & & & & 82 \\
\hline ESCC & $\begin{array}{l}\mathbf{0} \\
1\end{array}$ & 6167 & 0 & 1 & $\begin{array}{c}6157 \\
10\end{array}$ \\
\hline
\end{tabular}

ESCF - escore visual do fígado; ESCC - escore visual do coração.

\subsection{Componentes de (Co) Variância}

Os componentes de (co) variância resultantes das análises uni e bi características realizadas pelo programa MTDFREML são apresentados nas Tabelas 16, 17 e 18, referentes às (co) variâncias genéticas, ambientais e fenotípicas, respectivamente. 
TABELA 16 - Estimativas de variâncias (na diagonal) e covariâncias genéticas das características de desempenho, carcaça e composição corporal resultantes das análises no programa MTDFREML

\begin{tabular}{|c|c|c|c|c|c|c|c|c|c|c|c|c|c|c|c|c|c|c|c|}
\hline & $\mathbf{P M}$ & PC & PF & PGA & PI & PV & PE & PPEI & PPER & RCAR & RPEI & RPER & PS & US1 & US2 & EA & CA & ING & ESCC ESCF \\
\hline $\mathbf{P M}$ & 16,58 & & & & & & & & & & & & & & & & & & \\
\hline PC & $-0,08$ & 0,98 & & & & & & & & & & & & & & & & & \\
\hline $\mathbf{P F}$ & $-1,24$ & 1,33 & 7,88 & & & & & & & & & & & & & & & & \\
\hline PGA & 2,39 & 0,29 & 1,20 & 43,67 & & & & & & & & & & & & & & & \\
\hline PI & $-3,44$ & 1,42 & 5,81 & 12,88 & 28,30 & & & & & & & & & & & & & & \\
\hline PV & 56,53 & 18,70 & 82,21 & 115,06 & 134,31 & 4470,92 & & & & & & & & & & & & & \\
\hline $\mathbf{P E}$ & 27,75 & 8,78 & 46,52 & 42,03 & 64,42 & 3303,96 & 2675,88 & & & & & & & & & & & & \\
\hline PPEI & 7,81 & 0,92 & 3,11 & $-17,77$ & $-15,76$ & 678,00 & 745,71 & 533,99 & & & & & & & & & & & \\
\hline PPER & 7,79 & 3,47 & 23,76 & 19,64 & 23,75 & 1315,02 & 1004,24 & 96,68 & 542,37 & & & & & & & & & & \\
\hline RCAR & $-0,27$ & $-0,12$ & $-0,54$ & $-1,28$ & $-1,41$ & 14,78 & 14,75 & 9,89 & 4,21 & 0,41 & & & & & & & & & \\
\hline RPEI & 0,03 & $-0,07$ & $-0,43$ & $-1,54$ & $-1,45$ & $-10,96$ & 19,33 & 19,50 & $-9,94$ & 0,32 & 1,11 & & & & & & & & \\
\hline RPER & 0,27 & 0,02 & 0,36 & 0,34 & 0,45 & 10,88 & 5,86 & $-8,95$ & 10,39 & $-0,06$ & $-0,57$ & 0,48 & & & & & & & \\
\hline PS & 20,31 & 9,59 & 31,62 & 44,53 & 55,72 & 951,01 & 1283,17 & 344,46 & 442,03 & 1,31 & $-0,96$ & 0,73 & 180,60 & & & & & & \\
\hline US1 & 0,57 & 0,12 & $-0,03$ & $-0,99$ & $-1,00$ & 18,53 & 19,59 & 15,16 & 3,67 & 0,25 & 0,52 & $-0,19$ & 6,43 & 0,87 & & & & & \\
\hline US2 & 0,22 & 0,10 & $-0,02$ & $-0,87$ & $-0,88$ & 18,68 & 20,63 & 17,24 & 3,67 & 0,28 & 0,61 & $-0,24$ & 7,30 & 0,91 & 0,99 & & & & \\
\hline EA & 0,03 & $-0,001$ & $-0,02$ & $-0,04$ & 0,004 & $-0,31$ & $-0,16$ & 0,15 & $-0,01$ & 0,003 & $-0,001$ & 0,002 & $-0,01$ & 0,002 & 0,002 & 0,0005 & & & \\
\hline CA & 0,03 & 0,01 & 0,04 & 0,15 & 0,09 & 1,50 & 1,06 & 0,15 & 0,15 & 0,41 & $-0,01$ & $-0,01$ & 0,05 & $-0,002$ & $-0,004$ & $-0,002$ & 0,004 & & \\
\hline ING & 1,55 & 18,95 & 53,24 & 172,92 & 177,70 & 1700,95 & 22,75 & 736,74 & 380,38 & $-0,23$ & $-3,33$ & 12,31 & 158,68 & $-0,73$ & 0,54 & $-0,03$ & 0,34 & 224,64 & \\
\hline ESCC & - & - & - & - & - & - & - & - & - & - & - & - & - & - & - & - & - & & 0,0007 \\
\hline ESCF & - & - & - & - & - & - & - & - & - & - & - & - & - & - & - & - & - & & 0,0007 \\
\hline
\end{tabular}


TABELA 17 - Estimativas de variâncias (na diagonal) e covariâncias ambientais das características de desempenho, carcaça e composição corporal resultantes das análises no programa MTDFREML

\begin{tabular}{|c|c|c|c|c|c|c|c|c|c|c|c|c|c|c|c|c|c|c|c|c|}
\hline & $\mathbf{P M}$ & PC & PF & PGA & PI & PV & PE & PPEI & PPER & RCAR & RPEI & RPER & PS & US1 & US2 & EA & CA & ING & ESCC & ESCF \\
\hline PM & 26,09 & & & & & & & & & & & & & & & & & & & \\
\hline PC & 0,19 & 1,61 & & & & & & & & & & & & & & & & & & \\
\hline PF & 0,75 & 2,01 & 23,07 & & & & & & & & & & & & & & & & & \\
\hline PGA & $-3,19$ & 2,02 & 6,86 & 39,48 & & & & & & & & & & & & & & & & \\
\hline PI & $-0,67$ & 2,64 & 9,33 & 11,88 & 68,44 & & & & & & & & & & & & & & & \\
\hline PV & 144,20 & 67,05 & 226,32 & 341,71 & 440,83 & 14161,39 & & & & & & & & & & & & & & \\
\hline PE & 105,23 & 49,27 & 153,17 & 245,65 & 277,47 & 10476,16 & 8420,52 & & & & & & & & & & & & & \\
\hline PPEI & 35,89 & 14,76 & 41,71 & 60,01 & 71,26 & 3229,00 & 2589,88 & 1102,84 & & & & & & & & & & & & \\
\hline PPER & 35,92 & 16,24 & 46,39 & 90,38 & 98,42 & 3363,66 & 2615,61 & 807,50 & 1087,09 & & & & & & & & & & & \\
\hline RCAR & $-0,13$ & $-0,01$ & $-0,29$ & $-0,13$ & $-1,20$ & 35,47 & 35,49 & 10,37 & 7,00 & 0,96 & & & & & & & & & & \\
\hline RPEI & 0,36 & 0,06 & $-0,07$ & $-0,49$ & $-0,51$ & 13,89 & 21,28 & 21,01 & 4,04 & 0,06 & 1,07 & & & & & & & & & \\
\hline RPER & $-0,23$ & $-0,01$ & $-0,12$ & 0,48 & 0,26 & $-4,39$ & $-9,08$ & $-2,09$ & 12,03 & $-0,23$ & $-0,02$ & 0,88 & & & & & & & & \\
\hline PS & 18,62 & 12,10 & 45,05 & 63,81 & 71,52 & 3025,36 & 1934,86 & 567,51 & 630,24 & 4,34 & 1,34 & $-0,25$ & 268,4 & & & & & & & \\
\hline US1 & 0,74 & 0,25 & 1,27 & 1,31 & 1,35 & 55,78 & 47,28 & 18,99 & 11,92 & 0,31 & 0,40 & $-0,23$ & 12,25 & 2,11 & & & & & & \\
\hline US2 & 0,86 & 0,34 & 1,44 & 1,53 & 1,72 & 70,86 & 58,47 & 23,33 & 11,92 & 0,32 & 0,44 & $-0,26$ & 14,59 & 1,80 & 2,55 & & & & & \\
\hline EA & $-0,34$ & 0,05 & 0,24 & 0,20 & 0,20 & 3,79 & 2,41 & $-4,76$ & 0,65 & 0,02 & 0,03 & 0,03 & $-0,06$ & $-0,0005$ & 0,0004 & 0,003 & & & & \\
\hline CA & 0,45 & 0,16 & 0,40 & 0,70 & 0,89 & 15,07 & 3,73 & 3,66 & 3,12 & 0,08 & 0,13 & 0,07 & 0,11 & 0,01 & 0,01 & $-0,01$ & 0,02 & & & \\
\hline ING & 25,60 & 30,27 & $-0,92$ & $-27,60$ & $-99,21$ & 2455,74 & 2725,74 & 720,94 & 648,99 & $-11,37$ & 18,58 & $-24,08$ & 44,14 & 0,48 & 1,39 & 0,18 & $0,17 \xi$ & 895,33 & & \\
\hline ESCC & - & & - & - & - & - & - & & - & - & - & - & - & - & - & - & - & - & 0,0015 & \\
\hline ESCF & - & - & - & - & - & - & - & - & - & - & - & - & - & - & - & - & - & - & - & 0,0015 \\
\hline
\end{tabular}

PM - peso da moela; PC - peso do coração; PF peso do fígado; PGA - peso da gordura abdominal; PI - peso do intestino; PV - peso vivo; PE - peso eviscerado; PPEI - peso de peito; PPER - peso de pernas; RCAR - rendimento de carcaça; RPEI - rendimento de peito; RPER - rendimento de pernas; PS - peso à seleção; US1 - $1^{a}$ medida de ultra-som; US2 - $2^{a}$ medida de ultra-som; EA - eficiência alimentar; CA - conversão alimentar; ING - ingestão; ESCC - escore visual do coração; ESCF - escore visual do fígado. 
TABELA 18 - Estimativas de variâncias (na diagonal) e covariâncias fenotípicas das características de desempenho, carcaça e composição corporal resultantes das análises no programa MTDFREML

\begin{tabular}{|c|c|c|c|c|c|c|c|c|c|c|c|c|c|c|c|c|c|c|c|}
\hline & $\mathbf{P M}$ & PC & PF & PGA & PI & PV & PE & PPEI & PPER & RCAR & RPEI & RPER & PS & US1 & US2 & EA & CA & ING & ESCC ESCF \\
\hline PM & 42,67 & & & & & & & & & & & & & & & & & & \\
\hline PC & 0,12 & 2,59 & & & & & & & & & & & & & & & & & \\
\hline PF & $-0,49$ & 3,34 & 30,95 & & & & & & & & & & & & & & & & \\
\hline PGA & $-0,80$ & 2,30 & 8,06 & 83,15 & & & & & & & & & & & & & & & \\
\hline PI & $-4,11$ & 4,06 & 15,14 & 24,76 & 96,73 & & & & & & & & & & & & & & \\
\hline PV & 200,73 & 85,75 & 308,53 & 456,76 & 575,14 & 18632,31 & & & & & & & & & & & & & \\
\hline PE & 132,98 & 58,05 & 199,69 & 287,68 & 341,89 & 13780,12 & 11096,40 & & & & & & & & & & & & \\
\hline PPEI & 43,70 & 15,68 & 44,83 & 42,24 & 55,51 & 3907,00 & 3335,58 & 1636,83 & & & & & & & & & & & \\
\hline PPER & 43,71 & 19,71 & 70,15 & 110,03 & 122,16 & 4678,68 & 3619,85 & 904,18 & 1629,46 & & & & & & & & & & \\
\hline RCAR & $-0,40$ & $-0,13$ & $-0,82$ & $-1,41$ & $-2,61$ & 50,25 & 50,24 & 20,27 & 11,21 & 1,37 & & & & & & & & & \\
\hline RPEI & 0,40 & $-0,02$ & $-0,49$ & $-2,03$ & $-1,96$ & 2,93 & 40,62 & 40,51 & $-5,90$ & 0,38 & 2,18 & & & & & & & & \\
\hline RPER & 0,03 & 0,02 & 0,23 & 0,81 & 0,71 & 6,50 & $-3,22$ & $-11,04$ & 22,43 & $-0,29$ & $-0,60$ & 1,37 & & & & & & & \\
\hline PS & 38,93 & 21,69 & 76,67 & 108,33 & 127,24 & 3976,37 & 3218,03 & 911,97 & 1072,27 & 7,65 & 0,38 & 0,48 & 448,99 & & & & & & \\
\hline US1 & 1,31 & 0,36 & 1,24 & 0,31 & 0,34 & 74,31 & 66,87 & 34,15 & 15,59 & 0,56 & 0,92 & $-0,42$ & 18,67 & 2,98 & & & & & \\
\hline US2 & 1,08 & 0,45 & 1,41 & 0,65 & 0,84 & 89,54 & 79,10 & 40,57 & 15,59 & 0,60 & 1,05 & $-0,50$ & 21,90 & 2,71 & 3,55 & & & & \\
\hline EA & $-0,31$ & $-0,05$ & $-0,22$ & $-0,16$ & $-0,21$ & $-3,48$ & $-2,25$ & $-1,47$ & $-0,64$ & $-0,03$ & $-0,03$ & $-0,03$ & $-0,07$ & 0,002 & 0,003 & 0,003 & & & \\
\hline CA & 0,48 & 0,17 & 0,44 & 0,85 & 0,98 & 16,57 & 4,79 & 3,81 & 3,27 & 0,08 & 0,12 & 0,06 & 0,17 & 0,003 & 0,01 & $-0,01$ & 0,02 & & \\
\hline ING & 27,15 & 49,23 & 52,31 & 143,32 & 78,49 & 4156,69 & 2748,64 & 1457,68 & 1029,38 & 311,60 & 15,24 & 11,76 & 202,82 & $-0,25$ & 1,93 & 0,14 & 0,51 & 1119,98 & \\
\hline ESCC & - & - & - & - & - & - & - & - & - & - & - & - & - & - & - & - & - & - & 0,0016 \\
\hline ESCF & - & - & - & - & - & - & - & - & - & - & - & - & - & - & - & - & - & - & 0,0016 \\
\hline
\end{tabular}




\subsection{Herdabilidade}

As herdabilidades estimadas para as características de desempenho são apresentadas na Figura 13.

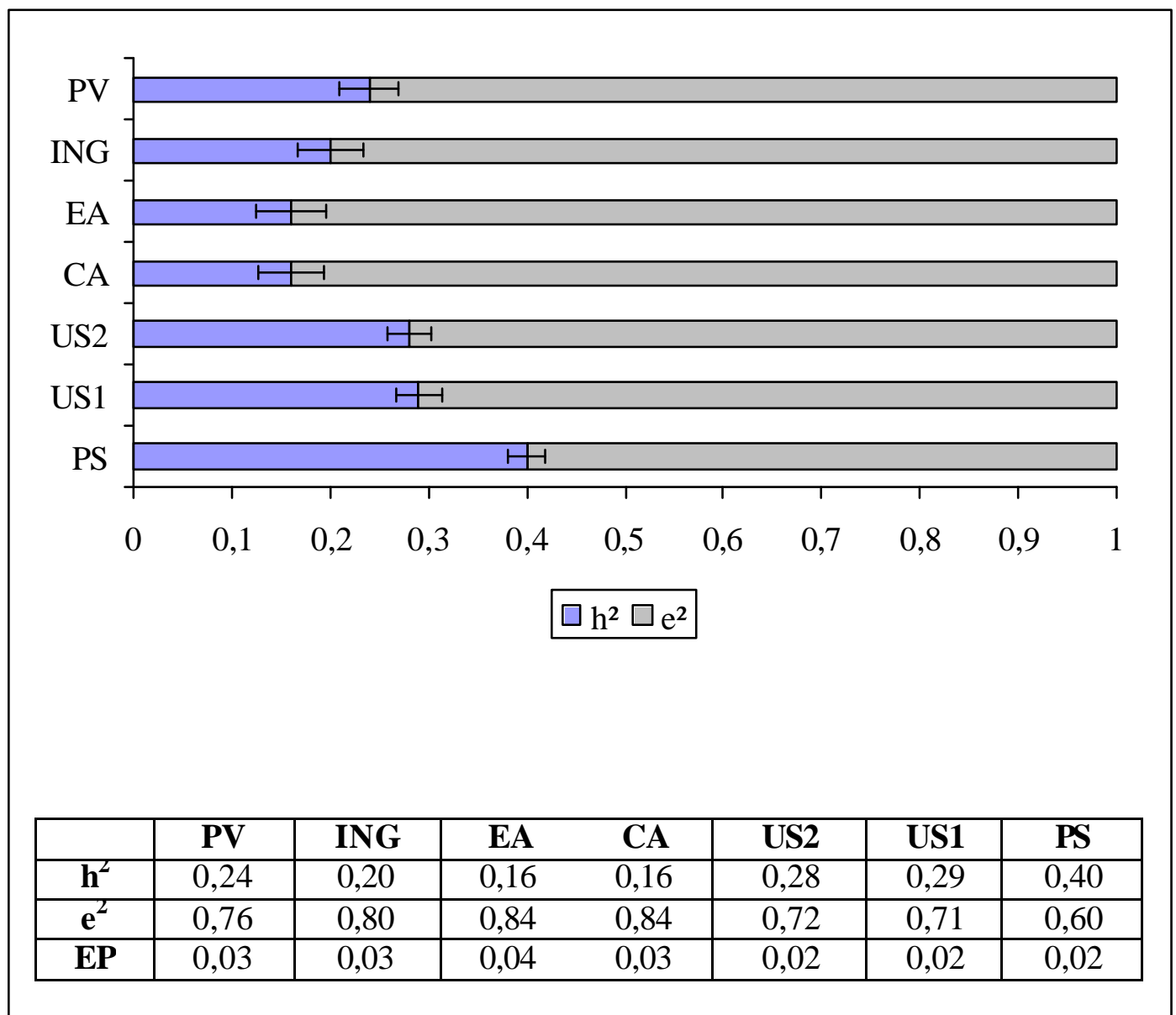

Figura 13 - Proporções da variância total devida aos efeitos genéticos aditivos diretos (ou herdabilidades $-\mathrm{h}^{2}$ ) e aos efeitos residuais $\left(\mathrm{e}^{2}\right)$ para as características de desempenho analisadas. A barra representa o erropadrão (EP) da herdabilidade

As herdabilidades das características de desempenho estimadas variaram entre baixas e moderadas. A herdabilidade encontrada para US1 foi moderada $(0,29 \pm 0,023)$, semelhante à descrita por Argentão et al. (2002). A herdabilidade 
encontrada para US2 também foi moderada $(0,28 \pm 0,023)$, diferente da herdabilidade alta $(0,51)$ encontrada por Argentão et al. (2002) para esta característica. Já para CA, a herdabilidade encontrada foi baixa $(0,16 \pm 0,033)$, semelhante à apresentada por Leenstra \& Pit (1988).

A estimativa de herdabilidade de PS foi moderada $(0,40 \pm 0,019)$, semelhante às descritas por Lopes \& Quaas (1997), e Argentão et al. (2002) para peso aos 35 dias. A herdabilidade de PV estimada foi moderada $(0,24 \pm 0,030)$, semelhante às descritas por Ledur et al. (1992) e Ledur et al. (1994) para peso aos 42 dias. Para EA e ING, as herdabilidades estimadas foram baixas $(0,16 \pm 0,035$ e $0,20 \pm 0,033$, respectivamente). Portanto, as herdabilidades estimadas para US1, US2, PS e PV indicam que estas são características capazes de responder à seleção, uma vez que segundo Campos \& Pereira (1999) as características com herdabilidade moderada a alta possuem esta particularidade. De acordo com Campos \& Pereira (1999) a conversão alimentar é uma característica importante em um programa de seleção, pois os gastos com alimentação representam boa parte dos custos na avicultura de corte (Wang et al., 1991). Todavia, a herdabilidade de CA apresentou-se baixa, o que sugere que esta característica não possui boa capacidade de responder à seleção, da mesma forma que EA e ING.

As herdabilidades estimadas para as características de carcaça são apresentadas na Figura 14. 


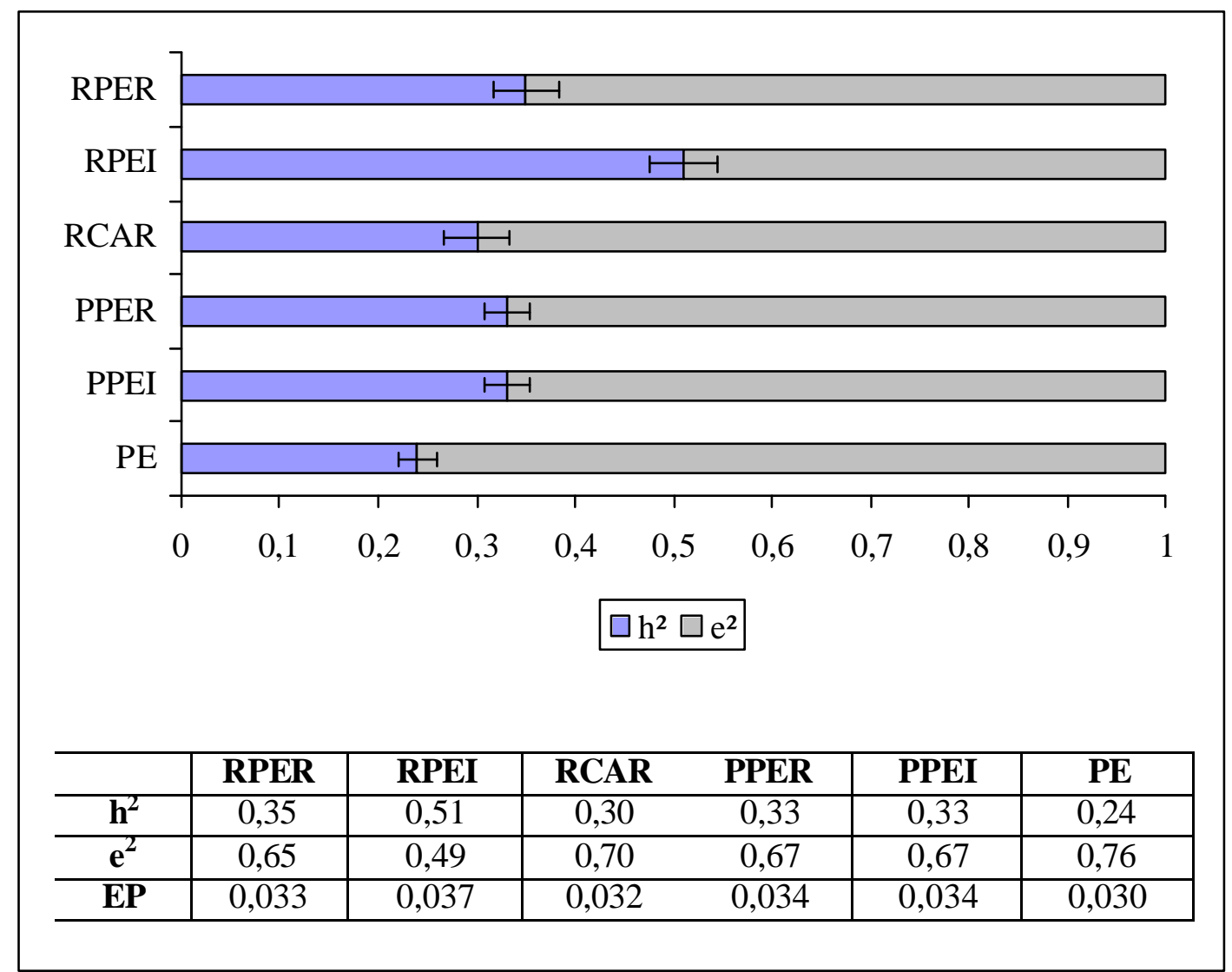

Figura 14 - Proporções da variância total devida aos efeitos genéticos aditivos diretos (ou herdabilidades $-\mathrm{h}^{2}$ ) e aos efeitos residuais $\left(\mathrm{e}^{2}\right)$ para as características de carcaça analisadas. A barra representa o erro-padrão (EP) da herdabilidade

As herdabilidades estimadas para as características de carcaça foram moderadas, com exceção de RPEI, cuja herdabilidade foi alta $(0,51 \pm 0,037)$, o que indica que todas as características de carcaça analisadas são capazes de responder à seleção, pois, como já mencionado, segundo Campos \& Pereira (1999) as características com herdabilidade moderada a alta possuem esta propriedade. A estimativa de herdabilidade de PPEI $(0,33 \pm 0,034)$ foi semelhante à descrita por Singh \& Trehan (1994), e a herdabilidade de PPER $(0,33 \pm 0,034)$ foi similar à apresentada por Argentão et al. (2002). A herdabilidade de PE foi moderada 
$(0,24 \pm 0,030)$, assim como a descrita por Argentão et al. (2002). As herdabilidades de

RCAR e RPER também foram moderadas $(0,30 \pm 0,032$ e $0,35 \pm 0,033$, respectivamente). De acordo com Le Bihan-Duval et al. (1998) a obtenção de maiores pesos de peito vem sendo um objetivo de seleção importante para as companhias de melhoramento de frangos. A herdabilidade encontrada para PPEI indica que esta característica é capaz de responder à seleção.

As herdabilidades estimadas para as características de composição corporal são apresentadas na Figura 15.

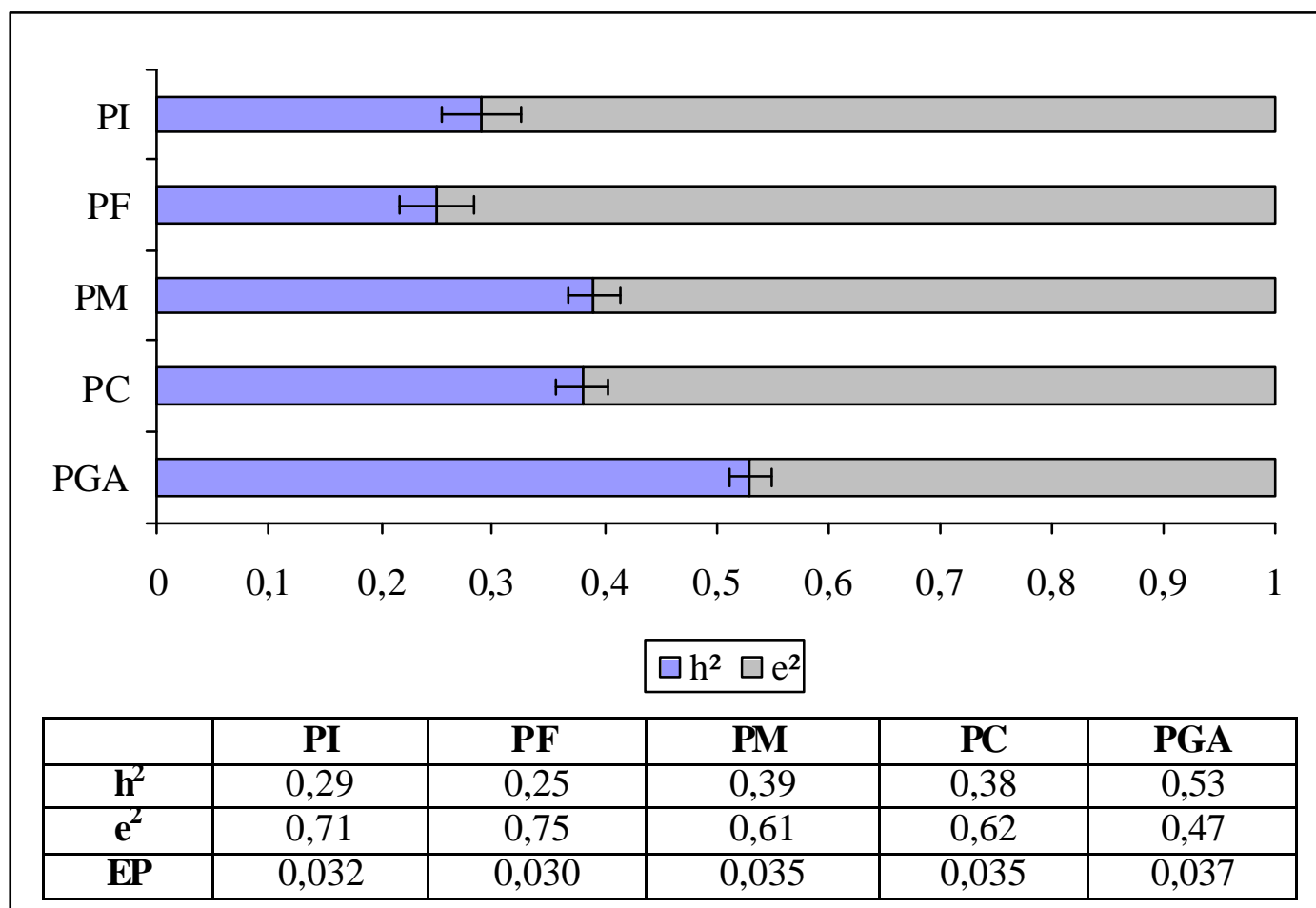

Figura 15 - Proporções da variância total devida aos efeitos genéticos aditivos diretos (ou herdabilidades $-\mathrm{h}^{2}$ ) e aos efeitos residuais $\left(\mathrm{e}^{2}\right)$ para as características de composição corporal analisadas. A barra representa o erro-padrão (EP) da herdabilidade 
As herdabilidades estimadas para as características de composição corporal foram moderadas, com exceção de PGA, cuja herdabilidade foi alta $(0,53 \pm 0,037)$. A estimativa de herdabilidade de PGA foi semelhante às descritas por Leenstra \& Pit (1988) e Rance et al. (2002). A herdabilidade de PC foi moderada $(0,38 \pm 0,035)$, assim como a descrita por Rance et al. (2002). A herdabilidade moderada de PM $(0,39 \pm 0,035)$ diferiu das descritas por Cahaner \& Nitsan (1985) e Rance et al. (2002), que foram altas $(0,57 \pm 0,24$ e $0,52 \pm 0,10$, respectivamente). Entretanto, algumas das estimativas de Rance at al. (2002) têm alto erro-padrão, devido ao pequeno número de animais analisados. A herdabilidade moderada encontrada para PF $(0,25 \pm 0,030)$ diferiu do valor baixo $(0,08 \pm 0,06)$ descrito por Rance et al. (2002). A herdabilidade de PI foi moderada $(0,29 \pm 0,032)$, semelhante à encontrada por Rance et al. (2002) para peso do duodeno. As herdabilidades das características de composição corporal, em especial PGA, indicam que estas características são capazes de responder à seleção, visto que, conforme citado anteriormente, segundo Campos \& Pereira (1999) as características que possuem herdabilidades moderadas a altas possuem esta aptidão.

Associada ao aumento do ganho de peso e de rendimentos de carcaça em frangos, vem ocorrendo uma diminuição no tamanho relativo dos órgãos das aves (McEntee et al. apud Rance et al., 2002), o que tem provocado um aumento na incidência de várias desordens fisiológicas (Shlosberg et al., 1996; Silversides et al., 1997; Buyse et al., 1999), especialmente na deficiência do coração em servir à demanda tecidual de oxigênio (Havenstein et al., 1994). Dessa forma, o estudo da herdabilidade do tamanho destes órgãos torna-se importante, pois a seleção a favor 
destas características pode ser necessária (Lin, 1981). Assim, os resultados encontrados sugerem que PC, PF, PM e PI são capazes de responder à seleção, se necessário.

\subsection{Correlações Genéticas e Fenotípicas}

As estimativas de correlações genéticas e fenotípicas das características de desempenho são apresentadas na Tabela 19.

TABELA 19 - Estimativas de correlações genéticas (acima da diagonal) e fenotípicas (abaixo da diagonal) entre as características de desempenho analisadas

\begin{tabular}{lccccccc}
\hline & PS & US1 & US2 & CA & EA & ING & PV \\
\hline PS & - & 0,50 & 0,52 & 0,07 & $-0,05$ & 0,61 & 0,99 \\
US1 & 0,51 & - & 0,90 & $-0,04$ & 0,12 & $-0,05$ & 0,28 \\
US2 & 0,55 & 0,83 & - & $-0,06$ & 0,10 & 0,04 & 0,27 \\
CA & 0,05 & 0,01 & 0,02 & - & $-1,00$ & 0,38 & 0,35 \\
EA & $-0,06$ & 0,02 & 0,02 & $-0,99$ & - & $-0,06$ & $-0,21$ \\
ING & 0,28 & 0,00 & 0,03 & 0,10 & 0,07 & - & 0,91 \\
PV & 0,95 & 0,32 & 0,35 & 0,78 & $-0,47$ & 0,91 & - \\
\hline
\end{tabular}

PS - peso à seleção; US1 - $1^{\text {a }}$ medida de ultra-som; US2 - $2^{\text {a }}$ medida de ultra-som; CA - conversão alimentar; EA - eficiência alimentar; ING - ingestão; PV - peso vivo.

As correlações encontradas das características US1 e US2 com CA, EA e ING foram fracas ou inversas fracas $(-0,06$ a 0,12$)$, tanto geneticamente como fenotipicamente. Assim, a seleção para US1 ou US2 pouco pode interferir em CA, EA e ING. NG apresentou fortes correlações genéticas com PS e com PV $(0,61$ e 0,91, respectivamente), assim como as descritas por Wang et al. (1991) entre peso aos 28 dias e ING dos 28 aos 42 dias e entre peso aos 42 dias e ING dos 28 aos 42 dias, respectivamente. Estes resultados sugerem que, quando se está selecionando para PS ou PV, está-se aumentando a capacidade de ingestão das aves. A correlação 
fenotípica encontrada entre ING e PV também foi forte $(0,91)$, já entre ING e PS a correlação fenotípica encontrada foi moderada $(0,28)$.

ING apresentou correlação genética moderada com CA $(0,38)$, mas quase nula com EA $(-0,06)$. A primeira estimativa indica que, geneticamente, aves de maior capacidade de ingestão de alimentos possuem pior capacidade de conversão. Fenotipicamente, tanto as correlações entre CA e ING como as entre EA e ING foram fracas $(0,10$ e 0,07 , respectivamente).

A correlação genética encontrada entre PV e CA foi moderada $(0,35)$, intermediária às descritas por Leenstra \& Pit (1988) entre peso aos 42 dias e CA dos 21 aos 42 dias $(0,16 \pm 0,27$ e $0,56 \pm 0,74)$. Já a correlação genética inversa moderada entre PV e EA encontrada (-0,21) foi diferente da descrita por Wang et al. (1991), que encontraram correlação genética fraca $(0,16)$ entre peso aos 42 dias e EA dos 28 aos 42 dias. A correlação fenotípica encontrada entre PV e CA foi forte $(0,78)$, e entre PV e EA, inversa moderada $(-0,47)$. A seleção para PV, portanto, é capaz de determinar piores CA e EA.

PS apresentou correlações genéticas e fenotípicas fracas com CA $(0,07$ e 0,05, respectivamente), enquanto Argentão et al. (2002) encontraram correlação genética moderada $(0,24)$ entre peso aos 35 dias e CA. PS apresentou também correlações genéticas e fenotípicas inversas fracas com EA $(-0,05$ e $-0,06$, respectivamente), enquanto Wang et al. (1991) encontraram correlação genética inversa moderada $(-0,23)$ e inversa forte $(-0,58)$ entre peso aos 28 dias e EA. A seleção para PS, portanto, pouco pode interferir em CA e EA, diferentemente da seleção para PV. 
Esperava-se em todos os momentos um comportamento exatamente inverso de CA e EA em relação às outras características, por serem calculadas a partir das mesmas informações, mas de maneira contrária. Entretanto, como foram retirados os outliers destas duas características separadamente, os conjuntos de dados restantes não corresponderam aos mesmos animais para as duas características, devido à distribuição diferenciada de cada uma delas. Desta forma, os comportamentos de CA e EA acabaram por ser diferentes, não representando, portanto, a mesma característica avaliada de duas formas. Tem-se como exemplo as correlações genéticas encontradas entre CA e ING e EA e ING, que são de 0,38 e -0,06, respectivamente. A título de confirmação da justificativa encontrada para tais divergências, realizou-se uma análise paralela na qual retiraram se os outliers apenas de CA e utilizaram se as medidas de EA dos animais não-outliers para CA. A análise realizada para teste foi entre a "nova" EA (criada a partir das informações de CA) e ING, cuja correlação genética resultou em $-0,36$, o que situa-se dentro do que se esperava inicialmente, uma vez que a correlação genética entre CA e ING é de 0,38, o que possivelmente explica o efeito da distribuição dos dados de CA e EA nos resultados de algumas das aná lises realizadas.

US1 apresentou correlações genéticas e fenotípicas moderadas com PV $(0,28$ e 0,32, respectivamente), assim como as descritas por Argentão et al. (2002) entre US1 aos 35 dias e peso aos 42 dias. US2 também apresentou correlações genéticas e fenotípicas moderadas com PV $(0,27$ e 0,35 , respectivamente), semelhante às descritas por Argentão et al. (2002) entre US2 aos 35 dias e peso aos 42 dias. US1 apresentou correlações genéticas e fenotípicas fortes com PS $(0,50$ e 0,51, respectivamente), enquanto os mesmos autores encontraram correlação genética 
moderada $(0,41)$ entre US1 aos 35 dias e peso aos 35 dias. US2 também apresentou correlações genéticas e fenotípicas fortes com PS (0,52 e 0,55, respectivamente), enquanto os mesmos autores encontraram correlação genética moderada $(0,43)$ entre US2 aos 35 dias e peso aos 35 dias. Estes autores também encontraram correlação fenotípica forte entre US2 aos 35 dias e peso aos 35 dias. Os resultados obtidos sugerem que a seleção para US1 e US2 favorece aves de maiores PS e PV.

Entre PS e PV as correlações genéticas e fenotípicas foram fortes $(0,99$ e 0,95, respectivamente), assim como as descritas por Ledur et al. (1992) entre peso aos 28 dias e peso aos 42 dias e Argentão et al. (2002) entre peso aos 35 dias e peso aos 42 dias. Ou seja, as correlações encontradas indicam que a seleção para um destes pesos favorece o outro. Também foram fortes as correlações genéticas e fenotípicas entre US1 e US2 (0,90 e 0,83, respectivamente). Do mesmo modo, estas correlações indicam que a seleção para uma das medidas de ultra-sonografia favorece a outra.

As estimativas de correlações genéticas e fenotípicas das características de carcaça são apresentadas na Tabela 20.

TABELA 20 - Estimativas de correlações genéticas (acima da diagonal) e fenotípicas (abaixo da diagonal) entre as características de carcaça analisadas

\begin{tabular}{lcccccc}
\hline & PE & PPEI & PPER & RCAR & RPEI & RPER \\
\hline PE & - & 0,61 & 0,85 & 0,44 & 0,79 & 0,16 \\
PPEI & 0,78 & - & 0,18 & 0,64 & 0,79 & $-0,54$ \\
PPER & 0,85 & 0,55 & - & 0,28 & $-0,41$ & 0,65 \\
RCAR & 0,41 & 0,43 & 0,24 & - & 0,46 & $-0,13$ \\
RPEI & 0,26 & 0,68 & $-0,10$ & 0,22 & - & $-0,74$ \\
RPER & $-0,03$ & $-0,23$ & 0,48 & $-0,21$ & $-0,35$ & - \\
\hline PE - peso eviscerado; PPEI - peso de peito; PPER - peso de pernas; RCAR - rendimento de \\
\multicolumn{7}{l}{ carcaça; RPEI - rendimento de peito; RPER - rendimento de pernas. }
\end{tabular}
carcaça; RPEI - rendimento de peito; RPER - rendimento de pernas. 
PE apresentou correlações genéticas e fenotípicas fortes com PPEI e PPER $(0,61$ a 0,85), semelhante às descritas por Argentão et al. (2002) e Rance et al. (2002), e correlação genética forte e fenotípica moderada com RPEI $(0,79$ e 0,26, respectivamente). PE apresentou correlação genética moderada com RCAR $(0,44)$ e fraca com RPER $(0,16)$, correlação fenotípica inversa fraca com RPER $(-0,03)$ e moderada com RCAR $(0,41)$, esta diferente da correlação fenotípica forte $(0,52)$ entre PE e RCAR aos 49 dias encontradas por Ávila et al. (1993).

PPEI apresentou correlação genética forte com RCAR e RPEI e inversa forte com RPER $(0,64,0,79$ e $-0,54$, respectivamente). PPEI apresentou correlação genética fraca com PPER $(0,18)$, diferindo das correlações genéticas fortes encontradas por Argentão et al. (2002) e Rance et al. (2002) entre estas características $(0,59$ e $0,65 \pm 0,07$, respectivamente). PPEI apresentou correlação fenotípica forte com PPER $(0,55)$, semelhante às apresentadas por Argentão et al. (2002) e Rance et al. (2002). PPEI apresentou também correlação fenotípica forte com RPEI $(0,68)$, moderada com $\operatorname{RCAR}(0,43)$ e inversa moderada com RPER $(-$ $0,23)$.

PPER apresentou correlação genética forte com RPER $(0,65)$, moderada com RCAR $(0,28)$ e inversa moderada com RPEI $(-0,41)$ e também correlação fenotípica moderada com RPER e RCAR e inversa fraca com RPEI $(0,48,0,24$ e -0,10, respectivamente). RCAR apresentou correlação genética moderada com RPEI $(0,46)$, mas inversa fraca com RPER $(-0,13)$. RCAR apresentou correlação fenotípica moderada com RPEI $(0,22)$ e inversa moderada com RPER $(-0,21)$. Entre RPEI e 
RPER, a correlação genética foi inversa forte $(-0,74)$ e a fenotípica foi inversa moderada $(-0,35)$.

Os resultados encontrados sugerem que a seleção para maiores PE, PPEI e PPER é capaz de aumentar, respectivamente, RCAR, RPEI e RPER. Entretanto, houve uma relação genética e fenotípica inversa entre RPEI e RPER, indicando que a seleção para uma destas características implica em diminuição da outra. A seleção para PE é capaz também de trazer benefícios em termos de PPEI e PPER, além de RCAR e RPEI, entretanto, tendo pouca influência sobre RPER. A seleção para PPEI, por sua vez, é capaz de melhorar PE, RPEI e RCAR, e a seleção para PPER pode trazer benefícios em PE, RPER e RCAR.

As estimativas de correlações genéticas e fenotípicas das características de composição corporal são apresentadas na Tabela 21.

TABELA 21 - Estimativas de correlações genéticas (acima da diagonal) e fenotípicas (abaixo da diagonal) entre as características de composição corporal analisadas

\begin{tabular}{lccccc}
\hline & PGA & PC & PM & PF & PI \\
\hline PGA & - & 0,04 & 0,09 & 0,07 & 0,36 \\
PC & 0,16 & - & $-0,02$ & 0,47 & 0,27 \\
PM & $-0,01$ & 0,01 & - & $-0,11$ & $-0,16$ \\
PF & 0,16 & 0,37 & $-0,01$ & - & 0,38 \\
PI & 0,28 & 0,26 & $-0,06$ & 0,28 & - \\
\hline
\end{tabular}

PGA - peso da gordura abdominal; PC - peso do coração; PM - peso da moela; PF peso do fígado; PI - peso do intestino.

PGA apresentou correlações genéticas e fenotípicas moderadas com PI $(0,36$ e 0,28 , respectivamente) e fracas ou inversas fracas com as demais características de composição corporal $(-0,01$ a 0,16$)$, diferentemente do descrito por Rance et al. (2002), que encontraram correlações genéticas moderadas entre PGA e PC 
$(0,35 \pm 0,15)$, PGA e PF $(0,42 \pm 0,26)$ e PGA e PM $(0,38 \pm 0,14)$ e fenotípicas fracas ou quase nulas entre estas características $(0,07,0,12$ e $-0,09$, respectivamente).

Segundo Cahaner et al. (1986) aves com maior deposição de gordura possuem maior capacidade digestiva. De acordo com Konarewski et al. (2000) a seleção para crescimento rápido culminou em um aumento marcante na capacidade do trato gastrintestinal das aves e conseqüentemente também na superfície absortiva intestinal de acordo com Uni et al. (1995), de modo que as aves selecionadas segundo este critério possuem maior capacidade de absorção de nutrientes, e por isso depositam mais gordura, afirmação que é sustentada pelas correlações moderadas encontradas entre PGA e PI.

As correlações genéticas e fenotípicas entre PGA e PC foram fracas $(0,04$ e 0,16, respectivamente), ou seja, a seleção contra PGA não tende a provocar maiores alterações em PC, o que é importante, já que esta característica representa um ponto crítico em relação às desordens metabólicas que vêm ocorrendo nos frangos (Havenstein et al., 1994). PC apresentou correlações genéticas e fenotípicas moderadas com PF (0,47 e 0,37, respectivamente), diferindo do encontrado por Rance et al. (2002), que apresentaram correlação genética fraca $(0,19 \pm 0,26)$ e fenotípica forte $(0,59)$ entre estas características. Entre PC e PI, as correlações genéticas e fenotípicas foram moderadas $(0,27$ e 0,26 , respectivamente), semelhantes às descritas por Rance et al. (2002) entre PC e peso do duodeno. Os resultados obtidos indicam, portanto, que aves com maior PC apresentam maiores PF e PI.

PM apresentou correlação genética inversa fraca com PF $(-0,11)$, assim como o descrito por Rance et al. (2002). Entretanto, PM apresentou correlação genética 
quase nula com PC $(-0,02)$ e inversa fraca com PI $(-0,16)$, o que divergiu destes autores, que encontraram correlação genética inversa moderada entre PM e PC ($0,49 \pm 0,19)$ e forte entre PM e peso do duodeno e do íleo $(0,61 \pm 0,17$ e $0,79 \pm 0,24$, respectivamente). A correlação fenotípica entre PM e PC foi fraca $(0,01)$, assim como a encontrada por Rance et al. (2002), e foi inversa fraca entre PM e PF (-0,01), diferente da correlação fenotípica fraca $(0,15)$ encontrada entre estas características por estes autores. Entre PM e PI encontrourse uma correlação fenotípica praticamente nula $(-0,06)$, todavia, Rance et al. (2002) descreveram fraca correlação fenotípica entre PM e peso do íleo $(0,08)$ e entre PM e peso do duodeno $(0,20)$. As estimativas encontradas sugerem, portanto, que PM não possui uma relação significante com o peso dos outros órgãos.

PF apresentou correlações genéticas e fenotípicas moderadas com PI (0,38 e 0,28, respectivamente), semelhante ao encontrado por Rance et al. (2002) entre PF e peso do duodeno, ou seja, aves de maior PF tendem a apresentar maior PI.

As estimativas obtidas de correlações genéticas e fenotípicas entre as características de desempenho e carcaça são apresentadas nas Tabelas 22 e 23.

TABELA 22 - Estimativas de correlações genéticas entre as características de desempenho e carcaça analisadas

\begin{tabular}{lcccccc}
\hline & PE & PPEI & PPER & RCAR & RPEI & RPER \\
\hline PS & 0,97 & 0,75 & 0,93 & 0,15 & $-0,07$ & 0,08 \\
US1 & 0,39 & 0,64 & 0,17 & 0,40 & 0,51 & $-0,29$ \\
US2 & 0,38 & 0,69 & 0,17 & 0,42 & 0,56 & $-0,34$ \\
CA & 0,32 & 0,10 & 0,10 & 0,00 & $-0,16$ & $-0,21$ \\
EA & $-0,14$ & $-0,10$ & $-0,01$ & 0,25 & $-0,04$ & 0,12 \\
ING & 0,03 & 0,86 & 0,68 & $-0,02$ & $-0,19$ & 0,69 \\
PV & 0,95 & 0,43 & 0,84 & 0,44 & $-0,16$ & 0,24 \\
\hline
\end{tabular}

PS - peso à seleção; US1 - $1^{\text {a }}$ medida de ultra-som; US2 - $2^{\text {a }}$ medida de ultra-som; CA - conversão alimentar; EA - eficiência alimentar; ING - ingestão; PV - peso vivo; PE - peso eviscerado; PPEI peso de peito; PPER - peso de pernas; RCAR - rendimento de carcaça; RPEI - rendimento de peito; RPER - rendimento de pernas. 
TABELA 23 - Estimativas de correlações fenotípicas entre as características de desempenho e carcaça analisadas

\begin{tabular}{lcccccc}
\hline & PE & PPEI & PPER & RCAR & RPEI & RPER \\
\hline PS & 0,95 & 0,86 & 0,81 & 0,23 & 0,01 & 0,02 \\
US1 & 0,37 & 0,49 & 0,22 & 0,28 & 0,36 & $-0,21$ \\
US2 & 0,40 & 0,53 & 0,20 & 0,27 & 0,38 & $-0,23$ \\
CA & 0,32 & 0,67 & 0,57 & 0,49 & 0,55 & 0,35 \\
EA & $-0,39$ & $-0,66$ & $-0,29$ & $-0,41$ & $-0,37$ & $-0,43$ \\
ING & 0,78 & 0,99 & 0,76 & 0,30 & 0,31 & 0,30 \\
PV & 0,96 & 0,71 & 0,85 & 0,31 & 0,01 & 0,04 \\
\hline
\end{tabular}

PS - peso à seleção; US1 - $1^{\mathrm{a}}$ medida de ultra-som; US2 - $2^{\mathrm{a}}$ medida de ultra-som; CA - conversão alimentar; EA - eficiência alimentar; ING - ingestão; PV - peso vivo; PE - peso eviscerado; PPEI peso de peito; PPER - peso de pernas; RCAR - rendimento de carcaça; RPEI - rendimento de peito; RPER - rendimento de pernas.

US1 e US2 apresentaram correlações genéticas com PPER fracas (ambas 0,17). Ainda, US1 e US2 apresentaram correlações genéticas e fenotípicas inversas moderadas com RPER $(-0,34$ a $-0,21)$. Portanto, da mesma forma que a seleção a favor de PPEI, a seleção para US1 e US2 é capaz de acarretar em menores PPER e RPER. US1 apresentou correlação fenotípica moderada com PPER $(0,22)$ e LS2 apresentou correlação fenotípica fraca com PPER $(0,20)$.

Os resultados encontrados sugerem que a seleção para US1 e US2 é eficiente como estratégia para favorecer aves de maiores PPEI, pois US1 e US2 apresentaram correlações genéticas fortes com PPEI e RPEI (0,51 a 0,69). As correlações fenotípicas entre US1 e US2 e PPEI e RPEI foram moderadas $(0,36$ a 0,49), com exceção da correlação fenotípica entre US2 e PPEI, que foi forte $(0,53)$. Geneticamente, os resultados encontrados entre US1 e PPEI e US2 e PPEI são semelhantes aos apresentados por Argentão et al. (2002), que estimaram fortes correlações genéticas e fenotípicas das características US1 e US2 aos 35 dias com PPEI aos 42 dias. 
US1 e US2 apresentaram correlações genéticas e fenotípicas moderadas com PE e RCAR $(0,27$ a 0,42), ou seja, a seleção para US1 e US2 é capaz de trazer benefícios não só ao PPEI e RPEI, mas também a PE e a RCAR.

PS apresentou fortes correlações genéticas e fenotípicas com PE (0,97 e 0,95, respectivamente), assim como descrito por Wang et al. (1991) entre peso aos 28 dias e PE aos 47 dias. PS também apresentou fortes correlações genéticas e fenotípicas com PPEI e PPER $(0,75$ a 0,93), correlações genéticas fracas com RCAR $(0,15)$ e RPER $(0,08)$ e correlação genética praticamente nula com RPEI $(-0,07)$. PS apresentou correlações fenotípicas fracas com RPEI $(0,01)$ e RPER $(0,02)$ e moderada com RCAR $(0,23)$. Estes resultados sugerem que a seleção para PS é capaz de favorecer aves de maiores PE, PPEI e PPER. Entretanto, a mesma seleção tende a não interferir em RCAR, RPEI e RPER.

PV apresentou correlação genética forte com PE (0,95), assim como as apresentadas por Cahaner \& Nitsan (1985), Singh \& Trehan (1994), Le Bihan-Duval et al. (1998), Argentão et al. (2002) e Rance et al. (2002). Da mesma forma, a correlação genética entre PV e PPER foi forte $(0,84)$, como também encontraram os mesmos autores. Já a correlação genética entre PV e PPEI foi moderada $(0,43)$, diferindo dos resultados encontrados pelos autores mencionados acima, que estimaram fortes correlações genéticas entre estas características $(0,76 \pm 0,03$ a 0,92 $\pm 0,02)$. As correlações fenotípicas entre PV e PE, PV e PPER e PV e PPEI foram fortes $(0,96,0,85$ e 0,71 , respectivamente), estando de acordo com Cahaner \& Nitsan (1985), Singh \& Trehan (1994), Le Bihan-Duval et al. (1998), Argentão et al. (2002) e Rance et al. (2002). As estimativas de correlações genéticas indicam que a 
seleção para PV favorece aves de maiores PE, PPEI e PPER, assim como a seleção para PS.

PV apresentou correlação genética moderada com $\operatorname{RCAR}(0,44)$, comprovando, portanto, as afirmações de Chambers (1990) e Barbato (1992), de que a seleção genética para peso é capaz de aumentar RCAR em frangos de corte. PV apresentou ainda correlação genética moderada com RPER $(0,24)$, mas inversa fraca com RPEI $(-0,16)$.

PV apresentou correlação fenotípica moderada com RCAR $(0,31)$, semelhante ao descrito por Ávila et al. (1993), e fraca com RPEI $(0,01)$ e RPER $(0,04)$. Diferentemente da seleção para PS, a seleção genética para PV é capaz de proporcionar aumento em RCAR.

CA apresentou correlação genética inversa moderada com RPER $(-0,21)$ e inversa fraca com RPEI $(-0,16)$. EA apresentou correlação genética inversa fraca com RPEI $(-0,04)$ e fraca com RPER $(0,12)$. Portanto, a seleção genética para CA ou EA pouco pode interferir em RPEI e RPER. CA apresentou ainda correlação fenotípica forte com RPEI $(0,55)$ e moderada com RPER $(0,35)$, já EA apresentou correlação fenotípica inversa moderada com RPEI $(-0,37)$ e RPER $(-0,43)$.

PE apresentou correlação genética moderada com CA $(0,32)$ e inversa fraca com EA $(-0,14)$, esta diferente da correlação genética forte $(0,53)$ entre PE aos 47 dias e EA dos 28 aos 42 dias, encontrada por Wang et al. (1991). PE apresentou correlação fenotípica moderada com CA $(0,32)$ e inversa moderada com EA $(-0,39)$. Logo, a seleção contra CA é capaz de acarretar na diminuição PE.

EA apresentou correlação genética moderada com $\operatorname{RCAR}(0,25)$ e CA não apresentou correlação genética com RCAR. Desta forma, aves com maior RCAR 
tendem a possuir melhor EA. A correlação fenotípica entre RCAR e CA foi moderada $(0,49)$ e entre RCAR e EA, inversa moderada $(0,41)$. PPEI e PPER apresentaram correlações genéticas fracas com CA (ambas 0,10) e inversas fracas com EA (-0,14 e-0,10, respectivamente), além de correlações fenotípicas fortes com CA (0,67 e 0,57, respectivamente). Portanto, a seleção genética para PPEI e PPER pouco pode interferir em CA e em EA. A correlação fenotípica entre PPEI e EA foi inversa forte $(-0,66)$, e entre PPER e EA, inversa moderada $(-0,29)$.

ING apresentou fortes correlações genéticas e fenotípicas com PPEI e PPER $(0,68$ a 0,99$)$, forte correlação genética com RPER $(0,69)$ e correlação genética inversa fraca com RPEI $(-0,19)$. Portanto, a seleção genética para PPEI e PPER é capaz de causar aumento em ING, embora não seja capaz de determinar piores CA e EA.

A correlação genética entre ING e PE $(0,03)$ e entre ING e RCAR $(-0,02)$ foram quase nulas. Desta forma, a seleção genética para PE pouco pode interferir em ING, assim como, geneticamente, um aumento em RCAR pouco pode interferir em ING e em RPEI. Todavia um aumento em RPER é capaz de acarretar em maior ING. A correlação fenotípica entre ING e PE foi forte $(0,78)$, e entre ING e RCAR, ING e RPEI e ING e RPER, as correlações fenotípicas foram moderadas $(0,30,0,31$ e 0,30, respectivamente).

As estimativas de correlações genéticas e fenotípicas entre as características de desempenho e composição corporal são apresentadas nas Tabelas 24 e 25, respectivamente. 
TABELA 24 - Estimativas de correlações genéticas entre as características de desempenho e composição corporal analisadas

\begin{tabular}{lccccc}
\hline & PGA & PC & PM & PF & PI \\
\hline PS & 0,46 & 0,60 & 0,35 & 0,68 & 0,65 \\
US1 & $-0,16$ & 0,12 & 0,15 & $-0,01$ & $-0,20$ \\
US2 & $-0,13$ & 0,10 & 0,05 & $-0,01$ & $-0,16$ \\
CA & 0,35 & 0,16 & 0,12 & 0,23 & 0,26 \\
EA & $-0,25$ & $-0,06$ & 0,12 & $-0,40$ & 0,03 \\
ING & 0,79 & 0,77 & 0,03 & 0,73 & 0,92 \\
PV & 0,26 & 0,28 & 0,21 & 0,43 & 0,37 \\
\hline
\end{tabular}

PS - peso à seleção; US1 - $1^{\text {a }}$ medida de ultra-som; US2 - $2^{\text {a }}$ medida de ultra-som; CA - conversão alimentar; EA - eficiência alimentar; ING - ingestão; PV - peso vivo; PGA - peso da gordura abdominal; PC - peso do coração; PM - peso da moela; PF peso do fígado; PI - peso do intestino.

TABELA 25 - Estimativas de correlações fenotípicas entre as características de desempenho e composição corporal analisadas

\begin{tabular}{lccccc}
\hline & PGA & PC & PM & PF & PI \\
\hline PS & 0,56 & 0,64 & 0,28 & 0,65 & 0,61 \\
US1 & 0,02 & 0,13 & 0,12 & 0,13 & 0,02 \\
US2 & 0,04 & 0,15 & 0,09 & 0,13 & 0,05 \\
CA & 0,66 & 0,76 & 0,47 & 0,56 & 0,70 \\
EA & $-0,33$ & $-0,59$ & $-0,86$ & $-0,71$ & $-0,38$ \\
ING & 0,48 & 0,91 & 0,12 & 0,28 & 0,24 \\
PV & 0,37 & 0,39 & 0,23 & 0,41 & 0,43 \\
\hline
\end{tabular}

PS - peso à seleção; US1 - $1^{\text {a }}$ medida de ultra-som; US2 - $2^{\text {a }}$ medida de ultra-som; CA - conversão alimentar; EA - eficiência alimentar; ING - ingestão; PV - peso vivo; PGA - peso da gordura abdominal; PC - peso do coração; PM - peso da moela; PF peso do fígado; PI - peso do intestino.

PGA apresentou correlação genética moderada com PS $(0,46)$, semelhante à descrita por Griffiths et al. (1978) entre estas características aos 28 dias, e também moderada com PV (0,26), como a apresentada por Rance et al. (2002). PGA apresentou, ainda, correlações genéticas inversas fracas com US1 $(-0,16)$ e US2 (0,13) e fenotípicas fracas com US1 $(0,02)$ e US2 $(0,04)$. Ou seja, a seleção contra PGA pouco pode interferir em US1 e US2.

PGA apresentou correlação genética moderada com CA $(0,35)$, como a encontrada por Leenstra \& Pit (1988) e inversa moderada com EA (-0,25), semelhante à descrita por Wang et al. (1991). PGA apresentou correlação genética 
forte com ING $(0,79)$ e correlação fenotípica forte com PS $(0,56)$, mas moderada com PV (0,37), esta semelhante ao apresentado por Cahaner \& Nitsan (1985) entre PGA e peso aos 63 dias e por Singh \& Trehan (1994). A correlação fenotípica foi forte entre PGA e CA $(0,66)$, inversa moderada entre PGA e EA $(-0,33)$ e moderada entre PGA e ING $(0,48)$.

Como discutido anteriormente, os resultados indicam que quando as aves são selecionadas para PV, está selecionando indiretamente para maior ING. ING, por sua vez, é capaz de determinar aumento em PGA. Portanto, a seleção para PV pode acarretar em maior deposição de gordura, confirmando a afirmação de Lin (1981), Leenstra (1986) e Havenstein et al. (1988), de que a ave que é selecionada para maior peso vivo, de modo geral, ingere mais alimento e o converte mal, e por este motivo deposita mais gordura. Ainda sustenta esta afirmação o fato de que a seleção para PV é capaz de ocasionar também pior CA e EA e a própria ING parece estar relacionada a uma maior CA. Entretanto, a diminuição da deposição de gordura nas aves pode ser alcançada através da seleção para menor CA ou para maior EA, devido às correlações encontradas entre estas características. De acordo com Leenstra (1986), Leenstra \& Pit (1987) e Buyse et al. (1999) a seleção contra a deposição de gordura está normalmente associada a uma melhor CA. Esta influência negativa da gordura sobre a eficiência alimentar está relacionada ao desvio de nutrientes pelo organismo para o tecido adiposo (Farrel et al., 1982), uma vez que segundo Lin (1981) a gordura possui alta densidade energética, e, portanto, consome bastante energia para ser depositada.

PC apresentou correlação genética e fenotípica forte com PS (0,60 e 0,64, respectivamente) e correlação genética e fenotípica moderada com PV $(0,28$ e 0,39, 
respectivamente), enquanto Rance et al. (2002) encontraram correlação genética forte $(0,61 \pm 0,13)$ entre PC e PV. Assim, a seleção para PS e PV é capaz de favorecer aves de maior PC. PC apresentou correlações genéticas e fenotípicas fracas com US1 e US2 $(0,10$ a 0,15$)$, correlação genética fraca com CA $(0,16)$ e inversa fraca com EA $(-0,06)$ e correlação fenotípica forte com CA $(0,76)$ e inversa forte com EA (0,59). A seleção genética para US1, US2, CA e EA, portanto, pouco pode interferir em PC. PC apresentou ainda correlação genética e fenotípica forte com ING $(0,77$ e 0,91, respectivamente). Ou seja, apesar de PC não ter apresentado uma relação significativa com CA, aves de maior PC tendem a possuir maior ING.

PM apresentou correlações genéticas e fenotípicas moderadas com PS $(0,35$ e 0,28 , respectivamente) e também com PV $(0,21$ e 0,23 , respectivamente), enquanto Rance et al. (2002) encontraram correlação genética moderada entre PM e PV, mas correlação fenotípica fraca entre estas características. Desta forma, a seleção para PS ou PV é capaz de determinar aumento em PM. PM apresentou correlações genéticas e fenotípicas fracas com US1 e US2 $(0,05$ a 0,15$)$ e correlações genéticas fracas com EA, CA (ambas 0,12) e ING $(0,03)$. Já a correlação fenotípica foi moderada entre PM e CA $(0,47)$, inversa forte entre PM e EA $(-0,86)$ e fraca entre PM e ING $(0,12)$. Portanto, a seleção genética para US1, US2, EA e CA pouco pode interferir em PM. PF apresentou correlação genética e fenotípica forte com PS $(0,68$ e 0,65, respectivamente) e moderada com PV (0,43 e 0,41, respectivamente), estas semelhantes às encontradas por Rance et al. (2002). Desta forma, a seleção para PS ou PV é capaz de favorecer aves de maior PF. PF apresentou correlações genéticas inversas fracas com US1 e US2 (ambas -0,01), moderada com CA $(0,23)$, inversa 
moderada com EA $(-0,40)$ e forte com ING $(0,73)$. Portanto, a seleção genética para US1 e US2 pouco pode interferir em PF, entretanto, aves de maior CA e maior ING tendem a possuir maior PF. A correlação fenotípica foi forte entre PF e CA $(0,56)$, inversa forte entre PF e EA $(-0,71)$ e moderada entre PF e ING $(0,28)$. PF apresentou ainda correlações fenotípicas fracas com US1 e US2 (ambas 0,13).

PI apresentou correlação genética e fenotípica forte com PS $(0,65$ e 0,61, respectivamente) e moderada com PV $(0,37$ e 0,43 , respectivamente), estas semelhantes às descritas por Rance et al. (2002) entre peso do duodeno e PV aos 42 dias, o que comprova a afirmação de Konarewski et al. (2000), de que a seleção para maior peso corporal causa um aumento em tamanho e capacidade do trato gastrintestinal das aves. PI apresentou correlações genéticas inversas fracas com US1 $(-0,20)$ e US2 $(-0,16)$, fenotípicas fracas com US1 $(0,02)$ e US2 $(0,05)$ e correlação genética moderada com CA $(0,26)$, fraca com EA $(0,03)$ e forte com ING $(0,92)$, além de correlação fenotípica forte com CA $(0,70)$, inversa moderada com EA $(-$ $0,38)$ e moderada com ING $(0,24)$. Novamente, as estimativas obtidas sugerem que aves com maior PI possuem maior capacidade de ingestão e pior CA, suportando a afirmação de Konarewski et al. (2000), de que o aumento na capacidade do trato gastrintestinal das aves, ocasionado pela seleção para maiores pesos, está relacionado com o aumento da capacidade de ingestão destes animais. Além disso, conforme mencionado anteriormente, animais com maior PI tendem a possuir maior PGA, e PGA, por sua vez, é capaz de determinar aumento em ING e CA.

As correlações estimadas entre peso e pesos dos órgãos confirmam a afirmação de Rance et al. (2002), de que a seleção com peso como critério incrementa o tamanho absoluto dos órgãos das aves. 
As estimativas de correlações genéticas e fenotípicas entre as características de carcaça e composição corporal são apresentadas nas Tabelas 26 e 27.

TABELA 26 - Estimativas de correlações genéticas entre as características de carcaça e composição corporal analisadas

\begin{tabular}{lcccccc}
\hline & PE & PPEI & PPER & RCAR & RPEI & RPER \\
\hline PGA & 0,12 & $-0,12$ & 0,13 & $-0,30$ & $-0,22$ & 0,07 \\
PC & 0,17 & 0,04 & 0,15 & $-0,19$ & $-0,07$ & 0,03 \\
PM & 0,13 & 0,08 & 0,08 & $-0,10$ & 0,01 & 0,09 \\
PF & 0,32 & 0,05 & 0,36 & $-0,30$ & $-0,15$ & 0,19 \\
PI & 0,23 & $-0,13$ & 0,19 & $-0,41$ & $-0,26$ & 0,12 \\
\hline PE - peso eviscerado; PPEI - peso de peito; PPER - peso de pernas; RCAR - rendimento de carcaça; \\
RPEI - rendimento de peito; RPER - rendimento de pernas; PGA - peso da gordura abdominal; PC - \\
\multicolumn{7}{l}{ peso do coração; PM - peso da moela; PF peso do fígado; PI - peso do intestino. }
\end{tabular}

TABELA 27 - Estimativas de correlações fenotípicas entre as características de carcaça e composição corporal analisadas

\begin{tabular}{lcccccc}
\hline & PE & PPEI & PPER & RCAR & RPEI & RPER \\
\hline PGA & 0,30 & 0,11 & 0,30 & $-0,13$ & $-0,15$ & 0,08 \\
PC & 0,34 & 0,24 & 0,30 & $-0,07$ & $-0,01$ & 0,01 \\
PM & 0,19 & 0,17 & 0,17 & $-0,05$ & 0,04 & 0,00 \\
PF & 0,34 & 0,20 & 0,31 & $-0,13$ & $-0,06$ & 0,04 \\
PI & 0,33 & 0,14 & 0,31 & $-0,23$ & $-0,14$ & 0,06 \\
\hline PE
\end{tabular}

PE - peso eviscerado; PPEI - peso de peito; PPER - peso de pernas; RCAR - rendimento de carcaça; RPEI - rendimento de peito; RPER - rendimento de pernas; PGA - peso da gordura abdominal; PC peso do coração; PM - peso da moela; PF pes o do fígado; PI - peso do intestino.

PGA apresentou correlação genética fraca com PE $(0,12)$, assim como o descrito por Wang et al. (1991) entre PGA e PE aos 47 dias. A correlação genética entre PGA e PPER também foi fraca $(0,13)$, diferindo da correlação moderada $(0,38 \pm 0,11)$ descrita por Rance et al. (2002) entre estas características. PGA apresentou correlação genética inversa fraca com PPEI $(-0,12)$, diferindo das correlações genéticas fracas $(0,15 \pm 0,35)$ encontradas entre estas características por Singh \& Trehan (1994) e das moderadas $(0,25 \pm 0,06$ e $0,27 \pm 0,10)$ encontradas por Le 
Bihan-Duval et al. (1998) e Rance et al. (2002). Assim, a seleção genética contra PGA pouco pode interferir em PE, PPEI e PPER. PGA apresentou correlação genética inversa moderada com RCAR $(-0,30)$ e RPEI $(-0,22)$ e fraca com RPER (0,07). Segundo Leenstra \& Pit (1988) a seleção para menor deposição de gordura está normalmente associada a maiores rendimentos de carcaça, o que se confirma no caso das correlações genéticas encontradas entre PGA e RCAR e entre PGA e RPEI.

PGA apresentou correlação fenotípica moderada com PE $(0,30)$, assim como a descrita por Ávila et al. (1993) entre PGA e PE aos 49 dias. PGA apresentou correlação fenotípica moderada com PPER $(0,30)$, diferentemente da correlação fenotípica fraca $(0,08)$ encontrada por Rance et al. (2002) entre estas características. PGA apresentou correlação fenotípica fraca com PPEI $(0,11)$, assim como as descritas por Singh \& Trehan (1994) e Rance et al. (2002) e também com RPER $(0,08)$. PGA apresentou correlação fenotípica inversa fraca com $\operatorname{RCAR}(-0,13)$, diferindo da correlação fenotípica inversa moderada $(0,21)$ encontrada por Ávila et al. (1993) entre PGA e RCAR aos 49 dias. PGA apresentou correlação fenotípica inversa fraca também com RPEI $(-0,15)$.

PM apresentou correlação genética fraca com PPER $(0,08)$, como o descrito por Rance et al. (2002). PM também apresentou correlações genéticas fracas com PE e PPEI (0,13 e 0,08, respectivamente), enquanto os mesmos autores encontraram correlações genéticas moderadas entre PM e PE $(0,22 \pm 0,15)$ e entre PM e PPEI $(0,29 \pm 0,15)$. PM apresentou correlações fenotípicas fracas com PE $(0,19)$, PPEI e PPER (ambas 0,17), assim como o descrito por Rance et al. (2002). PM apresentou 
correlação genética e fenotípica fraca com RPEI e RPER $(0,00$ a 0,09$)$ e inversa fraca com RCAR (-0,10 e -0,05, respectivamente).

PF apresentou correlação genética e fenotípica moderada com PE $(0,32$ e 0,30, respectivamente), assim como as descritas por Rance et al. (2002), e genética inversa moderada com RCAR (-0,30). PF apresentou correlação genética inversa fraca com RPEI $(-0,15)$, fraca com RPER $(0,19)$ e fraca com PPEI $(0,05)$, esta última diferente da correlação genética moderada $(0,24 \pm 0,21)$ encontrada por Rance et al. (2002) entre estas características. A correlação genética entre PF e PPER foi moderada $(0,36)$, semelhante à descrita por Rance et al. (2002).

PF apresentou correlação fenotípica inversa fraca com $\operatorname{RCAR}(-0,13)$ e correlação fenotípica moderada com PPEI $(0,20)$ e PPER $(0,31)$, assim como as descritas por Rance et al. (2002). PF apresentou também correlação fenotípica inversa fraca com RPEI $(-0,06)$ e fraca com RPER $(0,04)$.

PI apresentou correlação genética e fenotípica moderada com PE $(0,23$ e 0,33, respectivamente), assim como as descritas por Rance et al. (2002) entre peso do duodeno e PE e entre peso do jejuno e PE. PI apresentou correlação genética e fenotípica inversa moderada com $\operatorname{RCAR}(-0,41$ e $-0,23$, respectivamente). PI apresentou correlação genética inversa fraca com PPEI $(-0,13)$, semelhante ao descrito por Rance et al. (2002) entre peso do íleo e PPEI. PI apresentou correlação genética inversa moderada com RPEI $(-0,26)$ e correlação fenotípica fraca com PPEI $(0,14)$, esta semelhante à descrita por Rance et al. (2002) entre peso do íleo e PPEI. PI apresentou correlação fenotípica inversa fraca com RPEI $(-0,14)$ e correlação genética fraca com PPER $(0,19)$, a qual diferiu da correlação genética moderada 
$(0,32 \pm 0,17)$ encontrada por Rance et al. (2002) entre peso do duodeno e PPER. PI apresentou também correlação genética fraca com RPER $(0,12)$ e correlação fenotípica moderada com PPER $(0,31)$, esta semelhante às apresentadas por Rance et al. (2002) entre peso do duodeno e PPER, peso do jejuno e PPER e peso do íleo e PPER. PI apresentou ainda correlação fenotípica fraca com RPER $(0,06)$.

PC apresentou correlações genéticas fracas com PE, PPEI e PPER $(0,17,0,04$ e 0,15 , respectivamente), que diferiram das correlações genéticas fortes encontradas por Rance et al. (2002) entre estas características $(0,64 \pm 0,13,0,55 \pm 0,12$ e 0,59 $\pm 0,13$, respectivamente). PC apresentou correlações genéticas inversas fracas com RCAR (0,19) e RPEI $(-0,07)$ e correlação genética fraca com RPER $(0,03)$. PC apresentou correlações fenotípicas moderadas com PE, PPEI e PPER (0,34, 0,24 e 0,30, respectivamente), enquanto Rance et al. (2002) encontraram correlação fenotípica moderada entre PC e PPEI, mas forte entre PC e PE $(0,55)$ e entre PC e PPER $(0,57)$. PC apresentou correlação fenotípica fraca com RPER $(0,01)$ e inversa fraca com RCAR e RPEI (-0,07 e -0,01, respectivamente).

Segundo Rance et al. (2002) pode-se antecipar fortes correlações entre o tamanho do coração e os tecidos por ele irrigados, entretanto, esta afirmação não foi comprovada através das correlações genéticas obtidas entre PC e as características de carcaça. Apenas fenotipicamente, as correlações entre PC e os pesos (PE, PPEI e PER) sugerem esta relação.

Os resultados obtidos indicam que a seleção genética para PE, PPEI e PPER pouco pode interferir em PC, e aumentos em RCAR, RPEI e RPER também pouco podem afetar PC. Em outras palavras, características de carcaça como objetivos de 
seleção não são capazes de causar muitas alterações em PC. Segundo McEntee et al. citados por Rance et al. (2002) a seleção para uma maior deposição protéica nas aves acarreta na diminuição do tamanho de seus órgãos, o que se comprova apenas através da relação encontrada entre algumas características de composição corporal e o rendimento de carcaça das aves. Quanto maiores PF e PI, menor tende a ser RCAR. Da mesma forma, quanto maior a PGA, menor tende a ser RCAR. Trata-se de um resultado coerente, uma vez que segundo Lin (1981) qualquer aumento em um componente do organismo, em termos relativos, acarreta na diminuição de outro. Entretanto, para PC e PM, este fundamento não foi constatado.

Observa-se que as características de composição corporal correlacionadas com PE, PPEI e PPER não necessariamente foram correlacionadas com seus respectivos rendimentos (RCAR, RPEI, RPER).

As diferenças entre os resultados encontrados e vários dos valores apresentados em literatura para muitas das características analisadas devem-se, principalmente, ao fato de que os parâmetros genéticos e fenotípicos de uma característica são, segundo Eler (2001), propriedades inerentes não apenas à característica, mas também à população em questão, conforme mencionado anteriormente. Desta forma, as diferenças de parâmetros estatísticos (médias, variâncias), estrutura genética (genealogia e laços de parentesco), método de estimativa, efeitos fixos utilizados, efeitos de seleção, de endogamia e dos diferentes tipos de ação gênica (linkage, crossing-over), entre outros, são capazes de interferir nos resultados obtidos, que são pertinentes a cada população. 
As estimativas de kerdabilidade obtidas para os escores visuais de fígado e coração mediante o uso do método da máxima verossimilhança restrita são apresentadas na Tabela 28.

TABELA 28 - Herdabilidades $\left(h^{2}\right)$ dos escores visuais estimadas por máxima verossimilhança restrita, com o respectivo erro-padrão (EP) entre parênteses

\begin{tabular}{cc}
\hline Característica & $\mathbf{h}^{\mathbf{2}}(\mathbf{E P})$ \\
\hline ESCC & $0,05(0,020)$ \\
ESCF & $0,05(0,020)$ \\
\hline
\end{tabular}

ESCC - escore visual do coração; ESCF - escore visual do fígado.

As estimativas de herdabilidade dos escores visuais encontradas através do método da máxima verossimilhança restrita foram fracas, não havendo, portanto, variação destas características devida a fatores genéticos, segundo este método.

A utilização do método $\mathrm{R}$ para as análises dos escores não foi bem sucedida, uma vez que este método trabalha com sub-amostras de $50 \%$ dos dados, o que aumenta as possibilidades de, então, serem obtidas amostras de grupos de contemporâneos sem variabilidade (com todos os animais dentro de uma mesma categoria), o que dificulta a convergência e o processamento das análises. Possivelmente, portanto, a distribuição dos dados dos escores visuais de fígado e coração não permitiu a conclusão das análises por este método.

Foram encontradas alterações histopatológicas na maior parte das amostras de tecido hepático enviadas para o Laboratório de Patologia Veterinária da USP. Entretanto, o laudo não apontou uma causa definida para tais alterações. 


\subsection{Tendência Genética do Peso da Gordura Abdominal}

Os gráficos da tendência genética do peso da gordura abdominal são apresentados nas Figuras 16 e 17.

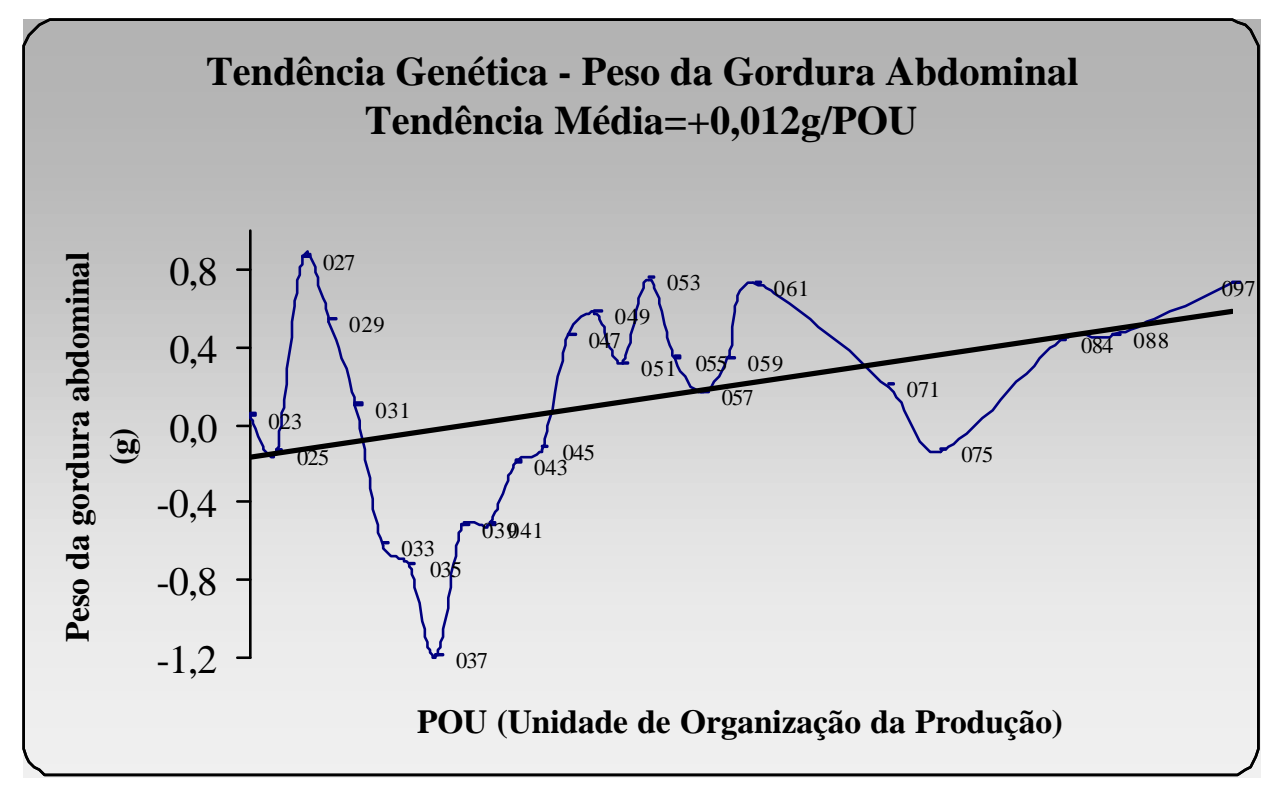

Figura 16 - Tendência genética do peso da gordura abdominal por POU (unidade de organização da produção)

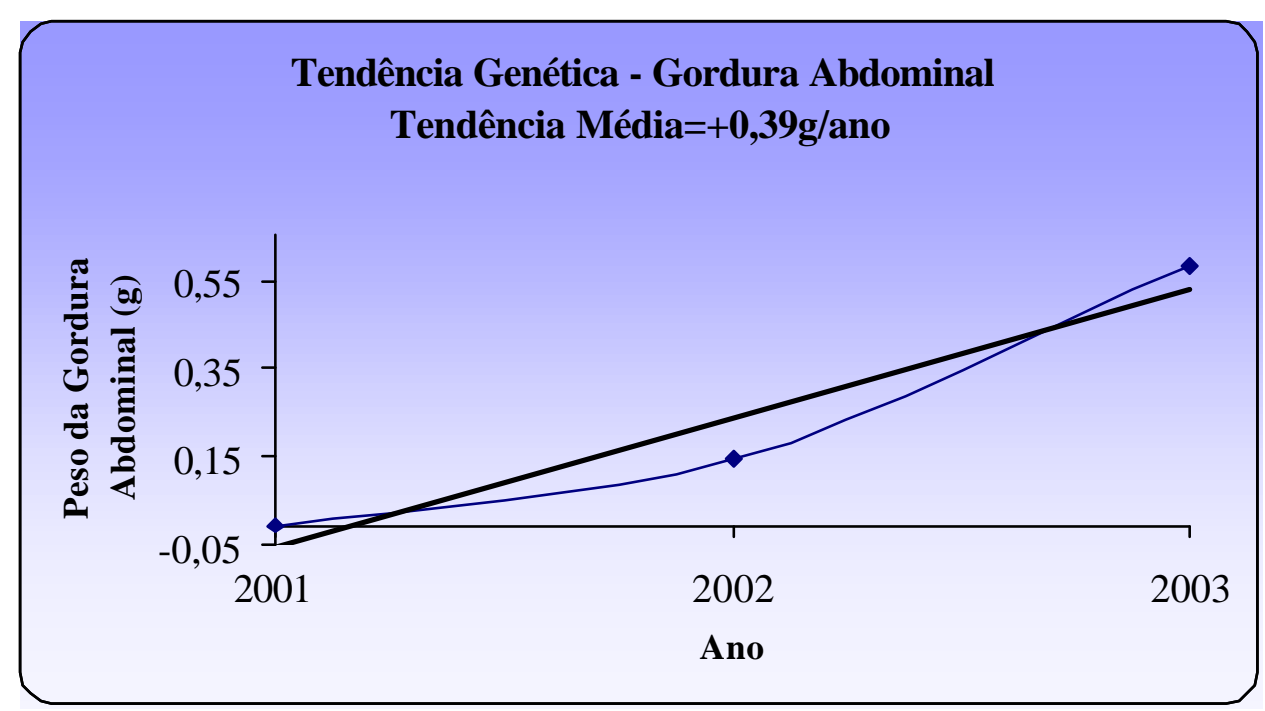

Figura 17 - Tendência genética do peso da gordura abdominal por ano 
Os coeficientes de determinação de ambas as retas apresentaram se significativos, considerando-se a margem de erro de 5\%, sendo o coeficiente de tendência genética do peso da gordura abdominal por POU de 0,0019, e o de tendência genética do peso da gordura abdominal por ano de 0,0022. O estudo da tendência genética do peso da gordura abdominal indica que ao longo do trabalho de seleção a deposição de gordura na linhagem analisada tende a aumentar, tanto em termos de POU como de ano.

Ao longo dos 25 POUs estudados, a média dos valores genéticos do peso da gordura abdominal passou de $+0,049 \mathrm{~g} / \mathrm{POU}$ para $+0,728 \mathrm{~g} / \mathrm{POU}$, resultando em uma tendência média de $+0,012 \mathrm{~g} / \mathrm{POU}$, ainda que em 9 dos 25 POUs estudados o valor genético médio do peso da gordura abdominal tenha sido negativo. Da mesma forma, a tendência genética da gordura abdominal ao longo dos anos é crescente, tendo sido obtida uma tendência média de $+0,39 \mathrm{~g} /$ ano durante os três anos estudados, embora no primeiro ano estudado o valor genético médio do peso da gordura abdominal tenha sido negativo. Analisando-se os critérios de seleção empregados no ano e nos POUs que tiveram valores genéticos médios negativos, poderia-se talvez esclarecer a razão destes declínios.

Segundo Lin (1981), Leenstra (1986), Havenstein et al. (1988), Cartwright (1991), Kessler et al. (2000) e Rance et al. (2002) os critérios de seleção empregados vêm aumentando a deposição de gordura nas aves, o que foi confirmado através do estudo da tendência genética do peso da gordura abdominal na linhagem analisada.

Apesar das aves estudadas não serem selecionadas diretamente a favor da gordura abdominal, esta característica vem obtendo um aumento de quase $1 \%$ da média ao ano. Caso permaneçam os critérios de seleção utilizados sem que se tome 
nenhuma medida para diminuir a deposição de gordura nestes animais, os prejuízos resultantes da grande deposição de gordura nas aves serão agravados ainda mais ao longo do tempo. 


\section{CONCLUSÕES E IMPLICAÇÕES}

A seleção para conversão alimentar ou eficiência alimentar parece ser capaz de diminuir a deposição de gordura abdominal nas aves, entretanto, as herdabilidades de conversão alimentar e eficiência alimentar foram baixas. Desta forma, o uso da própria gordura abdominal como critério de seleção poderá ser mais eficiente para tal fim, pois a mesma apresentou alta herdabilidade.

A capacidade de ingestão das aves pode ser aumentada através da seleção para peso vivo, o que ocasiona maior peso de gordura abdominal e pior conversão alimentar. Todavia, a seleção para peso vivo poderá proporcionar maiores pesos eviscerado, de peito e de pernas, além de maiores rendimentos de carcaça e de pernas.

A seleção para as medidas de ultra-sonografia do músculo peitoral pode ser eficiente em proporcionar maiores peso e rendimento de peito, além de melhorar o peso eviscerado e o rendimento de carcaça. 
As medidas de ultra-sonografia e os pesos eviscerado, de peito e de pernas parecem ser pouco alterados pela seleção contra a gordura abdominal. Entretanto, esta seleção parece favorecer os maiores rendimentos de carcaça e de peito.

A seleção que busca maiores rendimentos de carcaça nas aves pode provocar a diminuição dos pesos do fígado e do intestino, porém, deverá alterar pouco as características do coração e da moela.

A situação do tamanho do coração frente aos programas de seleção deve ser mais bem estudada, pois parece haver uma discrepância entre os achados deste trabalho com os relatos da literatura quanto à sua relação com os rendimentos de carcaça.

O estudo da tendência genética da característica gordura abdominal na linhagem analisada indica que os critérios de seleção atualmente empregados têm levado ao aumento indireto da deposição de gordura abdominal nas aves. 


\section{REFERÊNCIAS BIBLIOGRÁFICAS}

AGROCERES ROSS. Manual de manejo de frangos. Campinas: Ígnea Design, 2000 .

ANUALPEC. Anuário da pecuária brasileira. São Paulo: FNP Consultoria \& Comércio/Argos, 2002. 400 p.

ARGENTÃO, C.; MICHELAN FILHO, T.; MARQUES, J. B.; SOUZA, E. M.; ELER, J. P.; FERRAZ, J. B. S. Genetic and phenotypic parameters of growth and carcass traits of a male line of broilers raised in tropical conditions. In: CONGRESS ON GENETICS APPLIED TO LIVESTOCK PRODUCTION, 7., 2002, Montpellier. Proceedings... Castanet - Tolosan: Organising comitee WCGALP, 2002. v. 30. p. 333-336.

ÁVILA, V. S. de; LEDUR, M. C.; BARIONI JR, W.; SCHMIDT, G. S.; COSTA, C. N. Desempenho e qualidade de carcaça em linhagens comerciais de frangos de corte. Pesquisa Agropecuária Brasileira, v. 28, p. 649-656, 1993.

BARBATO, G. F. Genetic architecture of carcass composition in chickens. Poultry Science, v. 71, p. 789-798, 1992.

BECKER, W. A.; SPENCER, J. V.; MIROSH, L. W.; VERSTRATE, J. A. Abdominal and carcass fat in five broiler strains. Poultry Science, v. 60, p. 693$697,1981$.

BOLDMAN, K. G.; KRIESE, L.; VAN VLECK, L. D.; KACHMAN, S. D. A manual for use of MTDFREML: a set of programs to obtain estimates of variances and covariances. USDA-ARS, 1993. $112 \mathrm{p}$. 
BUYSE, J.; LEENSTRA, F. R.; ZEMAN, M.; RAHIMI, G.; DECUYPERE, E. A comparative study of different selection strategies to breed leaner meat-type poultry. Poultry and Avian Biology Reviews, v. 10, n. 3, p. 121-142, 1999.

CAHANER, A.; NITSAN, Z. Evaluation of simultaneous selection for live body weight and against abdominal fat in broilers. Poultry Science, v. 64, p. 1257-1263, 1985 .

CAHANER, A.; NITSAN, Z.; NIR, I. Weight and fat content of adipose and nonadipose tissues in broilers selected for or against abdominal adipose tissue.

Poultry Science, v. 65, p. 215-222, 1986.

CAMARGO, A. M. Noventa anos de história: de C\&Q a cães e gatos. Revista Avicultura Industrial, n. 1071, p. 20-65, 1999.

CAMPOS, E. J; PEREIRA, J. C. C. Melhoramento genético das aves. In: PEREIRA, J. C. C. Melhoramento genético aplicado à produção animal. Belo Horizonte: FEP-MVZ, 1999. p. 284-314.

CARTWRIGHT, A. L. Adipose cellularity in Gallus domesticus: investigations to control body composition in growing chickens. Journal of Nutrition, v. 121, n. 9, p. 1486-1497, 1991.

CHAMBERS, J. R. Genetics of growth and meat production in chickens. In:

CRAWFORD, R. D. Poultry breeding and genetics. Amsterdam: Elsevier Science, 1990. p. 614-631.

COSTA, A. R. C.; LOPES, P. S.; TORRES, R. de A.; EUCLYDES, R. F.;

REGAZZI, A. J.; SILVA, M. de A. e; PIRES, A. V. Tendências genéticas em características de desempenho de suínos das raças Large White, Landrace e Duroc.

Revista Brasileira de Zootecnia, v. 30, n. 2, p. 348-352, 2001.

ELER, J. P. Teorias e métodos em melhoramento genético animal 2. ed. Pirassununga: FZEA-USP, 2001. 262 p.

EUCLIDES FILHO, K. Melhoramento genético animal no Brasil: fundamentos, história e importância. Campo Grande: EMBRAPA - Gado de Corte, 1999. 63 p.

FALCONER, D. S. Introduction to quantitative genetics. Edinburgh: Oliver \& Boyd, 1960. 365 p.

FARREL, D. J.; ATMAMIHARDIA, S. I.; PYM, R. A. E. Calorimetric measurement of the energy and nitrogen metabolism of Japanese quail. British Poultry Science, v. 23, p. 375-382, 1982.

FERRAZ, J. B.; ELER, J. P. Sumário de touros Marchigiana 2000. São Paulo: FZEA-USP/ABCM, 2000. 25 p. 
FIGUEIREDO, E. P.; SCHMIDT, G. S.; ROSA, P. S.; LEDUR, M. C. O programa de melhoramento genético de aves da EMBRAPA. In: SIMPÓSIO NACIONAL DE MELHORAMENTO ANIMAL, 3., 2000, Belo Horizonte. Anais... Belo Horizonte: FEP-MVZ, 2000. p. 58-68.

FREUND, R. J.; WILSON, W. J. Statistical methods. Chestnut Hill: Academic Press, 1997. 384 p.

GOLDEN, B. L.; SNELLING, W. M.; MALLINCKRODT, C. H. Animal

breeder's toolkit: user's guide and reference manual. Colorado State University, Agricultural Experiment Station. Technical Bulletin LTB92-2, 1992.

GRIFFITHS, L.; LEESON, S.; SUMMERS, J. D. Studies on abdominal fat with four commercial strains of male broiler chicken. Poultry Science, v. 57, p. 1198$1203,1978$.

GYLES, N. R. Poultry, people and progress. Poultry Science, v. 68, p. 1-8, 1989.

HAVENSTEIN, G. B.; FERKET, P. R.; SCHEIDELER, S. E.; RIVES, D. V. Carcass composition and yield of 1991 vs 1957 broilers when fed "typical" 1957 and 1991 broiler diets. Poultry Science, v. 73, p. 1795-1804, 1994.

HAVENSTEIN, G. B.; TOELLE, V. D.; NESTOR, K. E.; BACON, W. L. Estimates of genetic parameters in turkeys. 2. Body weight and carcass characteristics. Poultry Science, v. 67, p. 1388-1399, 1988.

HOPKINS, K. D.; HOPKINS, B. R.; GLASS, G. V. Basic statistics for the behavioral sciences. 3. ed. Boston: Allyn and Bacon, 1996. $406 \mathrm{p}$.

KESSLER, A. M.; SNIZEK JR., P. N.; BRUGALLI, I. Manipulação da quantidade de gordura na carcaça de frangos. In: CONFERÊNCIA APINCO DE CIÊNCIA e TECNOLOGIA AVÍCOLAS, 2000, Campinas. Anais... Campinas: APINCO, 2000. p. 108-133.

KONARZEWSKI, M.; GAVIN, A.; McDEVITT, R.; WALLIS, I. R. Metabolic and organ mass responses to selection for high growth rates in the domestic chicken (Gallus domesticus). Physiological and Biochemical Zoology, v. 73, n. 2, p. 237248, 2000.

LE BIHAN-DUVAL, E.; MIGNON-GRASTEAU, S.; MILLET, N.; BEAUMONT, C. Genetic analysis of a selection experiment on increased body weight and breast muscle weight as well as on limited abdominal fat weight. British Poultry Science, v. 39, p. 346-353, 1998. 
LEDUR, M. C.; SCHMIDT, G. S.; AVILA, V. S. de; FIGUEIREDO, E. P.; MUNARI, D. P. Parâmetros genéticos e fenotípicos para peso corporal em diferentes idades em linhagens de frango de corte. Revista da Sociedade Brasileira de Zootecnia, v. 21, p. 667-673, 1992.

LEDUR, M. C.; SCHMIDT, G. S.; FIGUEIREDO, E. P. et al. Parâmetros genéticos e fenotípicos em linhagens de aves selecionadas para corte. Pesquisa Agropecuária Brasileira, v. 29, p. 503-508, 1994.

LEENSTRA, F. R. Effect of age, sex, genotype and environment on fat deposition in broiler chickens - a review. World's Poultry Science Journal, v. 42, p. 12-25, 1986.

LEENSTRA, F. R.; PIT, R. Fat deposition in a broiler sire strain. 2. comparisons among lines selected for less abdominal fat, lower feed conversion ratio, and higher body weight after restricted and ad libitum feeding. Poultry Science, v. 66, p. 193202, 1987.

LEENSTRA, F. R.; PIT, R. Fat deposition in a broiler sire line: heritability of and genetic correlations among body weight, abdominal fat, and feed conversion.

Poultry Science, v. 67, p. 1-9, 1988.

LEENSTRA, F. R.; VEREIJKEN, P. F. G.; PIT, R. Fat deposition in a broiler sire strain I. phenotypic and genetic variation in, and correlations between abdominal fat, body weight and feed conversion. Poultry Science, v.65, p. 1225-1235, 1986.

LEESON, S.; SUMMERS, J. D. Broiler bre eder production Guelph: University Books, 2000. 329 p.

LIN, C. Y. Relationship between increased body weight and fat deposition in broilers. World's Poultry Science Journal, v. 37, n. 2, p. 106-110, 1981.

LOPES, P. S.; QUAAS, R. L. Estimação de parâmetros genéticos em aves de corte. Revista Brasileira de Zootecnia, v. 26, n. 6, p. 1119-1123, 1997.

MACHADO, C. R. Crescimento do tecido adiposo. In: MACARI, M.; FURLAN, R. L.; GONZALES, E. Fisiologia aviária aplicada a frangos de corte. Jaboticabal: FUNEP/UNESP, 2002. p. 299-311.

MICHELAN FILHO, T. Seleção para diminuição do conteúdo de gordura em frangos. Concórdia: EMBRAPA-CNPSA, 1986.

MIGNON-GRASTEAU, S.; BEAUMONT, C.; LE BIHAN-DUVAL, E.; POIVEY, J. P.; DE ROCHAMBEAU, H; RICARD, F. H. Genetic parameters of growth curve parameters in male and female chickens. British Poultry Science, v. 40, p. 44-51, 1999. 
PIRCHNER, F. Population genetics in animal breeding. Londres: Plenum, 1983. $414 \mathrm{p}$.

PRES, W. H.; FLANNERY, B. P.; TEUKOLSKY, S. A.; VETTERLING, W. T. Numerical recipes. Cambridge University Press: Cambridge.

RANCE, K. A.; McENTEE, G. M.; McDEVITT, R. M. Genetic and phenotypic relationships between and within support and demand tissues in a single line of broiler chicken. British Poultry Science, v. 43, p. 518-527, 2002.

RAUW, W. M.; KANIS, E.; NOORDHUIZEN-STASSEN, E. N.; GROOMERS, F. J. Undesirable side effects of selection for high production efficiency in farm animals: a review. Livestock Production Science, v. 56, p. 15-33, 1998.

REVERTER, A.; GOLDEN, B. L.; BOURDON, R. M.; BRINKS, J. S. Method R variance components procedure: application on the simple breeding value model. Journal of Animal Science, v. 72, p. 2247-2253, 1994.

REZENDE, F. M. de; GAYA, L. de G.; MATTOS, E. C. de.; MOURÃO, G. B.; FIGUEIREDO, L. G. G.; ELER, J. P. Estimação de componentes de variâncias iniciais para características produtivas em linhagem macho de frango de corte. In: SIMPÓSIO INTERNACIONAL DE INICIAÇẪO CIENTÍFICA DA USP, 11. 2003, Piracicaba. Anais... Piracicaba: ESALQ/USP, 2003. CD-ROM. (Nota n. 2319).

SAS $^{\circledR}$ - STATISTICAL ANALYSIS SYSTEMS. User's guide . V. 8. Cary: SAS Institute Inc., 1999.

SCHMIDT, G. S.; COSTA, C. N.; LEDUR, M. C.; ÁVILA, V. S. de. Herdabilidade do peso aos 42 dias de linhagens de aves para corte. Revista da Sociedade Brasileira de Zootecnia, v. 21, n. 5, p. 772-778, 1992.

SCHMIDT, G. S.; CUSTÓDIO, R. W. S. Peso corporal, linhagem, sexo, rendimento de carcaça e deposição de gordura abdominal em frangos de corte. In: CONFERÊNCIA APINCO DE CIÊNCIA E TECNOLOGIA AVÍCOLAS, 1995, Curitiba. Anais... Campinas: FACTA, 1995. p. 245-246.

SCHMIDT, G. S.; FIGUEIREDO, E. P. Situação atual e perspectivas do programa de melhoramento genético de aves do CNPSA/EMBRAPA. In: SIMPÓSIO NACIONAL DE MELHORAMENTO ANIMAL, 1., 1996, Ribeirão Preto. Anais... Ribeirão Preto: SBMA/FMRP, 1996. p. 99-122.

SHLOSBERG, A.; BELLAICHE, M.; ZEITLIN, G.; YA'ACOBI, M.; CAHANER, A. Hematocrit values and mortality from ascites in cold-stressed broilers from parents selected by hematocrit. Poultry Science, v. 75, p. 1-5, 1996. 
SILVA, M. V. G. B. da; FERREIRA, W. J.; COBUCI, J. A.; GUARAGNA, G. P.; OLIVEIRA, P. R. P. de. Estimativas de tendência genética para características produtivas em um rebanho do ecótipo Mantiqueiral. Revista Brasileira de Zootecnia, v. 30, n. 5, p. 1466-1475, 2001.

SILVERSIDES, F. G.; LEFRANCOIS, M. R.; VILLNEUVE, P. The effect of strain of broiler on physiological parameters associated with ascites syndrome. Poultry Science, v. 76, p. 663-667, 1997.

SINGH, R.; TREHAN, P. K. Genetic and phenotypic parameters of body and muscle weights and abdominal fat in meat-type chicken. Indian Journal of Animal Science, v. 64, p. 388-392, 1994.

SNEELING, W. M.; GOLDEN, B. L.; BOURDON, R. M. Within herd genetic analyses of stayability of beef females. Journal of Animal Science, v. 73, p. 9931001, 1995.

SONAIYA, E. B.; BENYI, K. Abdominal fat in 12-to 16-week-old broiler birds as influencied by age, sex and strain. Poultry Science, v. 62, p. 1793-1799, 1983.

SÜTÓ, Z.; JENSEN, J. F.; SORENSEN, P.; CSAPÓ, J. Carcass traits, abdominal fat deposition and chemical composition of commercial meat type chicken during a twenty week growing period. Archiv für geflügelkunde, v. 62, p. 21-25, 1998.

TROVO, J. B.; RAZOOK, A. G. Fundamentos da avaliação genética. In: CURSO SOBRE AVALIAÇÃO GENÉTICA EM BOVINOS DE CORTE, 1., 1995, Ribeirão Preto. Anais... Ribeirão Preto: FPCRP, 1995. p. 1-19.

UNI, Z.; NOY, Y.; SKLAN, D. Development of the small intestine in heavy and light strain chicks before and after hatching. British Poultry Science, v. 36, p. 63$71,1995$.

VAN MELIS, M. H. Utilização do método R na estimação de parâmetros genéticos em gado de corte. 2002. 85 p. Dissertação de Mestrado - Faculdade de Zootecnia e Engenharia de Alimentos, Universidade de São Paulo, Pirassununga.

VAN MELIS, M. H.; ELER, J. P.; FERRAZ, J. B. S. Tendências genéticas para características produtivas e de avaliação visual em bovinos da raça Nelore. In: REUNIÃO ANUAL DA SOCIEDADE BRASILEIRA DE ZOOTECNIA, 38., 2001, Piracicaba. Anais... Piracicaba: SBZ, 2001. p. 519-520.

VAN VLECK, L. D.; POLLAK, E. J.; OLTENACU, E. A. B. Genetics for the animal sciences. New York: W. H. Freeman and Company, 1987. 391 p.

WANG, L.; McMILLAN, I.; CHAMBERS, J. R. Genetic correlations among growth, feed and carcass traits of broiler sire and dam populations. Poultry Science, v. 70, p. 719-725, 1991. 
YANG, A.; EMMERSON E.; DUNNINGTON, E.; SIEGEL P. B. Heterosis and developmental stability of body and organ weight at hatch for parental line broiler breeders and specific crosses among them. Poultry Science, v. 78, p. 942-948, 1999. 